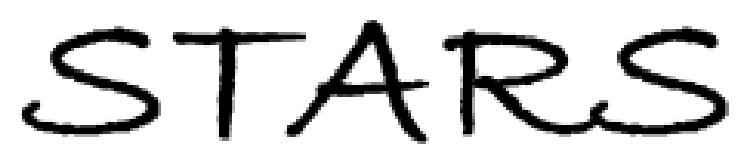

University of Central Florida

STARS

Retrospective Theses and Dissertations

1983

\title{
Visual and Part-Task Manipulations for Teaching Simulated Carrier Landings
}

Daniel J. Sheppard

University of Central Florida

Part of the Industrial and Organizational Psychology Commons

Find similar works at: https://stars.library.ucf.edu/rtd

University of Central Florida Libraries http://library.ucf.edu

This Masters Thesis (Open Access) is brought to you for free and open access by STARS. It has been accepted for inclusion in Retrospective Theses and Dissertations by an authorized administrator of STARS. For more information, please contact STARS@ucf.edu.

\section{STARS Citation}

Sheppard, Daniel J., "Visual and Part-Task Manipulations for Teaching Simulated Carrier Landings" (1983). Retrospective Theses and Dissertations. 719.

https://stars.library.ucf.edu/rtd/719

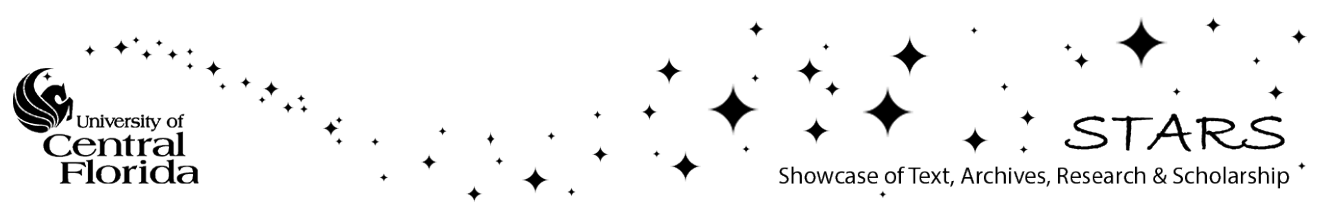




\title{
VISUAL AND PART-TASK MANIPULATIONS FOR
} TEACHING SIMULATED CARRIER LANDINGS

\author{
BY \\ DANIEL JOSEPH SHEPPARD \\ B.S., University of Massachusetts, 1976
}

\section{THESIS}

Submitted in partial fulfillment of the requirements for the Master of Science degree in Industrial Psychology

in the Graduate Studies Program of the College of Arts and Sciences University of Central Florida Orlando, Florida

Summer Term

1983 


\section{ACKNOWLEDGMENTS}

I extend my gratitude and appreciation to Drs. Gavan Lintern, Wayne Burroughs, and Janet Turnage, for their support, thoughtful criticism and guidance throughout the course of this research.

I also extend my appreciation for the technical support provided by the following individuals associated with the Visual Technology Research Simulator program: from the Naval Training Equipment Center (Code N-732), Walter Chambers, Dr. Stanley Collyer, Dr. Dennis Wightman, Bruce Riner, Patricia Daoust, Ed Ades and Hal McKinney; and from Essex Corporation, Dr. Robert Kennedy, Dr. Daniel Westra, Karen Thomley, Brian Nelson, and Helen Foard.

special thanks to my wife susan for the encouragement she provided in my graduate studies at the University of Central Florida. 
INTRODUCTION .........................

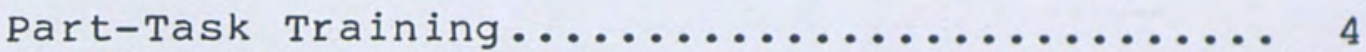

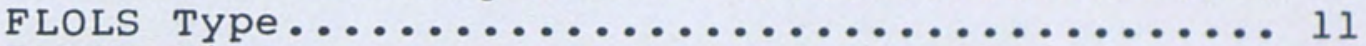

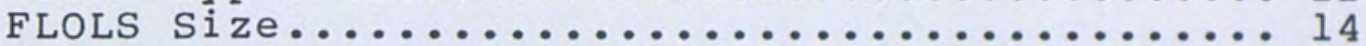

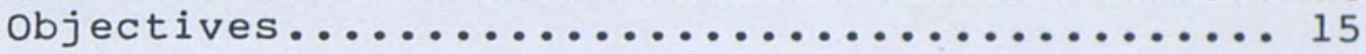

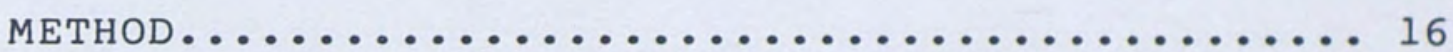

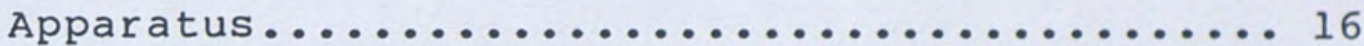

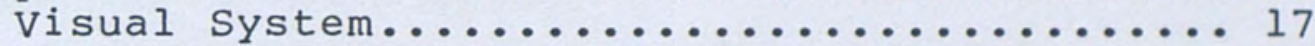

Fresnel Lens optical Landing system........ 19

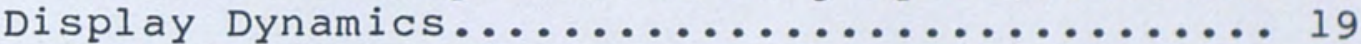

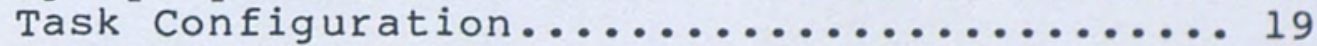

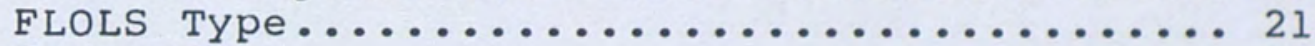

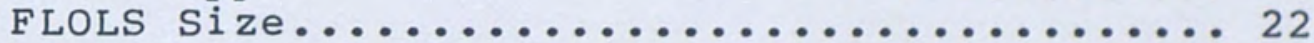

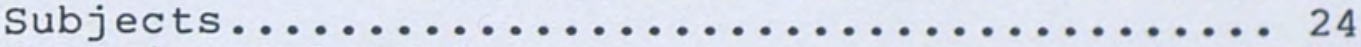

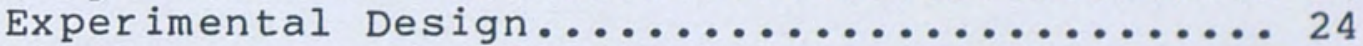

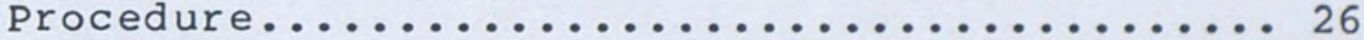

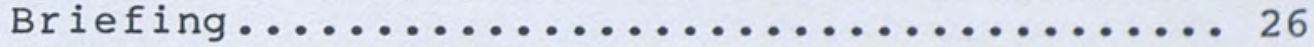

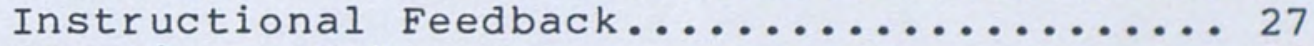

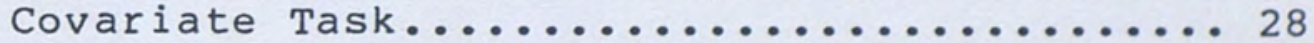

Performance Measurement and Data Analysis.... 29

RESULTS............................. 31

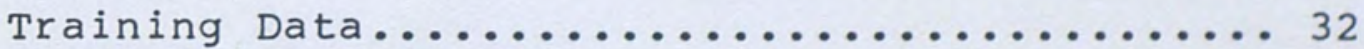

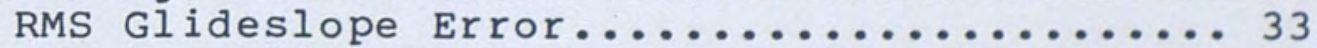

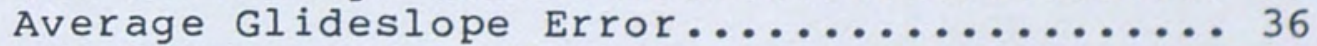

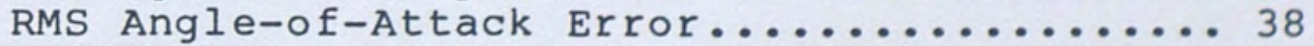

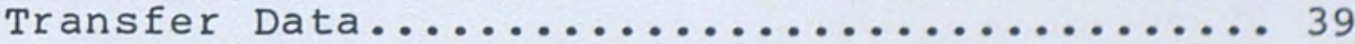

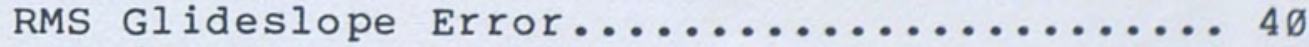

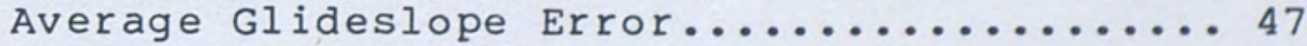

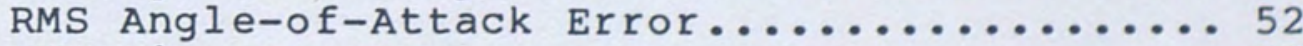

RMS Lineup Error................... 58

DISCUSSION.......................... $8 \emptyset$

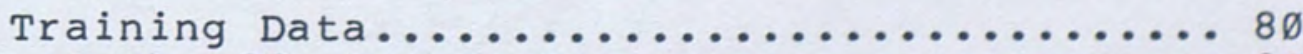

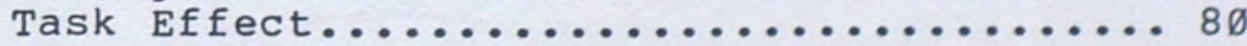

FLOLS Size......................... 81

FLOLS TYре...................... 81 
Transfer Data........................ 82

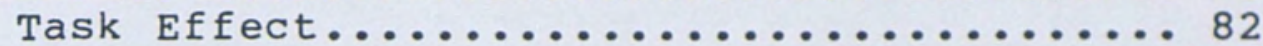

FLOLS TYpe........................ 86

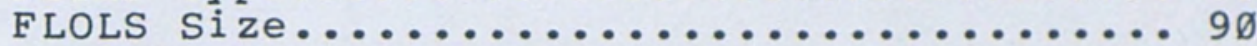

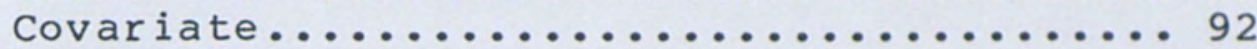

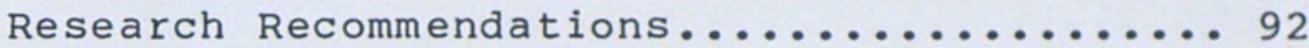

CONCLUSIONS........................... 94

APPENDICES

A. Carrier Landing Instructions.......... 97

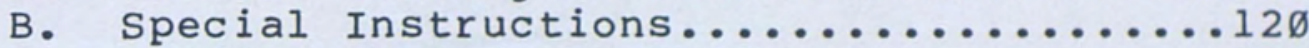

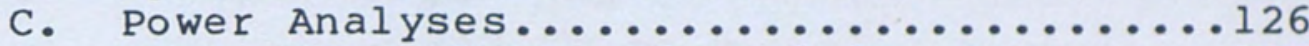

D. Mean and Analyses of Training Data......128

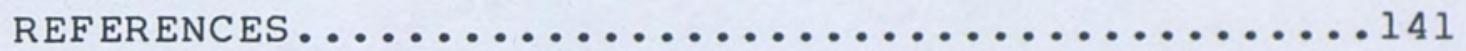




\section{LIST OF TABLES}

1 Experimental Design................... 25

2 Repeated Measures Analysis of Covariance of RMS Glideslope Error for Middle Segment During Transfer......... 64

3 Means of RMS Glideslope Error for Middle Segment During Transfer...... 65

4 Repeated Measures Analysis of Covariance of RMS Glideslope Error for Close-in Segment During Transfer.......66 66

5 Means of RMS Glideslope Error for Close-in Segment During Transfer.....6 67

6 Repeated Measures Analysis of Covariance of Average Glideslope Error for Middle Segment During Transfer......... 68

7 Means of Average Glideslope Error for Middle Segment During Transfer......... 69

8 Repeated Measures Analysis of Covariance of Average Glideslope Error for Close-in Segment During Transfer.....7 $7 \varnothing$

9 Means of Average Glideslope Error for Close-in Segment During Transfer........ 71

$1 \emptyset$ Repeated Measures Analysis of Covariance of RMS Angle-of-Attack Error for Middle Segment During Transfer...... 72

11 Means of RMS Angle of Attack Error for Middle Segment During Transfer...... 73

12 Repeated Measures Analysis of Covariance of RMS Angle-of-Attack for Close-in Segment During Transfer........ 74

13 Means of RMS Angle-of-Attack Error for Close-in Segment During Transfer..... 75

14 Repeated Measures Analysis of Covariance of RMS Lineup Error for Middle Segment During Transfer................... 76

15 Means of RMS Lineup Error for Middle Segment During Transfer...... 77

16 Repeated Measures Analysis of Covariance of RMS Lineup Error for Close-in Segment During Transfer.................. 78

17 Means of RMS Lineup Error for Close-in Segment During Transfer.... 79 


\section{LIST OF FIGURES}

1 Carrier Approach Schematic Depicting FLOLS Envelope, Tail Hook Glidepath and Arrestment Wire Locations............8

2 Computer-Generated Image of the Aircraft Carrier, with FLoLs and Portion of Wake... 18

3 Configuration of FLoLs Simulation, Showing Datum Bars, Rate Arrows, and Meatball.... 2ø

4 Three Representations of Possible RATE

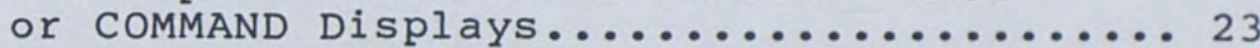

5 Task $x$ FLOLS Size Interactions for RMS Glideslope Error During Training........ 34

6 Block $x$ Task $x$ FLoLS Size Interaction of RMS Glideslope Error for Middle Segment During Training...... 35

7 Task $x$ FLoLS Size Interactions for Average Glideslope Error During Training........ 37

8 Block $x$ Task Interactions for RMS Glideslope Error During Transfer.................41

9 Block $x$ Task $x$ FLoLs Type Interaction of RMS Glideslope Error for Middle Segment

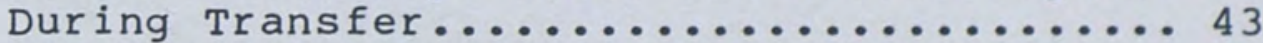

$1 \emptyset$ FLOLS Type Interactions of RMS Glideslope

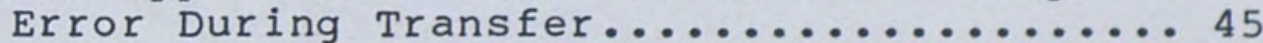

11 FLOLS Size Interactions of RMS Glideslope Error During Transfer...................46

12 Task $x$ FLOLS Type $x$ FLoLS Size Interaction of RMS Glideslope Error for Close-in Segment During Transfer........4 48

13 Block $x$ Task Interaction for Average Glideslope Error During Transfer........ 50

14 FLOLS Type Interactions for Average Glideslope Error During Transfer........ 51

15 Block $x$ Task and Block $x$ FLOLS Type Interactions of RMS Angle-of-Attack Error for Middle Segment During Transfer.......5 53

16 FLOLS Type and FLOLS Size Interactions of RMS Angle-of-Attack Error

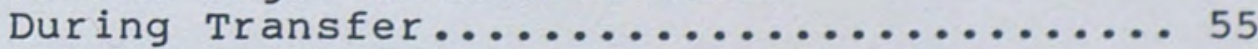

17 Block $x$ Task $x$ FLOLS Size Interaction of RMS Angle-of-Attack Error for the Middle Segment During Transfer.... 
18 Block $x$ Task $x$ FLoLs Type Interactions of RMS Lineup Error for the CLose-in Segment During Transfer........ 59

19 FLOLS Size $x$ FLoLS Type Interactions for RMS Lineup Error During Transfer.....6 61

$2 \emptyset$ FLOLS Type Interactions for RMS Lineup Error During Transfer.......... 63 


\section{INTRODUCTION}

The approach to and landing on an aircraft carrier is a demanding task for any pilot and is one of the most dangerous he can be called upon to perform. The flight skills required for the task are acquired primarily by repetitive practice on a land-based runway and in a simulator designed to represent the criterion device and environment as closely as possible. While many factors contribute to the carrier-landing problem (e.g., poor visual cues, limited landing area, deck movement), perceptual judgments of vertical position on the flight path and subsequent motor responses are the most critical factors in a carrier approach (Gold, 1974; Durand and Wasicko, 1967). The objective of this research is to investigate the development of an effective learning environment in a low-cost flight simulator to train the critical features of the carrier-landing task.

Flight simulators have long been viewed as substitute airplanes. They are designed to represent the criterion device and environment to a reasonable degree of fidelity. The goal of most flight simulators is to increase training effectiveness in a safe and cost-effective manner. 
However, increased training effectiveness is often considered to be almost synonymous with increased simulation realism (Bunker, 1978).

While technological advances such as high detail and large field-of-view visual systems, motion systems and G-seats have increased realism, the major emphasis should be to optimize skill development in the simulator. Simulators have provided relevant and important task information but neither maximum training efficiency nor maximum training effectiveness will ever be achieved until this information is organized (Stark, 1982).

The organization of this information would reflect a training philosophy that emphasized principles of learning rather than available technology. Research should examine methods of optimizing training in a simulator in terms of training time or cost-effectiveness for skill development. An appearance of correspondence with reality rather than an actual correspondence may be sufficient for training (Staples, 1978). Even an appearance of correspondence with reality may be unnecessary, and it may be adequate to provide the necessary information for teaching certain flight objectives in many different ways (Caro, 1977). Furthermore, departures from reality may not only be less 
expensive but may be more effective in acquiring the skill (Hennessy, Lintern, and Collyer, 1981). The application of the simulator's Freeze/Reset feature (freeze pilot in midflight to give feedback/Reset on course) to train the carrier-landing task (Hughes, Lintern, Wightman, Brooks, and Singleton, 1981) and the use of unconventional displays (e.g., outside viewpoint from behind the aircraft, instrument only) to teach basic flight tasks (Hennessy et al., 1981) reflect recent experiments that have addressed these issues.

Stark (1982) has also suggested that today's advanced simulation technology be applied to support individual training problems. Stark suggests that specific difficult and important skills and skill components should be trained outside the whole-task context in low cost, but high-fidelity, training settings designed to mediate only that information relevant to a specific task or task component.

The current study is an extension of this concept and philosophy of training and will explore the usefulness of part-task instruction and two methods of display augmentation for training the carrier-landing task. 
$\underline{\text { Part-Task }}$ Training

Part-task training is generally regarded as practice on a portion of the whole task prior to practice of the whole task. One part-task approach is to identify the specific components of the whole task that are either difficult to learn or are critical to the acquisition of the task. These components can then be subjected to extensive practice before the total skill is practiced. This procedure may lead to a more rapid acquisition of the task and possibly better performance. A modest amount of transition training to coordinate acquired skills would be sufficient and extensive practice in a high fidelity, whole-task simulator would not be required (Adams and Hufford, 1962).

Although some basic research has been done on part-task versus whole-task training, little has been undertaken with multi-dimensional perceptual-motor tasks and none with operationally relevant tasks such as carrier-landings. Nevertheless, the basic research provides some insight into the application of part-task training to operational tasks. 
Briggs and waters (1958) used a pitch and roll tracking task to study the value of task component interaction in part-task versus whole-task training. They found that pure part-task practice (practice on individual components) was progressively less beneficial, as the degree of component (part) interaction is increased in the transfer or whole task.

Naylor and Briggs (1963) used a prediction type task to study the value of task complexity and task organization in part-task versus whole-task training. They found that part-task training was less effective than whole-task training in a task of high difficulty and high component interaction.

Schendel, Shields and Katz (1978), in a review of the literature on variables known to affect the retention of learned motor behaviors, states the effectiveness of part-task as opposed to whole-task training methods varies with the difficulty of a task's independent subtasks and the degree to which the subtasks are interrelated. They stated that

It generally is easier to learn simple to moderately difficult tasks using whole-training methods rather than part-training methods, whereas the opposite is true for more difficult tasks. 
Tasks requiring high coordination and timing of their serial-motor components are learned faster using whole-training methods. In contrast, part-training methods tend to be more effective for tasks that can be divided in meaningful independent subtasks.

There appears to be an interaction between task difficulty and task organization that influences the relative effectiveness of part- and whole-training methods. Thus, training for tasks of high organization becomes increasingly more effective with whole practice as task difficulty increases. On the other hand, training for tasks of low organization is increasingly improved by part practice as task difficulty increases.

The carrier-landing task is a difficult task requiring high coordination of its motor components. It appears from the basic research that a part-task approach to training is unadvisable. Briggs and Waters (1958) suggest that this will be so because subjects will be unable to learn how specific components of the task interact when the components are practiced separately. Concurrent practice is needed to learn how specific components interact in a highly organized task. Briggs and Naylor (1962) also argue that similarity to the transfer task and the opportunity to develop efficient timesharing (concurrent practice of task components) behavior are both needed for effective learning. Thus, part-task training may be inefficient in a difficult and organized task for two reasons. The training and transfer tasks are dissimilar, but more important, there is no opportunity to learn to timeshare interacting 
task components. Thus, it is hypothesized that a part-task training strategy that allows efficent timesharing and learning of subtask interactions would provide efficient transfer for a difficult and highly organized task. The carrier-landing tas is suitable for testing this hypothesis and the following description of the task will suggest an approach to part-task training.

For a carrier approach, the pilot attempts to follow a designated glideslope (oblique path) so that a hook attached to the tail of the aircraft will contact the landing deck midway between the second and third of four arrestment wires (cables laid across the landing deck, Figure 1). The wires are stretched across the landing deck at different distances from the ramp (threshold of the landing deck). Under the aircraft's momentum the hook travels forward to snag the third wire for a trap (arrested landing). The first or second wire may be caught on a low approach and the fourth on a high approach. Very low approaches can result in a ramp strike (collision with the stern of the carrier) while high approaches can result in a bolter (a missed approach because of touchdown beyond the wire arrestment area) (Kaul, Collyer and Lintern, 198ø).

The pilot must not only maintain a precise glideslope but also must simultaneously maintain the correct angle of 


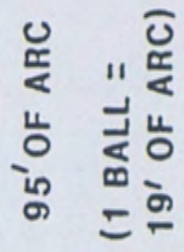

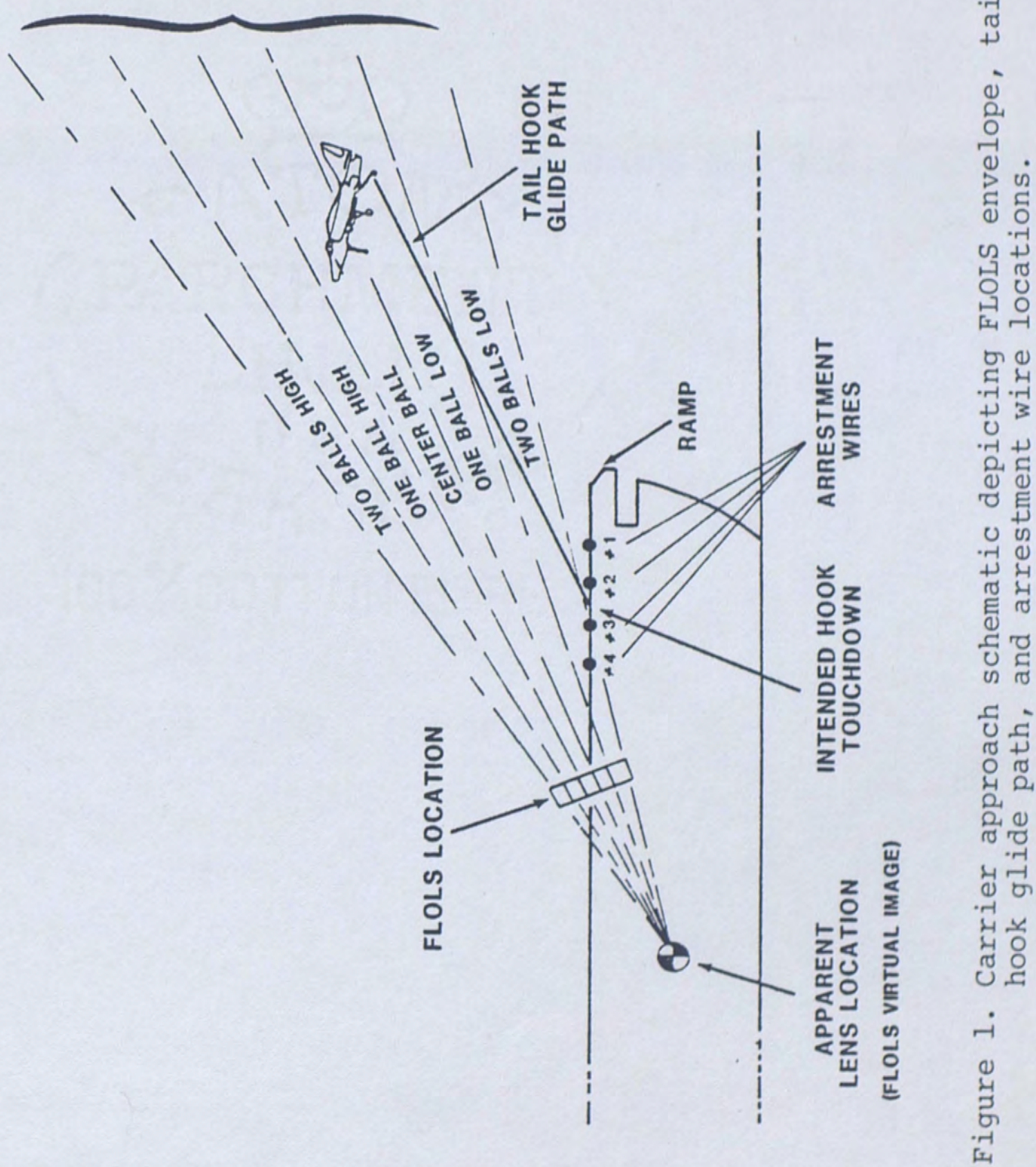


attack (angle at which the wing moves through the air), airspeed, vertical velocity and lineup with the landing area. If the pilot is successful in maintaining position and velocity errors within acceptable limits, he will execute a successful touchdown and trap (Gold, 1974). Although all dimensions are essential to safe and successful carrier-landings, glideslope control is the most critical and difficult.

The part-task training method proposed here is to freeze the aircraft at a point along the carrier approach so that the subject cannot fly forward to land on the carrier. The simulated aircraft will be permitted to move along all of its axes except for the lateral axis. The rationale for this part-task strategy is outlined below:

1. Subjects will have more opportunity to practice glideslope control in a less complex task. Briggs and Waters (1958) suggested a simplification method of part-task instruction may be appropriate for a high organization task. Holding (1961) also argues that positive transfer can occur in task simplification as long as proper information is provided for error detection and correction. 
2. All piloting tasks except lateral control will be timeshared. This will provide knowledge of component interaction. The lack of lineup practice was not considered serious. Lineup control does not constitute a major problem in the carrier landing and appropriate left and right stick responses was necessary to maintain the aircraft heading to that of the carrier. Thus, a few trials of transition training in the whole task was expected to be sufficient to coordinate the skills essential for lateral control.

3. A point on the glideslope at which the simulated aircraft was frozen resulted in a task of moderate difficulty.

In summary, this part-task training strategy allows extensive practice on error detection and correction of the most difficult and critical component of the carrier-landing task, glideslope control. Secondly, the strategy provides knowledge of component interaction which apparently is necessary for a highly organized task. Thus, a low-cost part-task trainer that can provide substantial positive transfer to an operationally relevant task would be of significant benefit. 
FLOLS Type

Primary glideslope displacement information for a carrier approach is provided by the Fresnel Lens optical Landing system (FLOLS). It consists of light sources behind five vertically stacked Fresnel lenses that are situated between two horizontal light arrays known as datum bars. The array of lenses and lamps provide a virtual image which appears to the pilot as a single light located $15 \emptyset$ feet behind the datum bars. This light is known as the meatball. The meatball is visible to the pilot through the center lens when he is within 9.5 minutes of arc of the glideslope and is seen as level with the datum bars. As the aircraft moves more than 9.5 minutes of arc above or below the glideslope, the meatball is seen through higher or lower Fresnel lenses to give the appearance of moving vertically above or below the line of the datum bars (Figure 1).

Although the FLoLs provides the primary displacement information for glideslope control, it has long been recognized that it is less than optimum (Brictson, 1967; Perry, 1968). Because the information from the meatball is of zero-order (displacement only), there are substantial lags between incorrect control inputs and the subsequent error information from the FLoLs. That is, a rate 
(first-order) error must exist for some short period of time before it produces a perceptible displacement (zero-order) error (Kaul et al., 198ø).

One technique to compensate for the lags between control inputs and subsequent error information would be to add a first-order component to the zero-order components that moves the meatball. However, this is less than desirable since the pilot would no longer have unambiguous information about his position above or below the glideslope. Kaul et al. (198ø) avoided this problem by adding another element to the FLOLS display. Vertical light arrays appearing as bars or arrows extending up or down from the inside of the datum bars were added to the FLOLS to provide a first-order display with no loss of the information presently available from the meatball.

Kaul et al. tested two configurations of the arrows. In one, the algorithm drove the arrows up or down depending on whether the meatball was moving up or down. This was designated the RATE display. In the other, the algorithm drove the arrows in proportion to the difference between the actual and the ideal descent rates so that null indicators from the arrows would return the pilot to, or maintain him on, the glideslope. This was designated the COMMAND display. 
Results of the study showed that the approach performance with the COMMAND display was more stable and accurate than with the CONVENTIONAL display. Root mean square (RMS) glideslope error scores (standard scores used to measure performance on a tracking task) for the COMMAND display were $4 \emptyset \%$ to $5 \emptyset$ o better than those for the CONVENTIONAL display. Performance with the RATE display tended to lie between performance with the CONVENTIONAL andd COMMAND displays (Kaul et al., 198ø).

The potential value of these first-order displays in increasing performance at the ship also suggest importance as a training aid. Weller (1979) has argued that first-order displays might teach approach glideslope control techniques for carrier landing. In addition, first-order displays might even help students learn to use a CONVENTIONAL FLOLS display more effectively (Kaul et al.., 1980). However, Westra (1982) found no performance advantage with the command display in teaching pilots the carrier-landing task. Nevertheless, in order to test this hypothesis, both the RATE and COMMAND displays were tested in this experiment. 
$\underline{\text { FLOLS }} \underline{\text { Size }}$

In the real environment, the flols display is generated by incandescent lights. In a flight simulator, it is more convenient and less expensive to computer generate the Flols display. Because the FloLs is relatively small and must be perceived accurately, a high-fidelity visual simulator is required to represent it. Alternatively, the FLOLS might be represented as larger than its normal size. The issue of whether the size of a simulated FLOLS needs to correspond to its size in the real environment remains unresolved. From an engineering perspective, a large FLoLs would be advantageous because to simulate the FloLs display accurately would require a high-detail visual system which is a very costly item. From a training perspective, a large FloLs may or may not be advantageous. It is also possible that it will be disadvantageous.

The FLoLs display is the primary source of glideslope information. To enlarge the FLoLs is to "augment" or "enhance" the display of the glideslope component of the carrier approach. Transfer to the normal sized FLoLS may have been negative. On the other hand, the enhanced display may help the student make better sense at what he 
is seeing when flying the simulator (Hennessy et al., 1981) as did the augmented feedback used by Lintern (198ø) to teach landings in a light aircraft may have. Thus, FLoLs size was included in the experiment to examine its relative effectiveness for simulator training.

In summary, this experiment was conducted to investigate visual and part-task manipulations to optimize visual displays in terms of cost and training effectiveness for teaching simulated carrier landings. Part-task vs whole-task training and two visual factors, FloLs type and FLols size were investigated at the Visual Technology Research Simulator. Flols type consisted of the conventional flols display and two first-order displays, RATE and COMMAND. FLOLS size consists of a simulated small and large FLOLS. 


\section{METHOD}

\section{Apparatus}

The Visual Technology Research Simulator (VTRS), described elsewhere by Collyer and Chambers (1978), consists of a fully instrumented $\mathrm{T}-2 \mathrm{C}$ Navy jet trainer cockpit, a six degree-of-freedom synergistic motion platform, a 32-element G-seat, a wide-angle visual system that can project computer-generated color images and an Experimenter/operator Control station.

The T-2C is the Navy's primary jet trainer. It is a twin turbojet, subsonic aircraft. All aircraft systems in the T-2C cockpit were simulated for normal operations. Carrier arrested landing and catapult takeoff capability is also provided.

The motion platform is a six-degree-of-freedom system which corresponds to the movement along and around the axes of an aircraft in flight. The G-seat has 32 elements in the seat and back pan to provide sustained simulation of acceleration vectors. The motion system and G-seat were not used in this experiment. 
The visual display is a monochrome wide angle real image presented on a $1 \varnothing$ foot radius spherical screen. The entire display system, consisting of the screen and two projectors, is mounted on the motion base.

The experimenter/operator station provides the capability of interacting with the computer and flight simulator for the purpose of developing, controlling, monitoring and recording the experiment.

Visual system. The background subtended $5 \emptyset$ degrees above to $3 \emptyset$ degrees below the pilot's eye level and $8 \emptyset$ degrees to either side at the cockpit. The carrier image, a daytime representation of the USS Forrestal (CVA 59), was generated by computer and projected onto the background through a 1ø25-1ine video system. The FLOLS and carrier wake were also generated by this method (Figure 2).

Average delay between control inputs and generation of the corresponding visual scene was approximately $117 \mathrm{msec}$. Calculation of new aircraft coordinates required $50 \mathrm{msec}$, while calculation of the coordinates for the visual scene corresponding to the viewpoint from the new aircraft coordinates required $17 \mathrm{msec}$. An updated visual scene was displayed every $33 \mathrm{msec}$. 


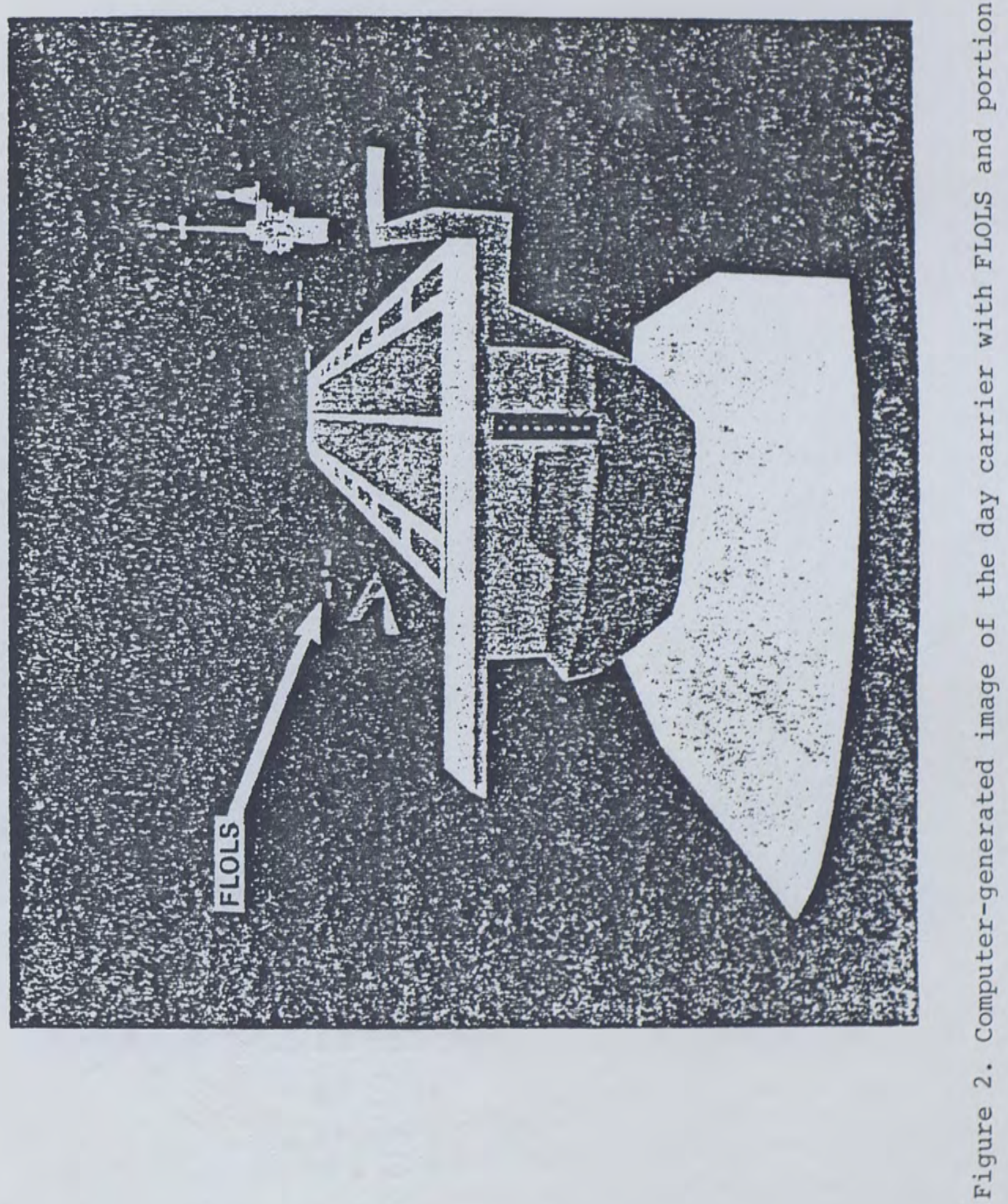


The sky was light blue and brightness was approximately .12 foot-Lambert ( $f L)$. The seascape was dark blue and brightness was approximately $.45 \mathrm{fL}$. The brightest area of the carrier was approximately $2.6 \mathrm{fL}$. Except for the horizon, there were no features represented in either the sky or sea.

The configuration of the FLOLS is shown in Figure 3 . The FLOS was centered 414 feet down the landing deck and 61 feet to the left of the centerline. It was set at a nominal 3.5 degree glideslope and with a lateral viewing wedge of 52 degrees.

\section{Display Dynamics}

Three factors--part-task training, Flols type and FLOLS size--were investigated as possible training aids for the carrier landing task.

Task Configuration. For the whole-task condition, the simulator was initialized with the aircraft at $9 \emptyset \emptyset \emptyset$ feet from the ramp, on glideslope and centerline, and in the approach configuration (hook and wheels down, speed brake out, 15 units AOA, half flaps, and power at $83 \%$ ). A trial was flown from the initial condition to wire arrestment or, in the case of a bolter, to løøø feet past the carrier. 


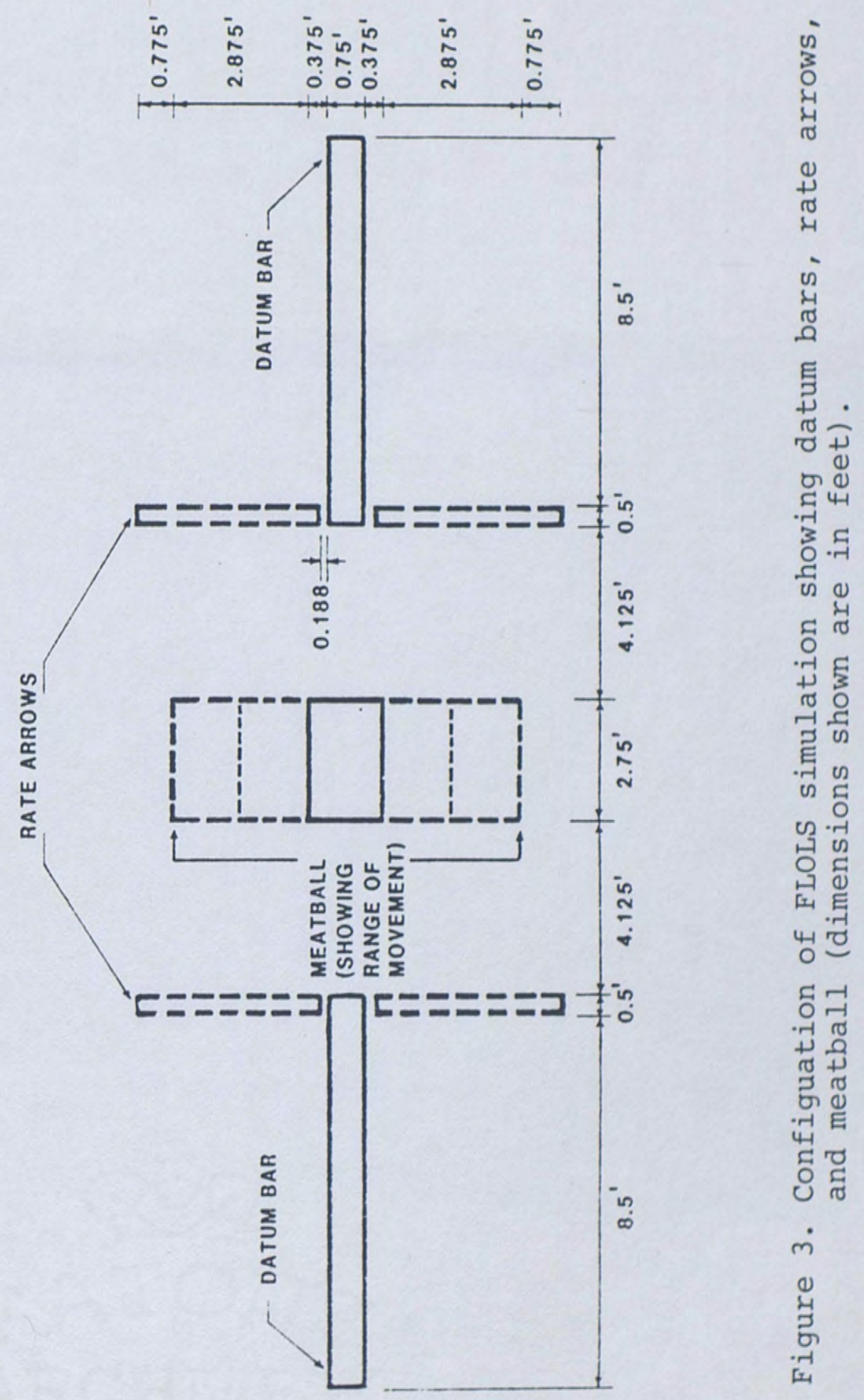


The carrier was set on a heading of $36 \emptyset$ degrees at $2 \emptyset$ knots. Environmental wind was set to produce a relative wind component of 25 knots down the deck with no effective crosswind.

For the part-task condition, the simulator was initialized with the aircraft at $18 \emptyset \emptyset$ feet from the ramp, on glideslope and centerline, and in the approach configuration (hook and wheels down, speed brake out, 15 units $A O A$, and half flaps). Power was set at $85 \%$ with vertical velocity set at approximately zero feet/minute. The aircraft was frozen in position on the grounds $X$ and $Y$ axes. In this condition, the aircraft could not converge on the carrier nor could it deviate from lineup. All other aircraft and simulator responses were the same as for the whole-task condition. A trial was flown for $6 \emptyset$ seconds after release from the initial condition. Sixty seconds of practice in the part-task condition corresponded approximately to the amount of time it took to fly a whole approach $(9 ø \emptyset \emptyset$ feet to the ramp). The carrier was set on a heading of $36 \emptyset$ degrees at $\emptyset$ knots.

FLOLS Type. The conventional version of the FLOLS display was one level of this factor. Two other levels of this factor involved the use of vertical bars displayed with the conventional Flols (Figure 3 ). These vertical 
bars provided glideslope rate of displacement information to the subjects. The two levels were designated RATE and COMMAND.

For the RATE display, the algorithm (Kaul et al., 198ø) drove the arrows in proportion to the difference between the aircraft actual descent rate and the descent rate that would maintain its present glideslope angle with respect to the FLOLS (Figure 4).

For the COMMAND display, the algorithm (Kaul et al., 1980) drove the arrows proportional to the difference between the glideslope displacement rate and a command rate which was a function of displacement. For a given aircraft velocity, range and glideslope deviation, the command function would guide the pilot back to the glideslope (Figure 4).

FLOLS Size. Since the simulated FLOLS is generated by the same system as the carrier image, it can only be as bright as the brightest areas of the ship (e.g., the white lines on the landing deck). To compensate for its lower relative brightness as opposed to the real environment, the small FLoLs was enlarged by a factor of $2 . \emptyset$ times its normal size when the distance behind the ramp was greater than $1 \emptyset \emptyset \emptyset$ feet. From $1 \emptyset \emptyset \emptyset$ feet, the size of the FLoLs was 

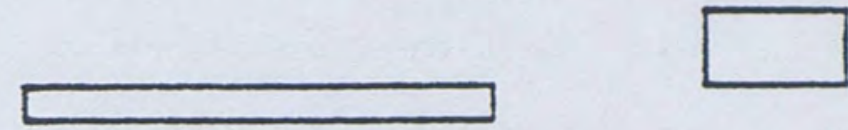

(a) A static CONVENTIONAL display does not permit a trend interpretation. For the RATE display this figure indicates that the one-ball high condition will be maintained, while for the COMMAND display that the pilot is returning to the reference glideslope at an appropriate rate.
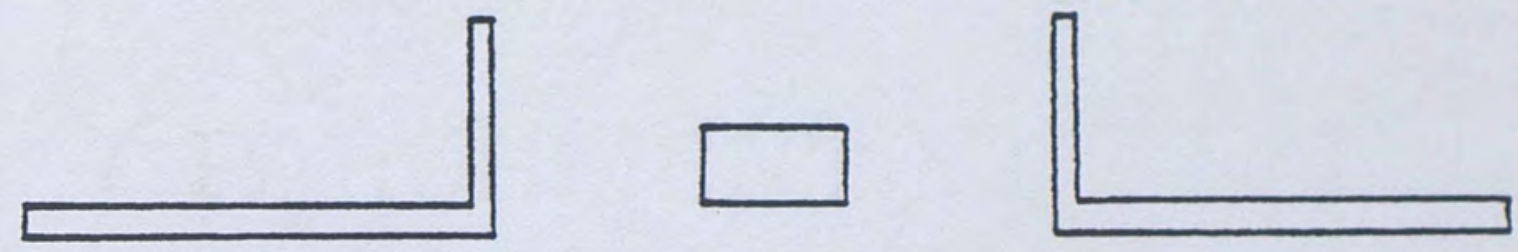

(b) For the RATE display this figure indicates one-ball high and going higher in relation to the reference glideslope. For the COMMAND display it indicates that the aircraft is high, and is not returning to the glideslope quickly enough (and may even be going higher).
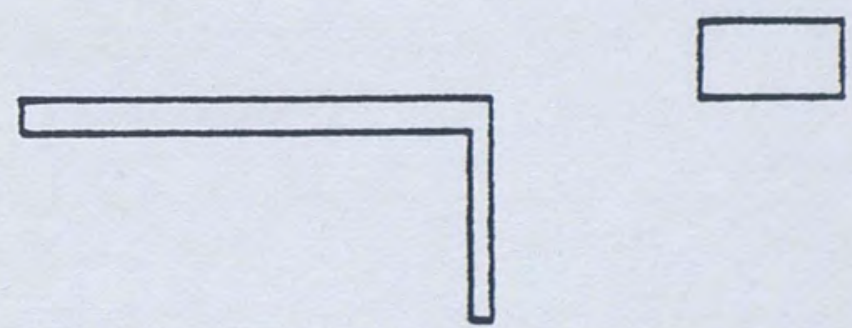

(c) For the RATE display this figure indicates that the pilot is returning to the glideslope, while for the COMMAND display that he is returning to it too quickly and will probably fly through it.

Figure 4. Three representations of possible RATE or COMMAND displays. Figure 4 (a) can also represent a CONVENTIONAL display. 
linearly reduced until it attained 1.5 times its normal size at 750 feet. It remained this size throughout the remainder of the approach.

The large FLOLS was enlarged by a factor of 4.5 its normal size when the distance behind the ramp was greater than 2250 feet. From $225 \emptyset$ feet the size of the Flols was linearly reduced until it attained 1.5 times its normal size at 750 feet. It remained this size throughout the remainder of the approach. At $18 \emptyset \emptyset$ feet from the ramp, the large FLOLS was enlarged by a factor of 3.6 .

$\underline{\text { subjects }}$

Thirty-six male college students between the age of 18 and 28 participated in the experiment at the Naval Training Equipment Center (NTEC). All subjects were paid volunteers with no flight experience.

Experimental Design

A $2 \times 2 \times 3$ full factorial quasi-transfer of training design was used in the experiment. Subjects were randomly assigned to train under one of the conditions of the basic design. All subjects were then tested on the condition that most closely represented the carrier-landing task, 
that is, the $9 \emptyset \emptyset \emptyset$ feet whole-task approach with the CONVENTIONAL display and small FLoLS (Table 1).

TABLE 1

EXPERIMENTAL DESIGN

\begin{tabular}{|c|c|c|c|c|c|}
\hline & & \multicolumn{2}{|c|}{ Conventional } & \multirow{2}{*}{$\frac{\frac{\text { Rate }}{112}}{112}$} & \multirow{2}{*}{$\frac{\text { Command }}{113}$} \\
\hline & $\begin{array}{l}\text { Small } \\
\text { FLOLS }\end{array}$ & 111 & & & \\
\hline & $\begin{array}{l}\text { Large } \\
\text { FLoLs }\end{array}$ & 121 & & 122 & 123 \\
\hline \multirow{2}{*}{$\begin{array}{l}\text { Part } \\
\text { Task }\end{array}$} & $\begin{array}{l}\text { Small } \\
\text { FLoLS }\end{array}$ & 211 & & 212 & 213 \\
\hline & $\begin{array}{l}\text { Large } \\
\text { FLOLS }\end{array}$ & 221 & & 222 & 223 \\
\hline \multicolumn{6}{|c|}{ Condition Codes: } \\
\hline $\begin{array}{l}\text { Whole Task } \\
\text { Small FLoLs } \\
\text { Conventional }\end{array}$ & $\begin{array}{l}=1 \\
=1 \\
=1\end{array}$ & $\begin{array}{l}\text { Part Task } \\
\text { Large FLOLS } \\
\text { Rate }\end{array}$ & $\begin{array}{l}=2 \\
=2 \\
=2\end{array}$ & Command & $=3$ \\
\hline
\end{tabular}




\section{Procedure}

Prior to flying the simulator, each subject played $3 \emptyset$ games of an ATARI (cartridge CX-26øl, game No. 24, difficulty 'b,' right controller) video game for use as a covariate. In subsequent discussion this game is referred to as Air Combat Maneuvering ( $A C M)$. Subjects were given a 1.5-hour briefing on carrier-landing procedures. Their simulator sequence consisted of $3 \emptyset$ training trials and $3 \emptyset$ transfer trials over a two-day period. No familiarization flights were permitted. Instructional feedback on their performance was given after each training trial by the experimenter. Feedback for lateral control was given on the first three transfer trials. There was no instructional feedback on the remaining transfer trials.

Briefing. The briefing materials consisted of information on carrier-landing procedures for each subject, and information on their specific training condition. A complete set of briefing material is presented in Appendices $A$ and $B$ Appendix $A$ contains the carrier-landing instructions and Appendix B contains the special instructions. Subjects read the briefing materials and were then briefed on carrier-landing procedures by the experimenter. The experimenter also described the location of cockpit instruments and controls. 
Instructional Feedback. Normally, the Landing Signal officer (LSO) provides feedback to the pilot during an approach. However, while the services of these personnel would be desirable, they are difficult to acquire. In addition, in previous student/instructor interactions, phenomena such as increased assistance have been apparent for those who do poorly (which may correspond to specific experimental treatments) (Lintern, Nelson, Sheppard, Westra, and Kennedy, 1981).

In an attempt to maintain experimental control of student/instructor interactions, personnel with a psychological background were trained to teach the required skills. While this approach may lose something in the quality of instruction, that loss would seem to be offset by gains in experimental control. This approach appeared to have worked successfully in a previous carrier-landing experiment where the experimenter provided feedback to Navy and Air Force pilots after an approach (Lintern et al., 1981).

Instructional feedback was given after every training trial by the trained experimenter. To aid in the instructional feedback, a graphic display provided plots of glideslope deviation, angle-of-attack deviation, lineup deviation, vertical velocity, aircraft pitch and power 
setting. Plots were provided for the final $6 \emptyset \emptyset \emptyset$ feet. of the whole-task condition and the entire $6 \emptyset$ seconds of the part-task condition. Feedback was limited to major problems or errors that occurred during the trial.

Covariate Task. In simulation research, individual differences tend to account for much of the unexplained variance (Westra, 1981). One method of reducing the unexplained variance is to assess subject aptitude for the task and account for some of the between-subject variance through an analysis of covariance. An ATARI video game was selected as a covariate since prior research had shown a high test-retest reliability and other characteristics desirable in a covariate (Jones, Kennedy and Bittner, 1981). Furthermore, the ATARI video game is a compensatory tracking task that involves similar abilities to the carrier-landing task (Lintern and Kennedy, 1982).

Data on the ATARI Air Combat Maneuvering game (Game No. 24, difficulty 'b', right controller) were collected prior to flying the simulator. All subjects completed a total of $3 \emptyset$ games. A subject's score for one game is the total number of hits during a game period. 
Performance Measurement and Data Analysis

Parameters of aircraft position were sampled at $3 \emptyset \mathrm{Hz}$ and used to derive summary scores from the desired approach path for the following segments.

\begin{tabular}{cc}
\hline Whole Task & Park Task \\
$6 \emptyset \emptyset \emptyset \mathrm{ft}$ to $45 \emptyset \emptyset \mathrm{ft}$ & $21 \mathrm{sec}$ to $3 \emptyset \mathrm{sec}$ \\
$45 \emptyset \emptyset \mathrm{ft}$ to $3 \emptyset \emptyset \emptyset \mathrm{ft}$ & $31 \mathrm{sec}$ to $4 \emptyset \mathrm{sec}$ \\
$3 \emptyset \emptyset \emptyset \mathrm{ft}$ to $15 \emptyset \emptyset \mathrm{ft}$ & $41 \mathrm{sec}$ to $5 \emptyset \mathrm{sec}$ \\
$15 \emptyset \emptyset \mathrm{ft}$ to Ramp & $51 \mathrm{sec}$ to $6 \emptyset \mathrm{sec}$ \\
\hline
\end{tabular}

Root-Mean Square (RMS) error scores were calculated for glideslope, lineup and angle of attack. The RMS scoring algorithm was: where $e$ is error at time $t$ and $\mathrm{N}$ is the number of data points sampled in the segment. Mean algebraic error scores were also calculated for glideslope.

Repeated measures analyses of covariance were the primary statistical tests of the data. Orthogonal comparison of main effects of Trials $1-5$ vs $26-3 \emptyset, 6-1 \emptyset$ vs 21-25 and $11-15$ vs $16-20$ were computed to assess interactions of effects with trials. This analysis gives similar information to the main effects $x$ trial block interactions of the main ANOVA, but provides a more powerful test of initial and brief effects at time of 
transfer. It was considered advisable to undertake this test and set statistical significance at the $\emptyset .1 \emptyset$ level in view of the limited power allowed by the number of subjects available for this experiment. The power analysis showing the probability of detecting a large, medium or small

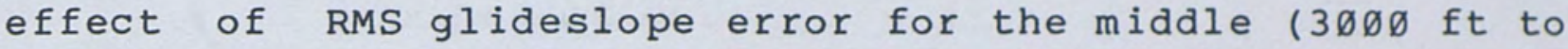

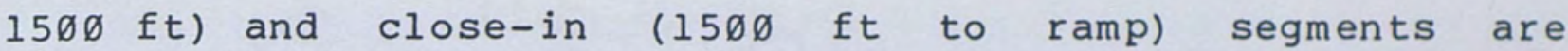
presented in Appendix C. The data was also blocked (5-trial means) to increase trial-to-trial reliability. Eta squared was calculated to estimate the proportion of variance accounted for by significant effects. 


\section{RESULTS}

Statistical analyses were conducted on both the training and transfer data. The training data were analyzed to check the effectiveness of the factor manipulations and to show that learning occurred. The transfer data were analyzed to show the effects of the factor manipulations on performance of the criterion task.

Data analyses are presented on Root Mean Square (RMS) and average glideslope error, RMS Angle-of-Attack error and RMS 1 ineup error for the middle ( $3 \emptyset \emptyset \emptyset$ ft to $15 \emptyset \emptyset$ ft) and close-in (15øø ft to ramp) segments of the approach. These final segments were selected because dependent measures were more stable and effects stronger and more consistent in the final part of the approach; the final part of the approach is the most critical and difficult portion of the task; the middle segment contained the position at which the part-task subjects were trained; and FLOLS size was a factor in the middle segment as opposed to the close-in segment ( $1 \emptyset \emptyset \emptyset$ ft to the ramp it was the same size). 
Preliminary analysis of the data to check for normality, symmetry and homogeneity of variances showed the RMS error scores to be highly skewed with unequal variances. Thus, prior to analysis of variance, RMS error scores were $\log (\mathrm{X}+1)$ transformed to satisfy the assumptions of normality and homogeneity of variance. Although transformation to correct for violation of these assumptions is often considered unnecessary, the failure to do so can result in a loss of statistical power (Levine and Dunlap, 1982). As there was no apparent disadvantage resulting from the transformation, and there were specific theoretical advantages, the log transform was applied routinely to all RMS scores. For descriptive purposes, algebraic means are presented in all tables and graphs.

\section{$\underline{\text { Training }} \underline{\text { Data }}$}

Since training data were not generally discussed and were analyzed to check learning and factor manipulations, all means and repeated measures' analysis of covariance summaries are presented in Tables $D-1$ to $D-12$ in Appendix D. Furthermore, no training data are presented on RMS lineup error since the part-task trained subjects could not deviate from lineup. 
RMS Glideslope Error. There were no statistically significant main effects for the training trials (Tables Dl and D3). There was a significant task $x$ FLols size interaction $(p<.05)$ in both segments. RMS glideslope error was lower for subjects trained in whole-task large FLOLS and part-task small FloLs (Figure 5). This effect accounted for $11 \%$ of the between-subjects experimental variance in the $3 \emptyset \emptyset \emptyset-15 \emptyset \emptyset$ foot segment and $1 \emptyset \%$ in the $15 \emptyset \emptyset$ foot to ramp segment.

The significant block effect $(p<. \emptyset 1)$ for both segments (Tables $D-1$ and $D-3$ ) indicates that subjects improved in the training trials. Inspection of the data suggest that most of the learning occurred in the first 15 trials but some learning continued throughout training. This effect accounted for $41 \%$ of the within-subjects experimental variance in the middle segment and $52 \%$ in the close-in segment of the approach.

There was a significant block $x$ task $x$ FLoLS size interaction $(p<. \emptyset 1)$ in the middle segment (Table $D-1)$. The interaction indicates subjects in different groups learned at different rates. RMS glideslope error was lower at the start of training for subjects trained with whole-task large FLOLS and part-task small FLOLS (Figure 6). Subjects trained on whole-task large FLOLS also had slightly lower 


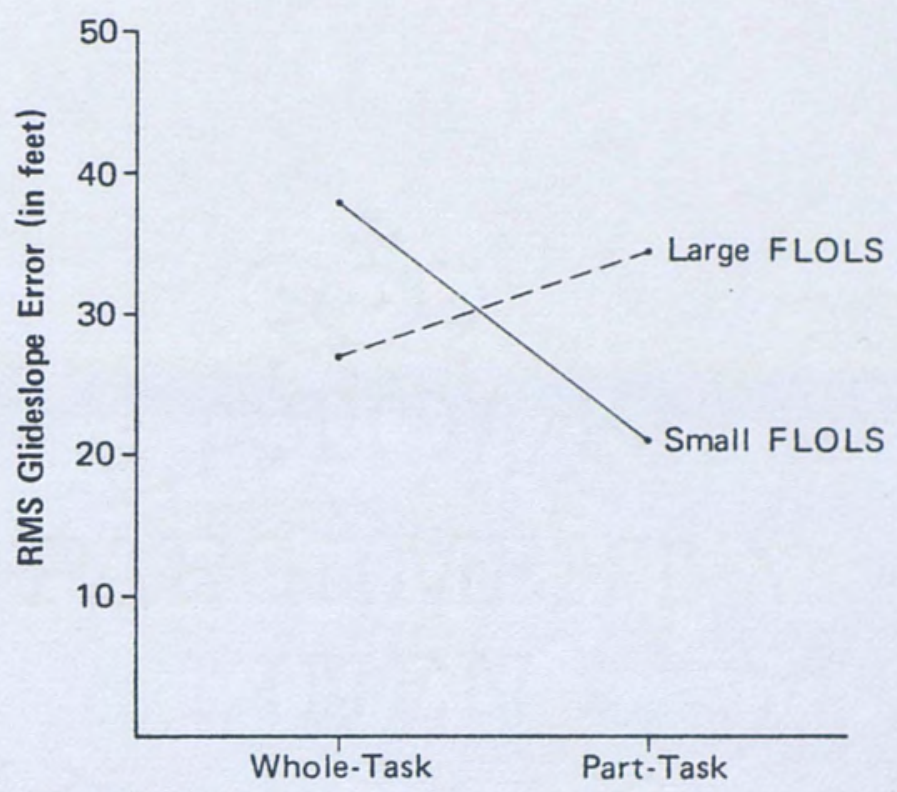

\section{(A) Middle Segment}

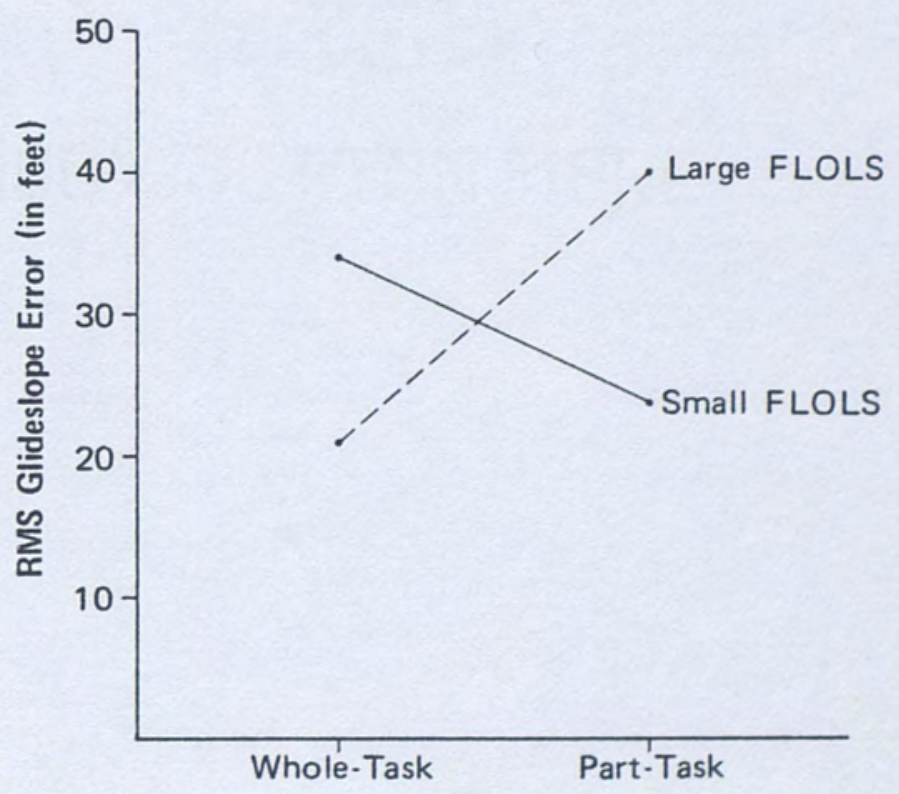

(B) Close-In Segment

Figure 5. Task $x$ FLOLS size interactions for RMS glideslope error during training. 


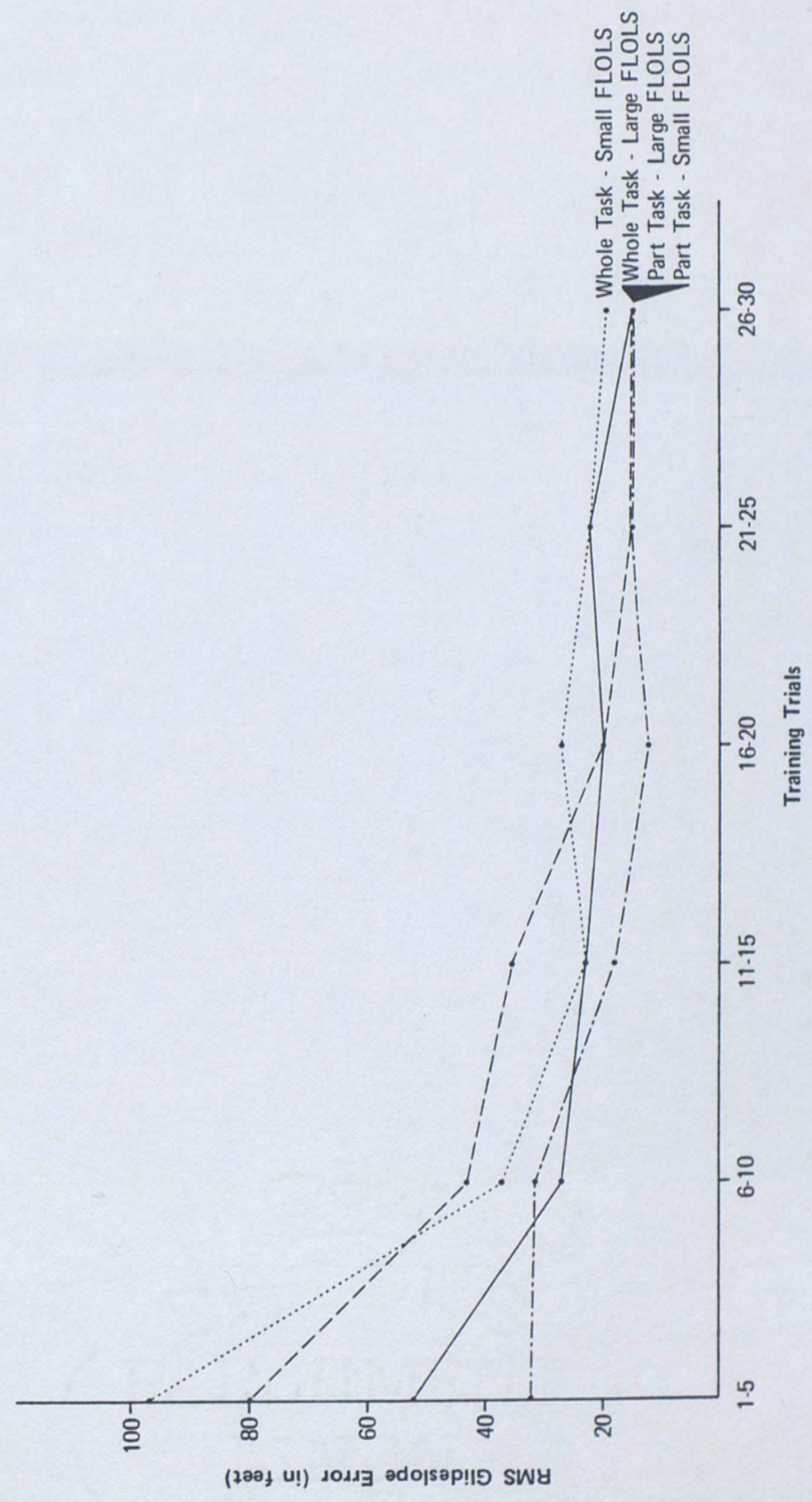


error scores at the end of training versus subjects trained on whole-task small FLoLs (Figure 6). On the other hand, subjects trained in the part-task display were at the same level of performance at the end of training regardless of FLOLS size. The block $X$ task $X$ FLOLS size interaction accounted for $5 \%$ of the within-subjects variance in the middle segment.

There was also a block $X$ Flols size $x$ Flols type interaction $(\mathrm{p}<. \emptyset 1)$ in the middle segment (Table D-1). This effect accounted for $8 \%$ of the within-subjects variance in the middle segment.

In addition to RMS glideslope error, average glideslope error was analyzed to examine approach bias of the factor manipulations.

Average Glideslope Error. There were no statistically significant main effects for the training trials (Tables D-5 and D-7). There was a significant Task X FLoLS size interaction $(p<. \emptyset 5)$ for both segments. Subjects trained on part-task small FLOLS and whole-task large FLoLs tended to fly closer to glideslope in comparison to subjects trained on whole-task small FLOLS and part-task large FLOLS (Figure 7). This effect accounted for $13 \%$ of the between-subjects 


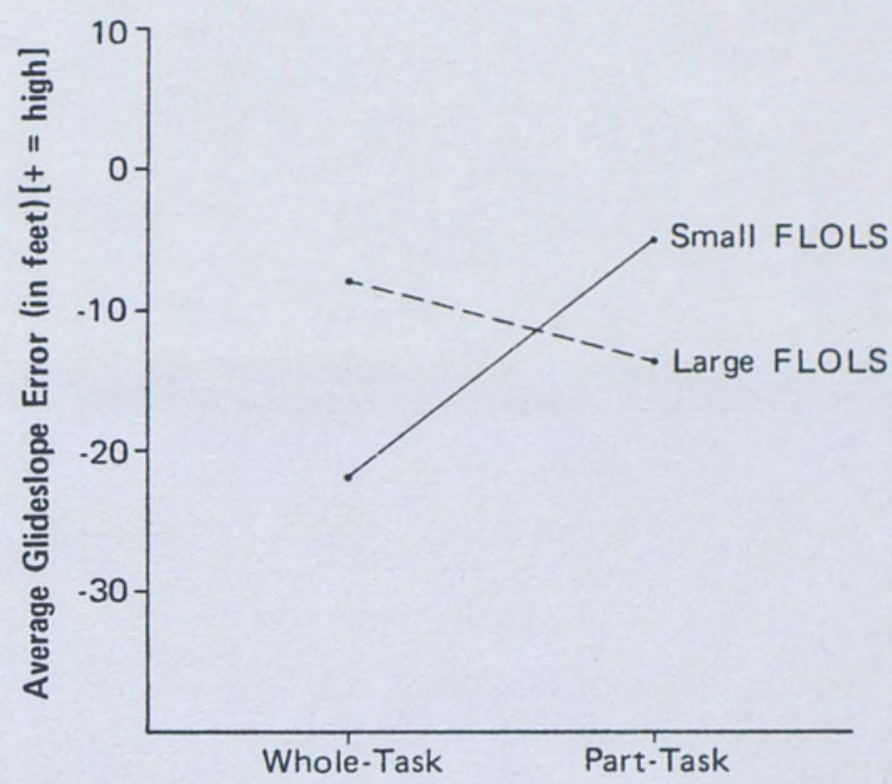

(A) Middle Segment

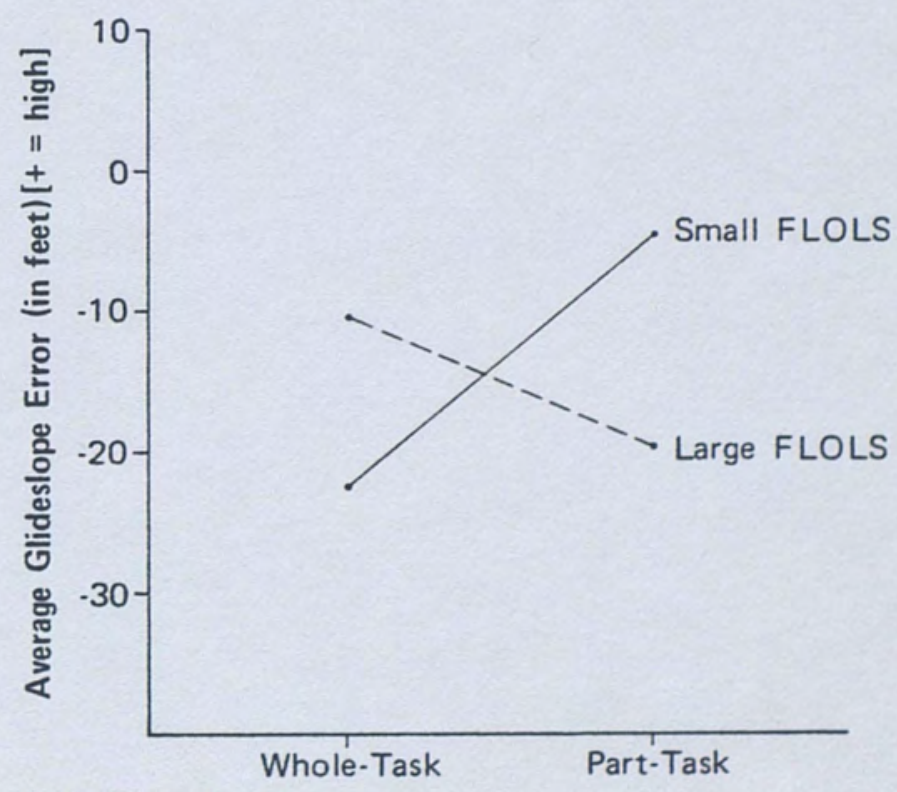

(B) Close-In Segment

Figure 7. Task $x$ FLoLs size interactions for average
glideslope error during training. 
experimental variance in the middle segment and $14 \%$ close-in.

There was a significant block ( $p<. \emptyset 1)$ effect for both segments (Tables $\mathrm{D}-5$ and $\mathrm{D}-7$ ). The main effects indicate that learning took place in the training trials. This effect accounted for $25 \%$ of the within-subjects experimental variance in both the middle and the close-in segments.

There was a significant block $X$ task $X$ FLoLs size interaction in both the middle $(p<.1 \emptyset)$ and close-in $(p<. \emptyset 5)$ segments. The interactions indicate that subjects with different tasks learned at different rates. This effect accounted for $5 \%$ of the within-subjects experimental variance in the middle segment and $7 \%$ in the close-in segment.

The correct AOA is essential in a carrier approach, otherwise, the pilot will land at the carrier with the wrong airspeed and pitch altitude. Thus RMS AOA error was analyzed to examine AOA control.

$\underline{\text { RMS }}$ Angle-of-Attack Error. Task type was the only statistically significant main effect for the training trials (Tables D-9 and D-11). RMS angle-of-attack error 
was lower for subjects trained on the part task versus those trained on the whole task. This effect accounted for $17 \%$ of the between subjects experimental variance in the middle segment $(p<. \varnothing 1)$ and $27 \%$ in the close-in segment $(p<. \varnothing 5) \cdot$

The significant block effect $(p<. \emptyset 1)$ in both segments indicates that learning took place in the training trials. This effect accounted for $2 \emptyset \%$ of the within-subjects experimental variance in the middle segment and $23 \%$ in the close-in segment.

There was a significant block $X$ FLOLS size $X$ FLOLS type interaction in both the middle ( $p<. \emptyset 1)$ and close-in $(p<. \emptyset 5)$ segment. This effect accounted for $12 \%$ of the within-subjects experimental variance in the middle segment and $1 \emptyset \%$ in the close-in segment.

Transfer Data

The transfer trials consisted of the approach most representative of the carrier-landing task (9øøø ft straight-in approach, conventional and small FLOLS). In addition, in order to make the results of the transfer data more coherent, all table means and repeated measures' 
analysis of covariance summaries are presented at the end of the Results section.

RMS Glideslope Error. Task type was the only statistically significant main effect for the transfer trials (Tables 2 and 4). RMS glideslope error was lower for subjects trained on the whole task versus those trained on the part task $(p<. \emptyset 5)$. This effect accounted for $13 \%$ of the between-subjects experimental variance in the middle segment and $1 \emptyset \%$ in the close-in segment.

There was a significant block $(p<. \emptyset 1)$ and significant block by task interaction $(p<. \emptyset 5)$ for both segments (Tables 2 and 4 ). The main effects indicate learning continued in the transfer trials and the interaction indicates the part-task versus whole-task trained subjects learned at different rates. Figure 8 shows that the part-task trained subjects started the transfer phase with higher error scores and rapidly improved their performance to be close to that of the whole-task trained subjects by the end of the transfer trials. The block effect accounted for $21 \%$ of the within-subjects variance in the middle segment and $35 \%$ in the close-in segment. The block $x$ task interaction accounted for $6 \%$ of the variance in the middle segment and $7 \%$ in the close-in segment. 


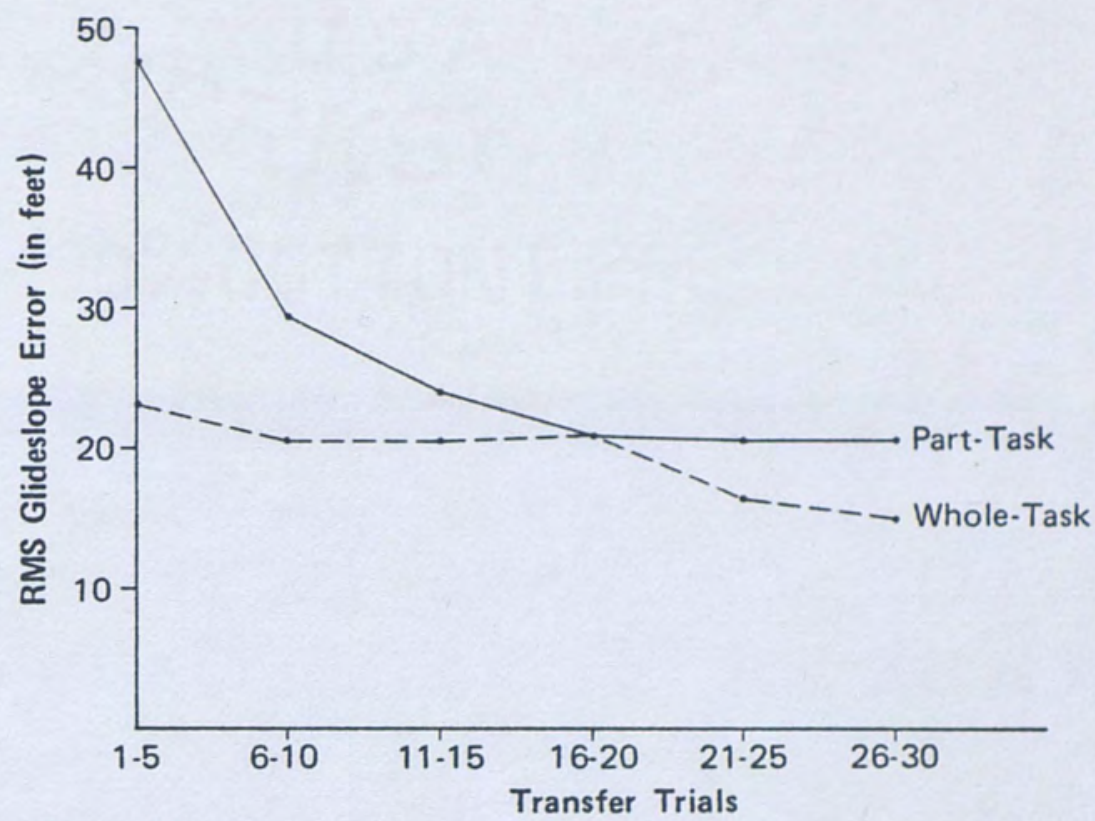

(A) Middle Segment

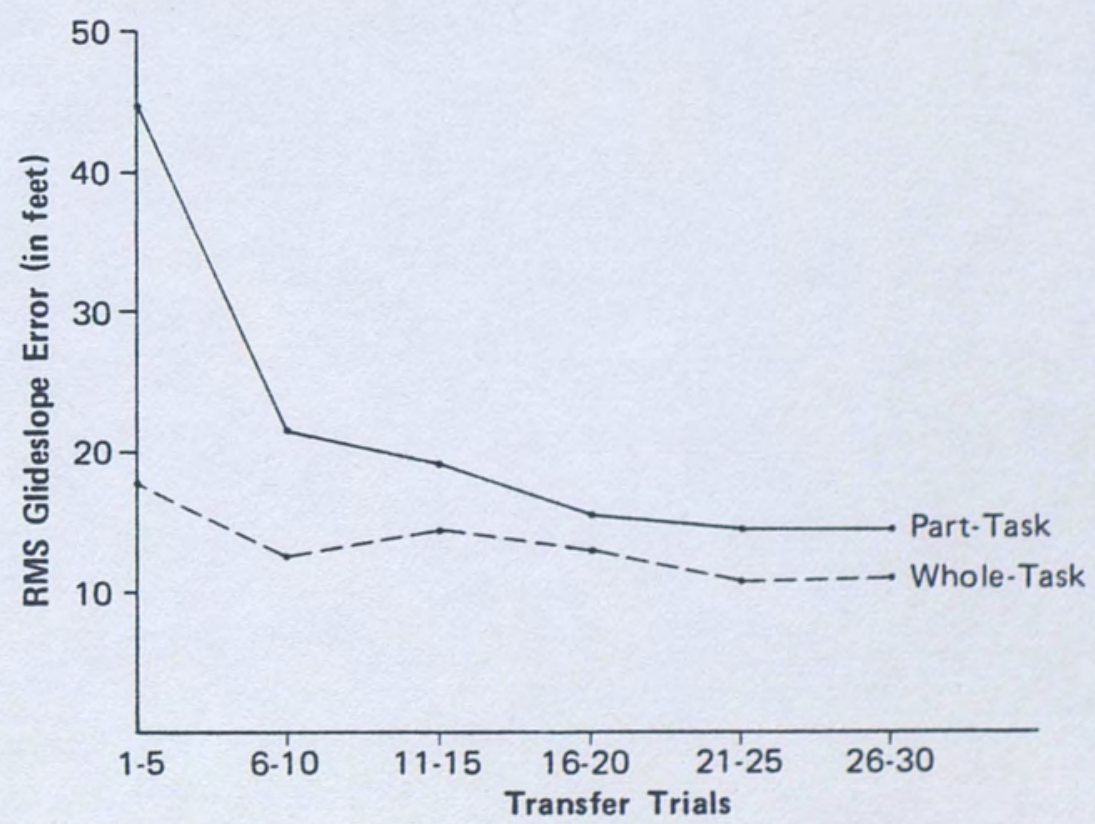

(B) Close-In Segment

Figure 8. Block $x$ task interactions for RMS glideslope error during transfer. 
There was an interaction of task type $F(1,12 \emptyset)=8.83$, $p<. \emptyset 1$ for trials $1-5$ versus $26-3 \emptyset$ in the close-in segment. RMS glideslope error was substantially lower for subjects trained on the whole task versus those trained in the part task in trials $1-5$ but not in trials 26-3ø (Figure 8). This effect is consistent with the block $x$ task interaction for this segment noted in the previous paragraph in showing the two groups learned at different rates. In addition, the failure to achieve significance in the other comparisons suggests that the major learning differential occurred in the first block. There was also a block $x$ task $x$ FLOLS type interaction $(p<.1 \emptyset)$ in the middle segment (Table 2). Figure 9 shows that subjects trained in part task with any of the Flols displays start the transfer phase with higher error scores and rapidly improve their performance. Subjects trained in part task with the RATE display had the lowest error scores for the part-task conditions at initial transfer. This interaction accounted for $8 \%$ of the within-subjects experimental variance in the middle segment.

There was an interaction of FLOLS type for trials 1-5 versus 26-3ø in both segments. The interaction was significant for the comparison of CONVENTIONAL versus COMMAND display in both the middle $F(1,12 \emptyset)=3.5 \emptyset, p<.1 \emptyset$ and close-in $\mathrm{F}(1,12 \emptyset)=6.19, \mathrm{p}<. \emptyset 5$ segments. The comparison of 


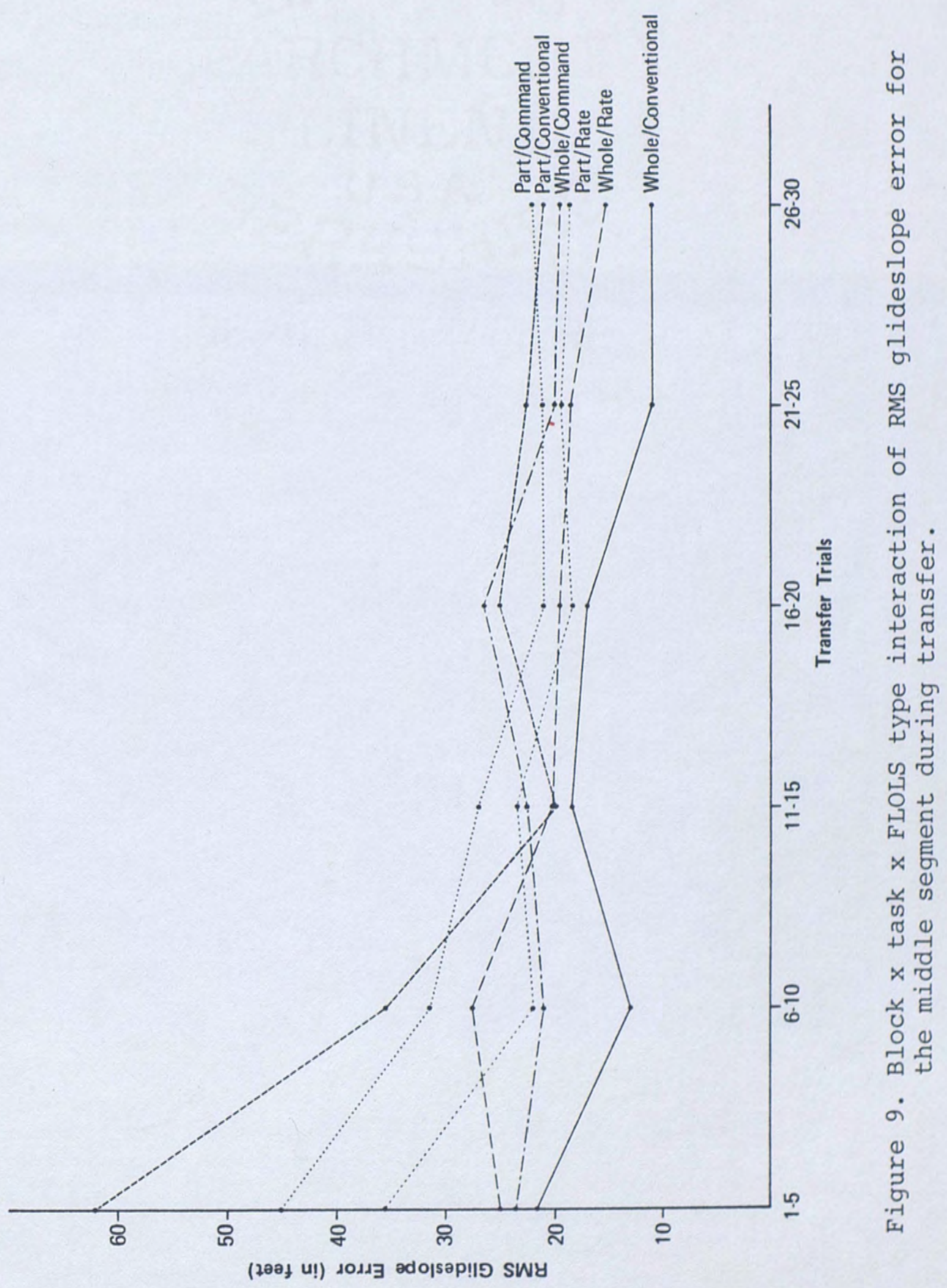


CONVENTIONAL versus RATE display was also significant in the close-in segment $F(1,2 \emptyset)=2.92, p<.1 \emptyset$. RMS glideslope error was lower for subjects trained with the COMMAND display versus those trained with the CONVENTIONAL display in trials $1-5$ (Figure 1ø). As transfer progressed, learning in the COMMAND display condition appeared to be inhibited. Thus, RMS glideslope error was lower for subjects trained with the CONVENTIONAL display versus those trained with the COMMAND display in trials 26-3ø (Figure 1ø). RMS glideslope error was also much lower for subjects trained with the RATE display versus those trained with the CONVENTIONAL display in trials 1-5 (Figure 1ø), although this effect dissipated by the end of the transfer session.

There was an interaction of FLoLs size for trials 6-1ø versus 2l-25 in both the middle $F(1,12 \emptyset)=4.5 \emptyset$, $p<. \emptyset 5$ and close-in $F(1,12 \emptyset)=4.48, p<. \emptyset 5$ segments. RMS glideslope error was lower for subjects trained with the large FLoLs versus those trained with the small FLOLS in trials 6-1ø. A slight reversal occurred in trials $21-25$ and RMS glideslope error in this transfer block was lower for subjects trained with the small FLoLs versus those trained with the large FLoLs (Figure 11).

There was a significant interaction of task $x$ FLOLS type $X$ FLOLS size $(p<. \emptyset 5)$ in the close-in segment (Table 


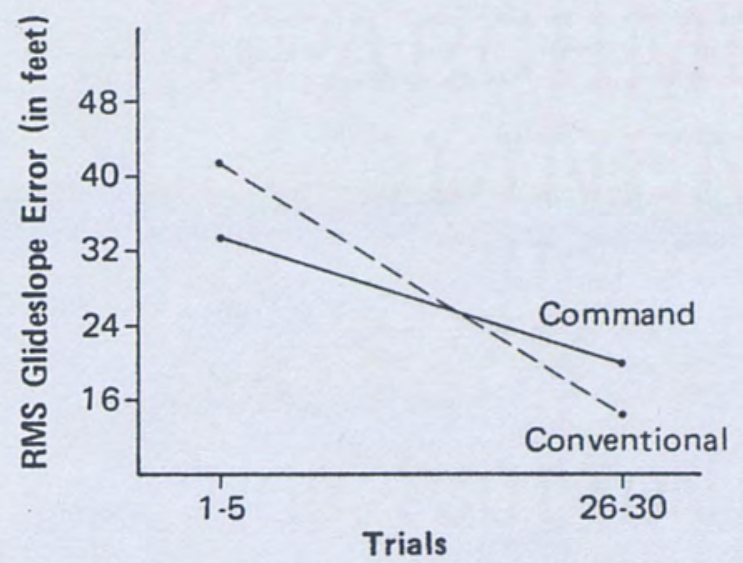

(A) Conventional $\times$ Command [Middle Segment]

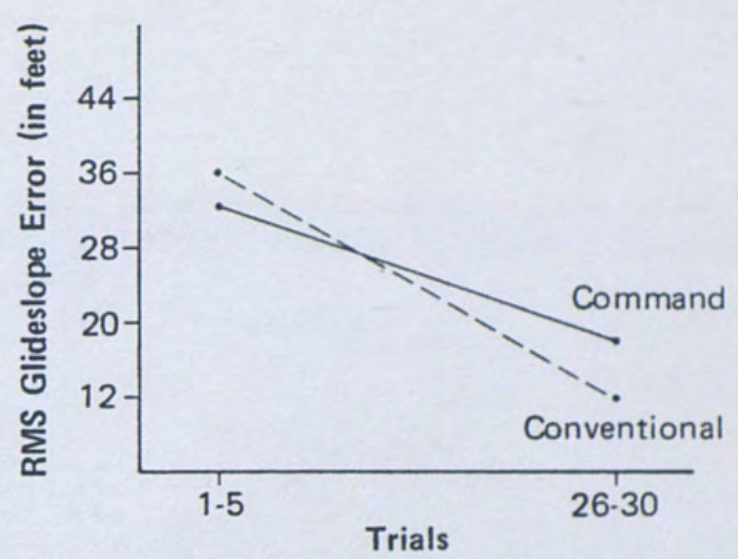

(B) Conventional $\times$ Command

[Close-In Segment]

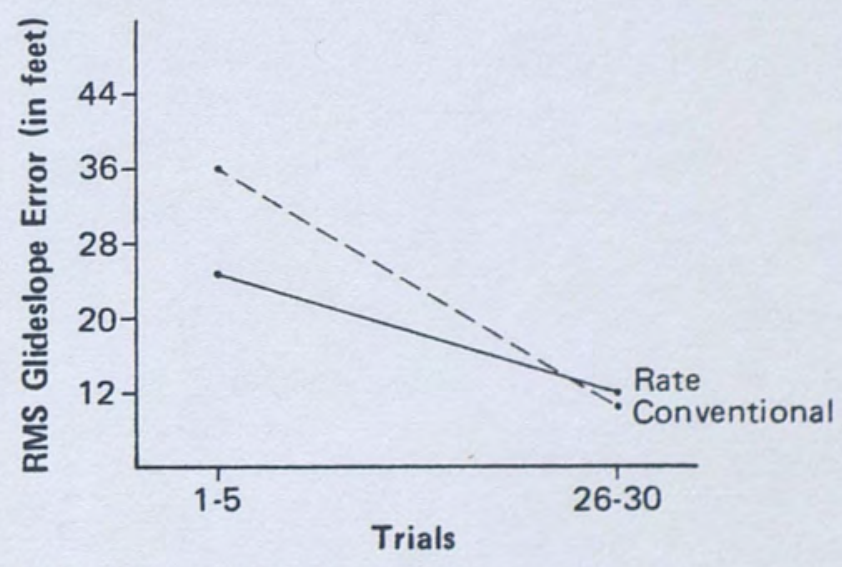

(C) Conventional $\times$ Rate

[Close-In Segment]

Figure 10. FLOLS type interactions of RMS glideslope error during transfer. 


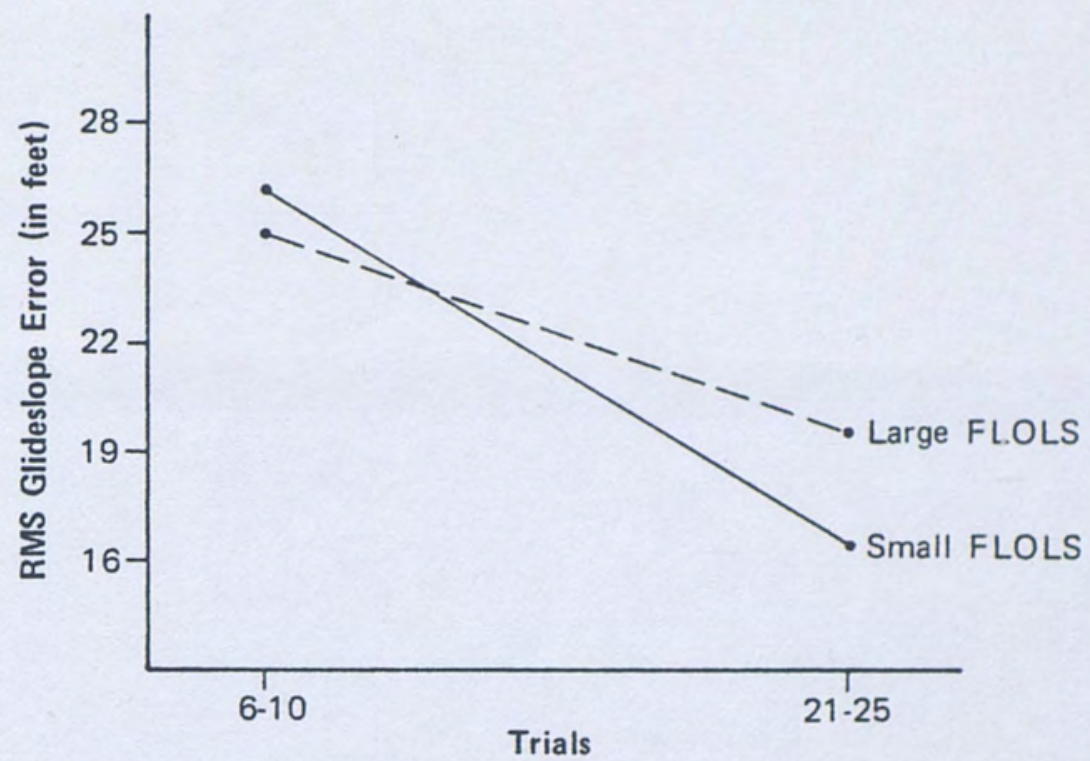

(A) Middle Segment

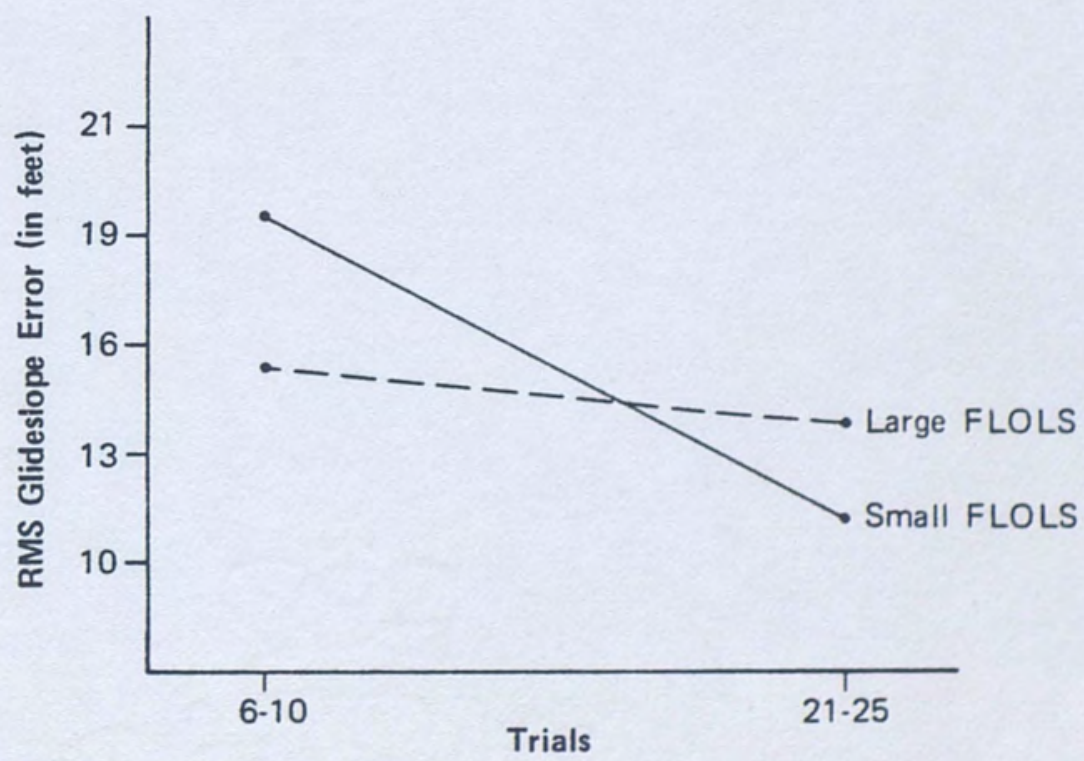

(B) Close-In Segment

Figure 11. FLOLS size interactions of RMS glideslope error during transfer. 
4). Transfer performance was superior for whole-task training conditions except when part-task training is combined with the RATE display and small FLoLS (Figure 12). Transfer performance for the part-task X RATE display $X$ small FLoLs condition is as good as performance under any of the whole-task conditions. This interaction accounted for $15 \%$ of the between-subjects experimental variance in the close-in segment.

The ATARI covariate was significant ( $p<. \emptyset 1)$ in the close-in segment (Table 4). Performance on the ATARI video game accounted for a substantial 198 of the between-subjects experimental variance in this segment.

Average Glideslope Error. Task type was the only statistically significant main effect for the transfer trials (Tables 6 and 8 ). Subjects trained on the part task flew lower on glideslope versus those trained on the whole task. This effect accounted for $23 \%$ of the between-subjects experimental variance in the middle segment $(p<. \emptyset 1)$ and $12 \%$ of the variance in the close-in segment $(p<.1 \emptyset)$.

There was a significant block ( $\mathrm{p}<. \emptyset 1)$ and block $\mathrm{X}$ task interaction ( $p<. \emptyset 1)$ for both segments (Tables 6 and 8 ). The main effects indicate learning in the transfer trials 


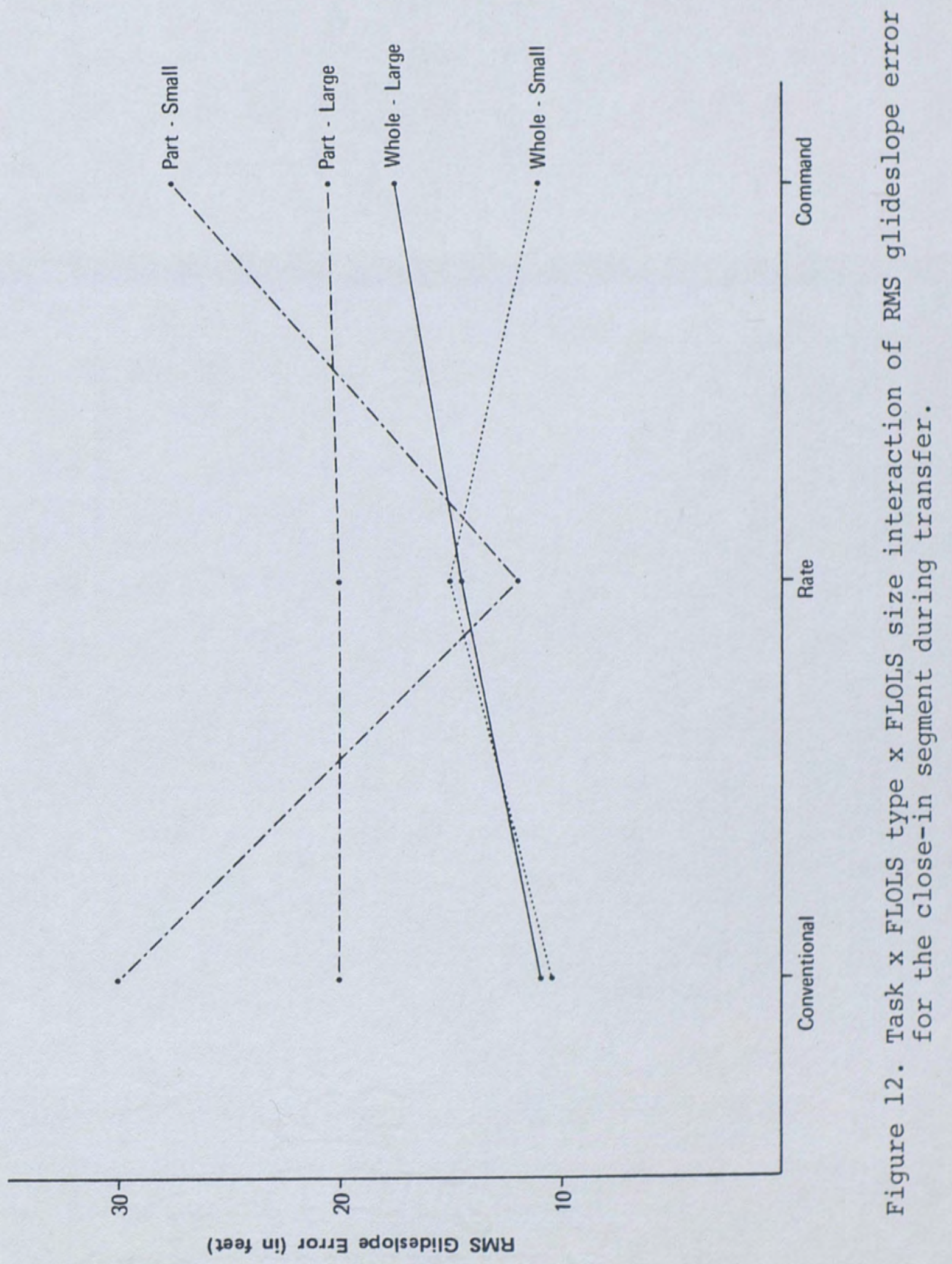


and the interaction indicates that part-versus whole-task trained subjects are learning at different rates. Figure 13 shows the the part-task trained subjects start the transfer phase substantially lower on glideslope and rapidly improved their performance. The block effect accounted for $13 \%$ of the within-subjects variance in the middle segment and $11 \%$ in the close-in segment. The block $x$ task interaction accounted for $4 \%$ of the variance in the middle and 58 close-in.

There was an interaction of task type (p<.ø1) for trials $1-5$ versus $26-3 \emptyset$ in both the middle $F(1,12 \emptyset)=15.6$, $\mathrm{p}<. \emptyset 1$ and close-in $F(1,12 \emptyset)=13.3, p<. \emptyset 1$ segments. Subjects trained in the part task flew substantially lower on glideslope versus those trained in the whole task in trials 1-5 (Figure 13). This effect is consistent with the block $\mathrm{X}$ task interactions in the segments.

There was an interaction of FLOLS type for trials 1-5 versus $26-3 \emptyset$ in both segments. The interactions were significant for the comparison of CONVENTIONAL versus RATE displays in the middle $F(1,12 \emptyset)=5.42, p<. \emptyset 5$ and close-in $(F(1,12 \emptyset)=4.79, p<.05$ segments. Subjects trained on the CONVENTIONAL display flew substantially lower on glideslope versus those trained on the RATE display in trials 1-5 (Figure 14). Inspection of the means in Tables 7 and 9 


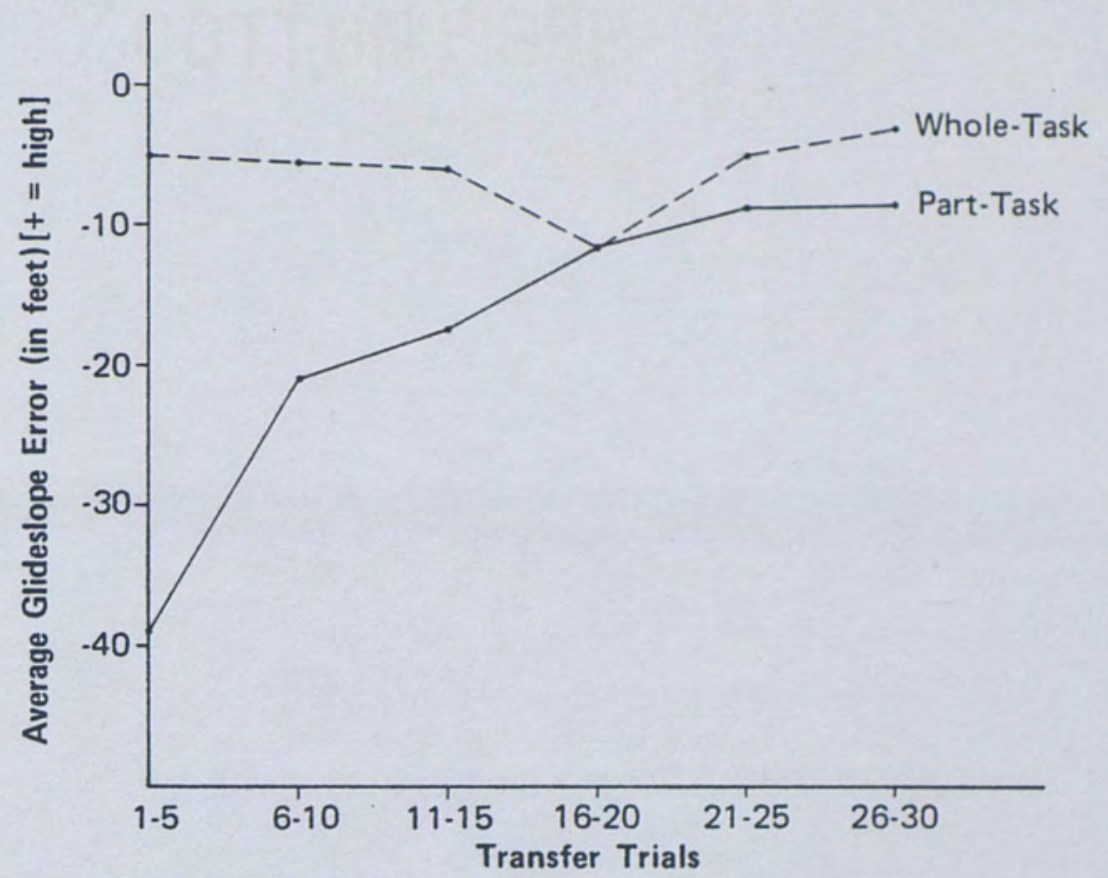

(A) Middle Segment

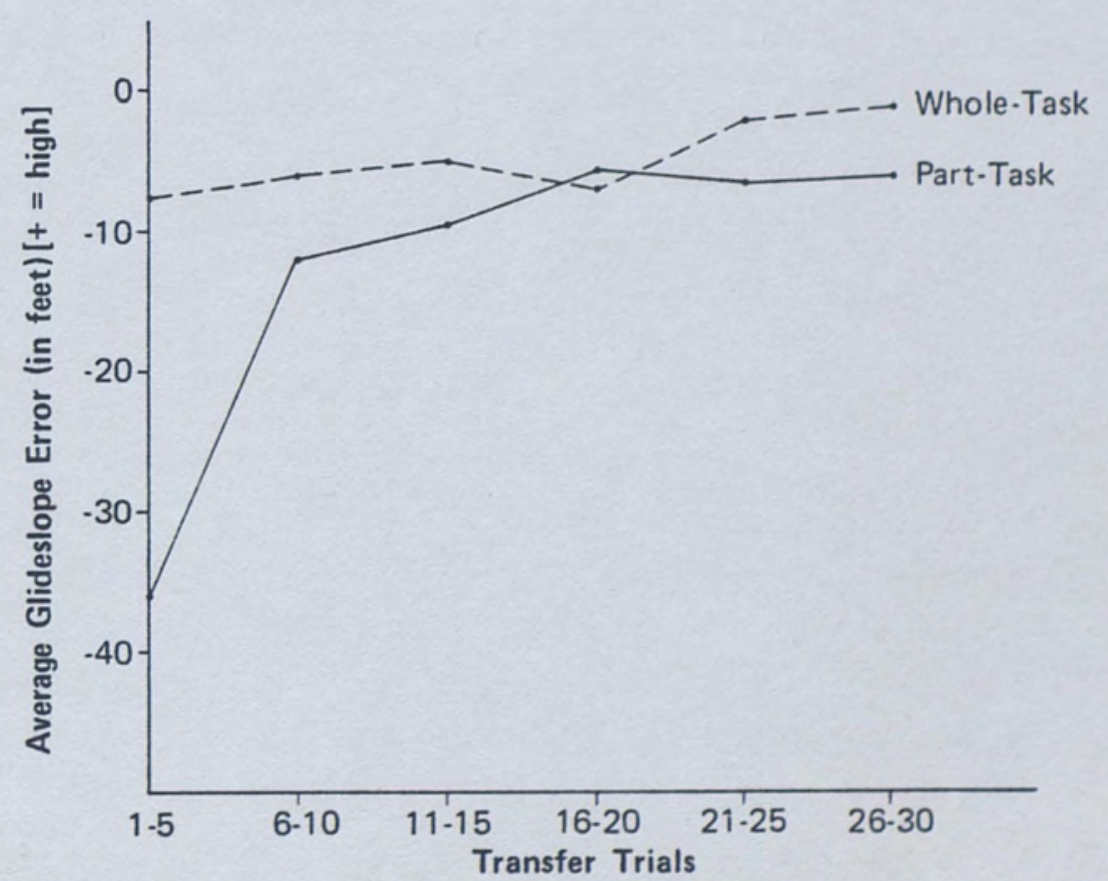

(B) Close-In Segment

Figure 13. Block $x$ task interactions for average glideslope error during transfer. 


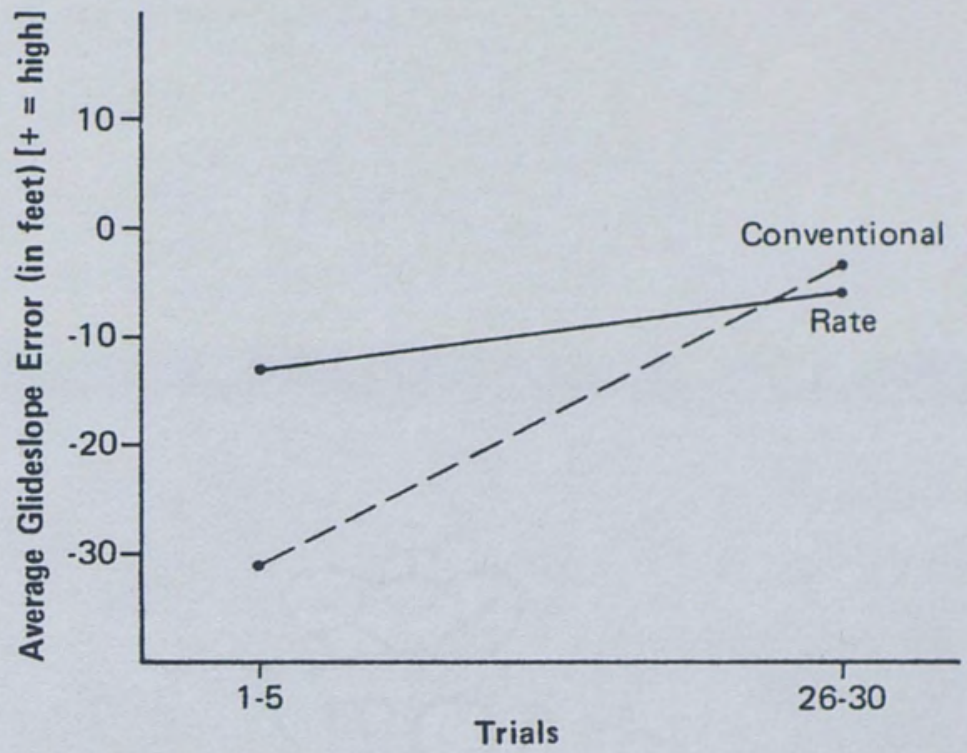

(A) Middle Segment

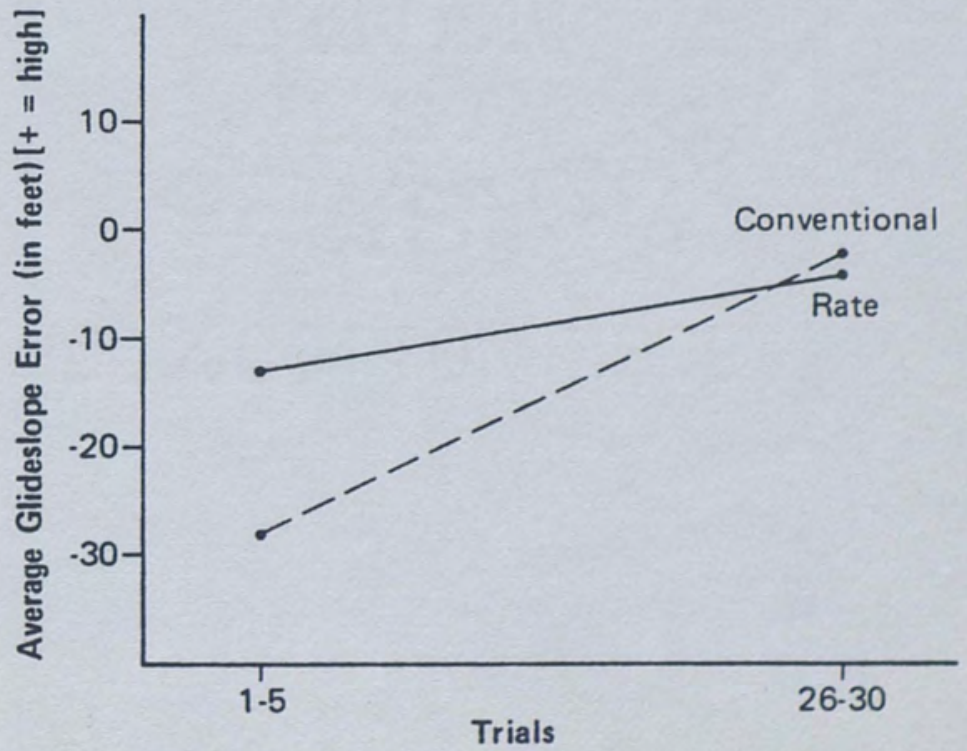

(B) Close-In Segment

Figure 14. FLOLS type interactions for average glideslope error during transfer. 
show that this effect continued through transfer trials 11-15, although the remaining flols type $x$ segment interactions were not statistically significant.

RMS Angle-of-AttacK. There were no statistically significant main effects for the transfer trials (Tables $1 \emptyset$ and 12).

Significant block effects accounted for $1 \emptyset \%$ of the variance in the middle segment ( $p<. \emptyset 1$, Table $1 \emptyset)$ and $5 \%$ in the close-in segment ( $p<.10$, Table 12).

There was a block $\mathrm{X}$ task interaction ( $p<.1 \emptyset)$ and block $x$ Flols type interaction $(p<. \emptyset 5)$ in the middle segment (Table 1ø). Figure 15 shows that the part-task trained subjects start the transfer phase with lower error scores and continued to be lower through transfer trials 21-25. The block $x$ task interaction accounted for $4 \%$ of the within-subjects experimental variance in the middle segment. Figure 15 shows that subjects trained with the RATE display started the transfer phase with the highest error scores and rapidly improved their performance. subjects trained with the COMMAND display started the transfer phase with the lowest error scores and continued to be lower through transfer trials 21-25. The block $\mathrm{x}$ 


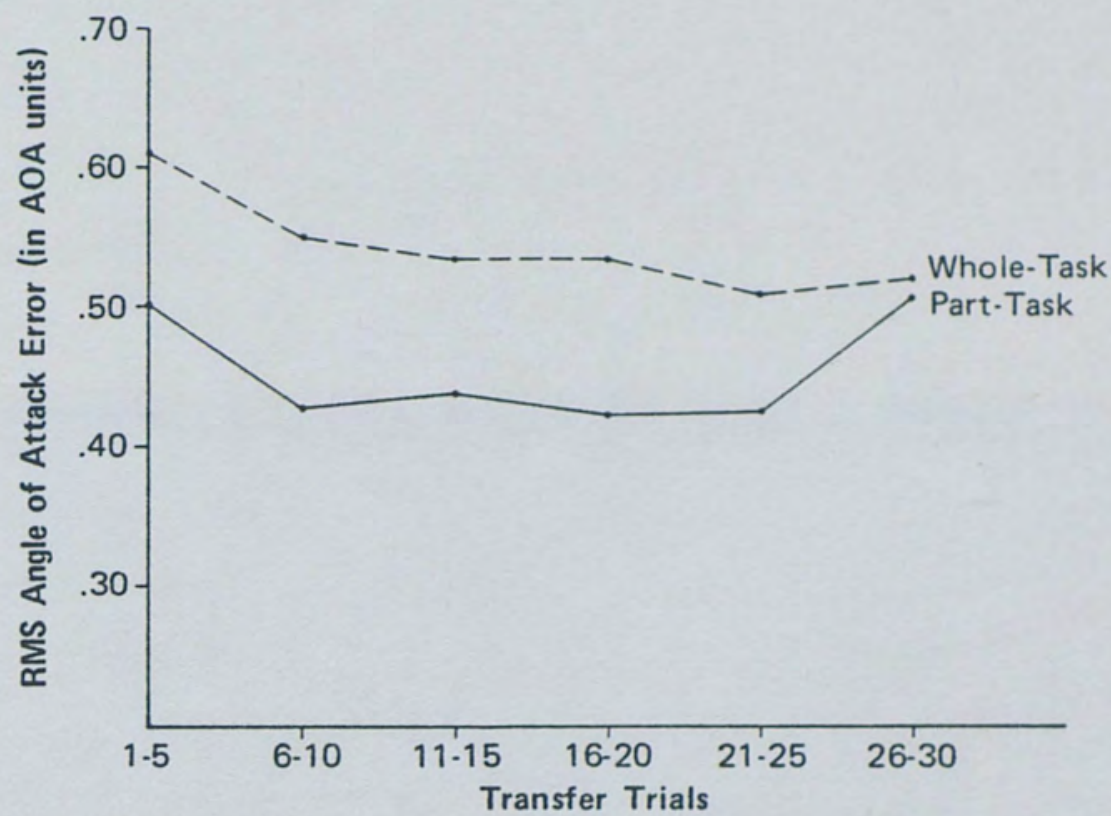

\section{(A) Block $\times$ Task}

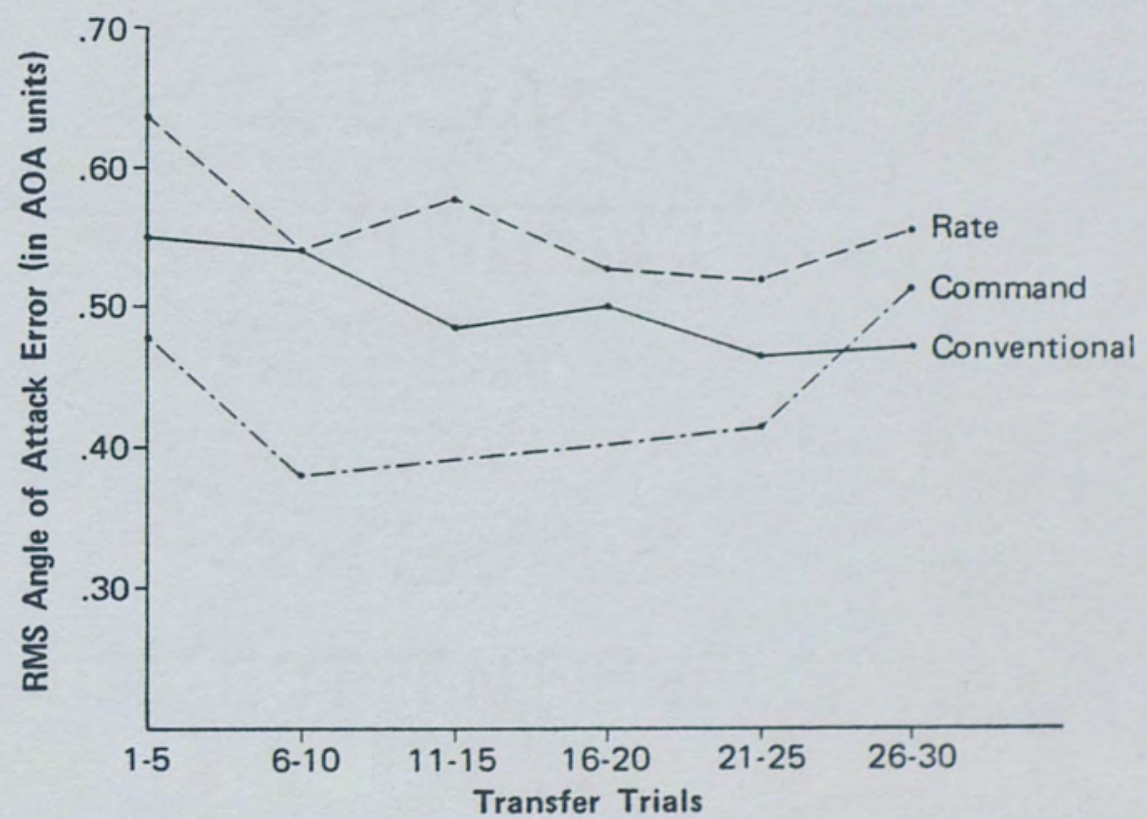

(B) Block $\times$ FLOLS Type

Figure 15. Block $x$ task and block $x$ FLOLS type interactions of RMS angle-of-attack error for the middle segment during transfer. 
FLOLS type interaction accounted for $1 \emptyset \%$ of the within-subjects experimental variance in the middle segment.

There was an interaction of task type for trials 1-5 versus $26-3 \emptyset$ in the middle segment $F(1,12 \emptyset)=3.77, p<.1 \emptyset$. RMS angle-of-attack error was lower for subjects trained on the part task versus those trained in the whole task in trials 1-5 (Figure 15). This effect is consistent with the block $x$ task interaction previously noted for this segment.

There was an interaction of FLoLs type for trials 1-5 versus 26-3ø in each segment. The interaction was significant for the comparison of CONVENTIONAL versus COMMAND displays in the middle $(F(1,120)=5.42, p<. \emptyset 5$ and close-in $F(1,12 \varnothing)=3.79, \quad p<.1 \varnothing \quad$ segments. RMS angle-of-attack error was lower for subjects trained with the COMMAND display versus those trained with the CONVENTIONAL display in trials $1-5$, continued to be lower through transfer trials 21-25, and reversed position in trials 26-3ø (Figure 16). There was also an interaction of FLoLs type for trials $6-1 \emptyset$ versus $21-25$ in the middle segment. The interaction was significant for the comparison of CONVENTIONAL versus COMMAND displays $F(1,12 \emptyset)=4.7 \emptyset, p<. \emptyset 5$. Inspection of the means in Table 11 shows RMS angle-of-attack error was substantially lower for 


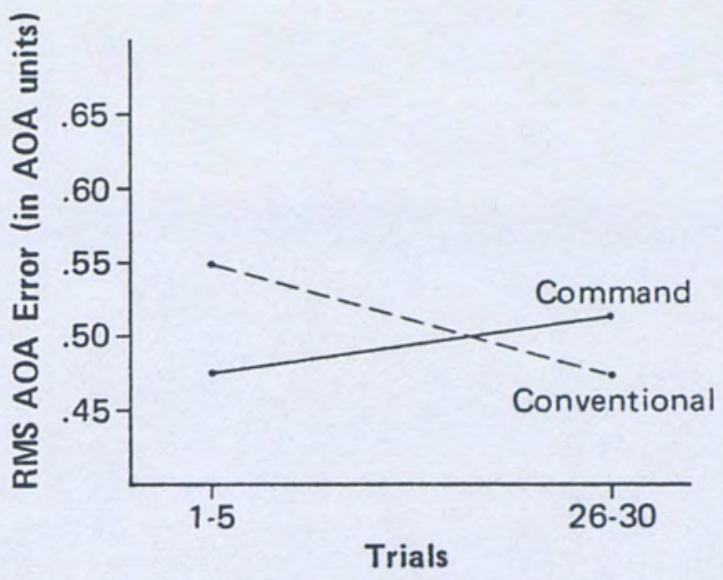

(A) FLOLS Type Interaction

[Middle Segment]

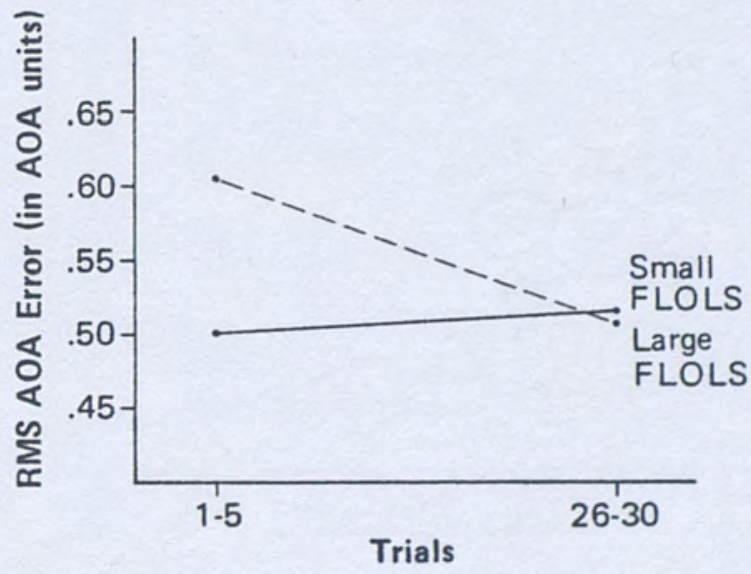

(C) FLOLS Size Interaction

[Middle Segment]

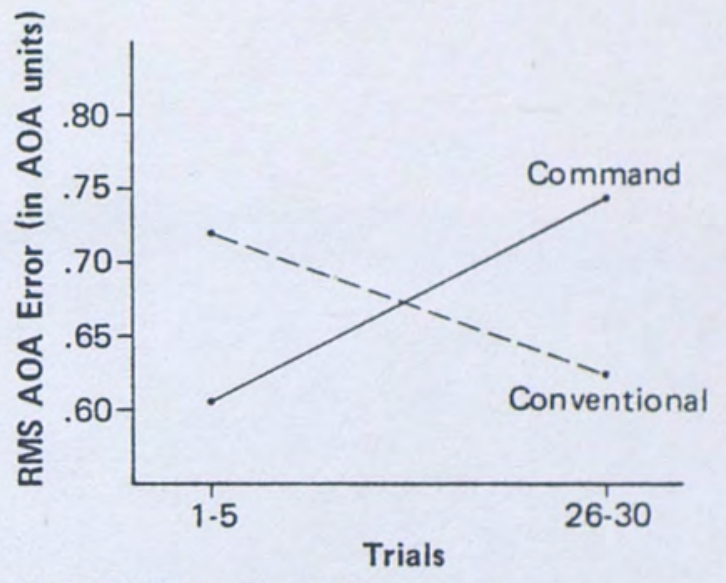

(B) FLOLS Type Interaction [Close-In Segment]

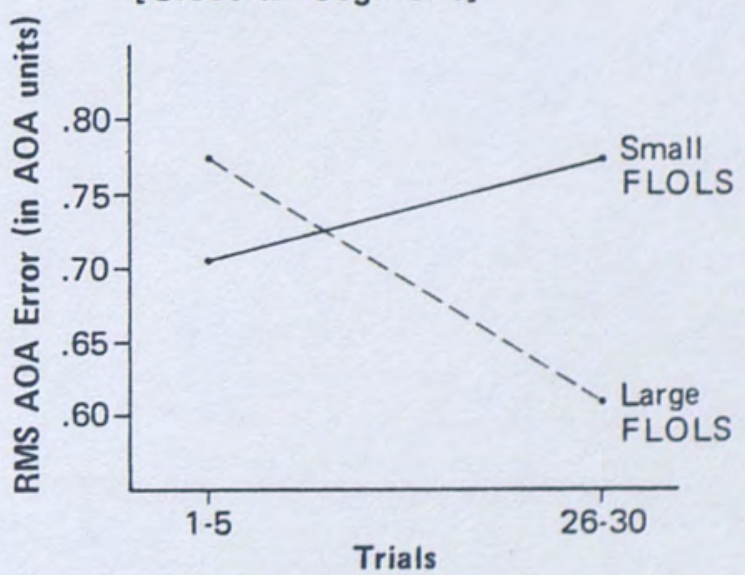

(D) FLOLS Size Interaction

[Close-In Segment]

Figure 16. FLOLS type and FLOLS size interactions of
RMS angle-of-attack error during transfer. 
subjects trained with the COMMAND display versus those trained with the CONVENTIONAL display in trials 6-1ø.

There was an interaction of FLoLs size for trials 1-5 versus $26-3 \emptyset$ in both the middle $F(1,12 \emptyset)=6.88, p<. \emptyset 1$ and close-in $F(1,12 \emptyset)=5.51, \quad \mathrm{p}<. \varnothing 5$ segments. RMS angle-of-attack error was lower for subjects trained with the small FLoLs versus those trained with the large FLoLS in trials 1-5 (Figure 16). A reversal occurred in trials 26-3ø in the close-in segment. RMS angle-of-attack error in trials $26-3 \emptyset$ was lower for subjects trained with the large FLoLs versus those trained with the small FLoLs.

There was a block $\mathrm{x}$ task $\mathrm{x}$ FLoLS size interaction for both the middle $(p<. \emptyset 1)$ and close-in $(p<.1 \emptyset)$ segments (Tables $1 \varnothing$ and 12). Inspection of Figure 17 shows that subjects trained under the whole-task large FLOLS condition start the transfer phase with the highest error scores and remain consistently high. The part-task small FLOLS subjects start the transfer phase with the lowest error scores. The whole-task small fLOLS and part-task large FLoLs subjects start the transfer phase with high error scores and rapidly improve their performance. The block $x$ task $X$ FLOLS size interaction in the close-in segment was similar to the interaction in the middle segment. The block $x$ task $x$ FLoLS size interaction accounted for $7 \%$ of 


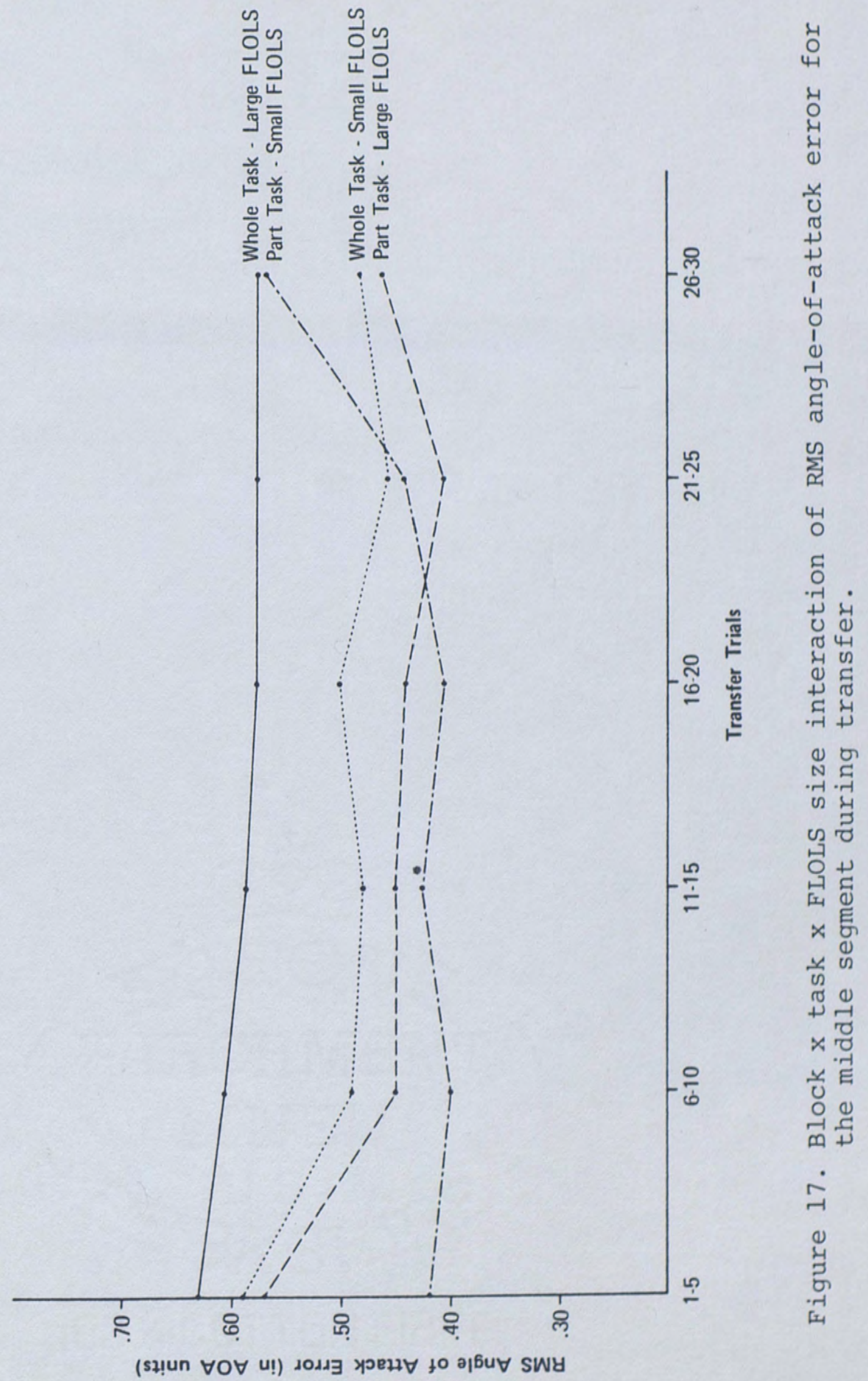


the within-subjects experimental variance in the middle segment and $5 \%$ in the close-in segment.

The ATARI covariate was significant $(p<.1 \emptyset)$ in the close-in segment (Table 12). The ATARI accounted for $1 \emptyset$ \% of the between-subjects experimental variance in the close-in segment.

RMS Lineup Error. FLOLS type for the middle segment was the only significant $(p<.1 \emptyset)$ main effect for the transfer trials (Tables 14 and 16). RMS lineup error was lower for subjects trained with the RATE and CONVENTIONAL displays versus subjects trained with the Command display. The Newman-Keuls Test for comparison of the mean differences between the RATE and COMMAND display and the CONVENTIONAL and COMMAND display approached significance to the .ø5 level. This effect accounted for $9 \%$ of the between-subjects experimental variance in the middle segment.

There was a significant block $(p<. \varnothing 1)$ effect, block $x$ task $(p<.1 \emptyset)$ interaction and block $x$ FloLs type $(p<. \emptyset 5)$ interaction in the close-in segment (Table 16). In the block $x$ task interaction, subjects trained with the part task start the transfer phase with higher error scores and rapidly improve their performance (Figure 18). In the 


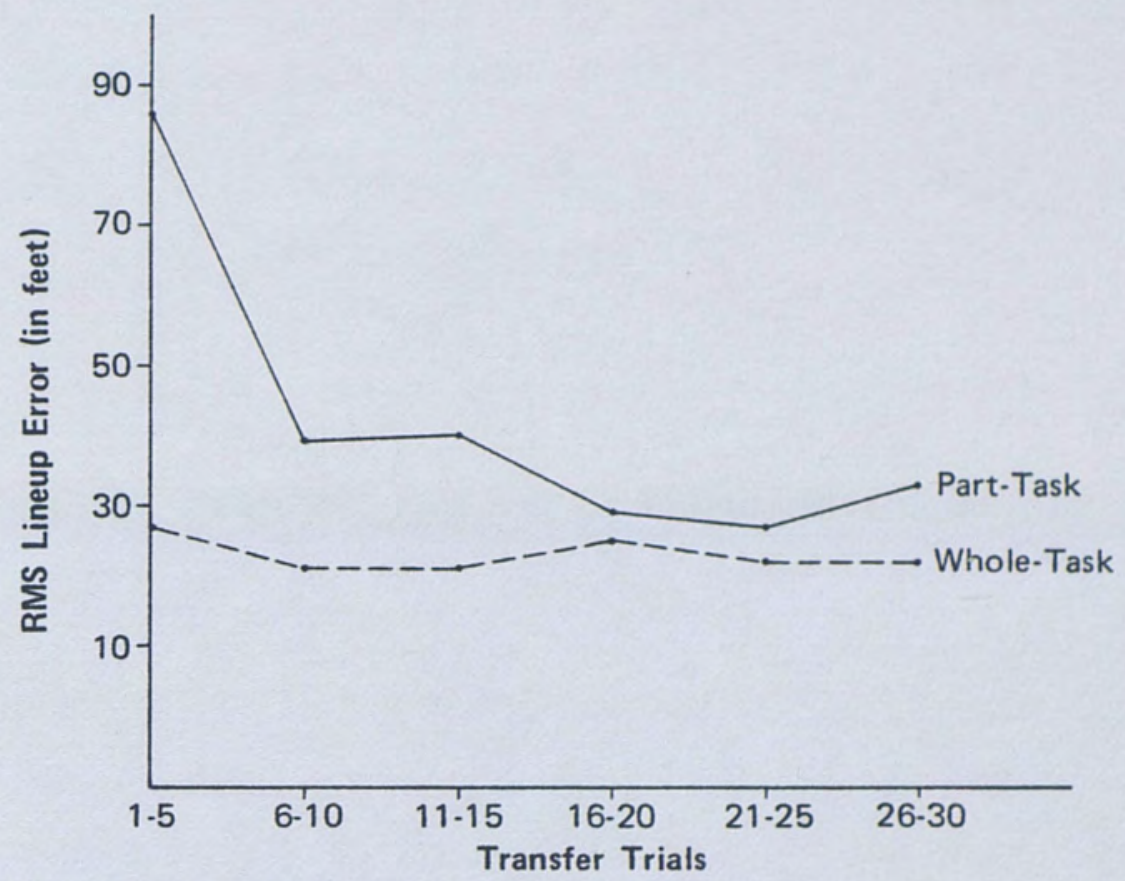

(A) Block x Task

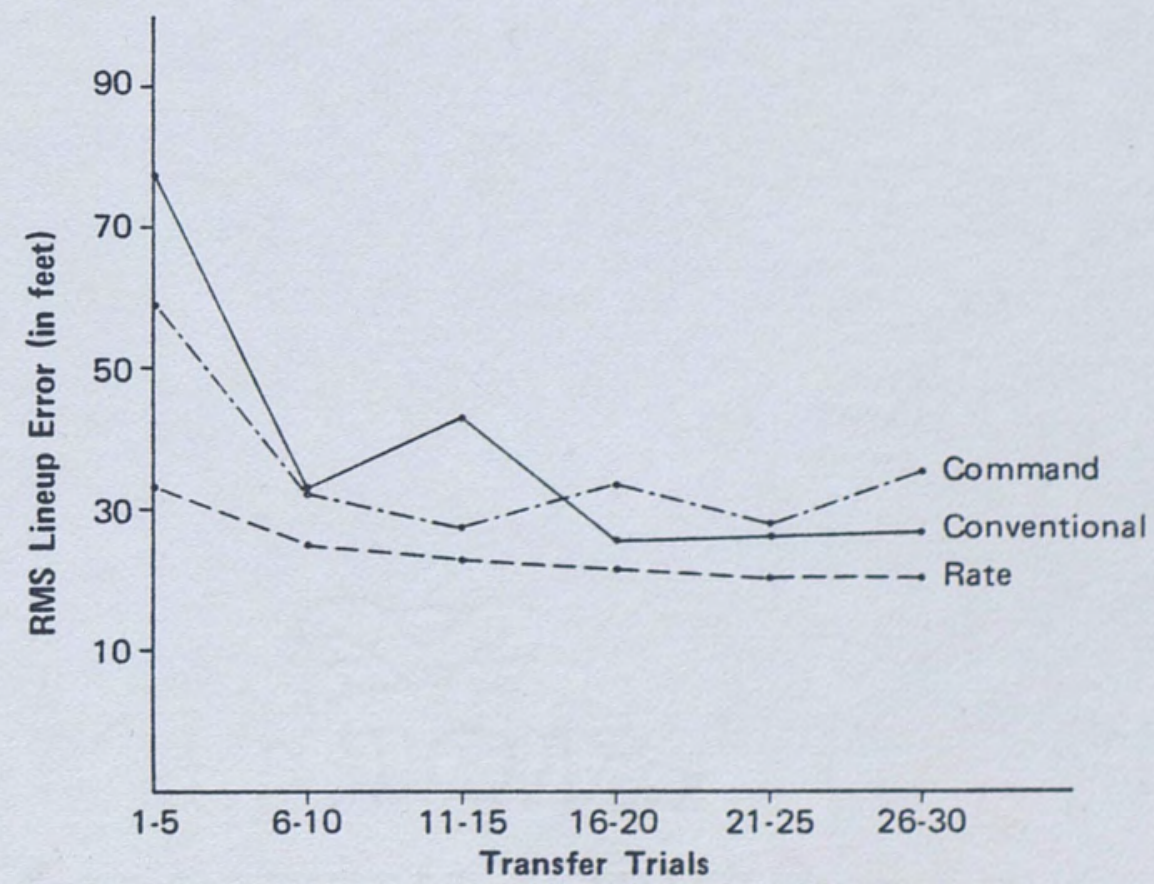

(B) Block x FLOLS Type

Figure 18. Block $x$ task and block $x$ FLOLS type interactions of RMS lineup error for the close-in segment during transfer. 
block $x$ FLoLs type interaction, subjects trained with the RATE display started the transfer phase with the lowest error scores and continued to be lower throughout the transfer trials (Figure 18). The block $x$ task interaction accounted for $5 \%$ at the within-subjects experimental variance in the close-in segment. The block $x$ FloLs type interaction accounted for 98 of the within-subjects experimental variance in the segment.

There was a significant FLOLS size $x$ FloLs type interaction for both the middle ( $p<.05)$ and close-in $(p<.1 \emptyset)$ segments (Tables 14 and 16$)$. Figure 19 shows that subjects trained with the small FLOLS and RATE display had the lowest error scores. The FLOLS size $x$ FLOLS type interaction accounted for $14 \%$ of the between-subjects experimental variance in the middle segment and $1 \emptyset \%$ in the close-in segment.

There was an interaction of FLOLS type for trials 1-5 versus 26-30. The interaction was significant for the comparison of CONVENTIONAL versus COMMAND display in the middle segment $F(1,12 \emptyset)=4.38, p<. \emptyset 5$ CONVENTIONAL versus COMMAND display in the close-in segment $F(1,12 \emptyset)=4.27, p<.1 \emptyset$ segment, and CONVENTIONAL versus RATE display in the close-in $F(1,12 \emptyset)=4.27, p<. \varnothing 5$. RMS 1 ineup error was lower for subjects trained with the Command display versus those 


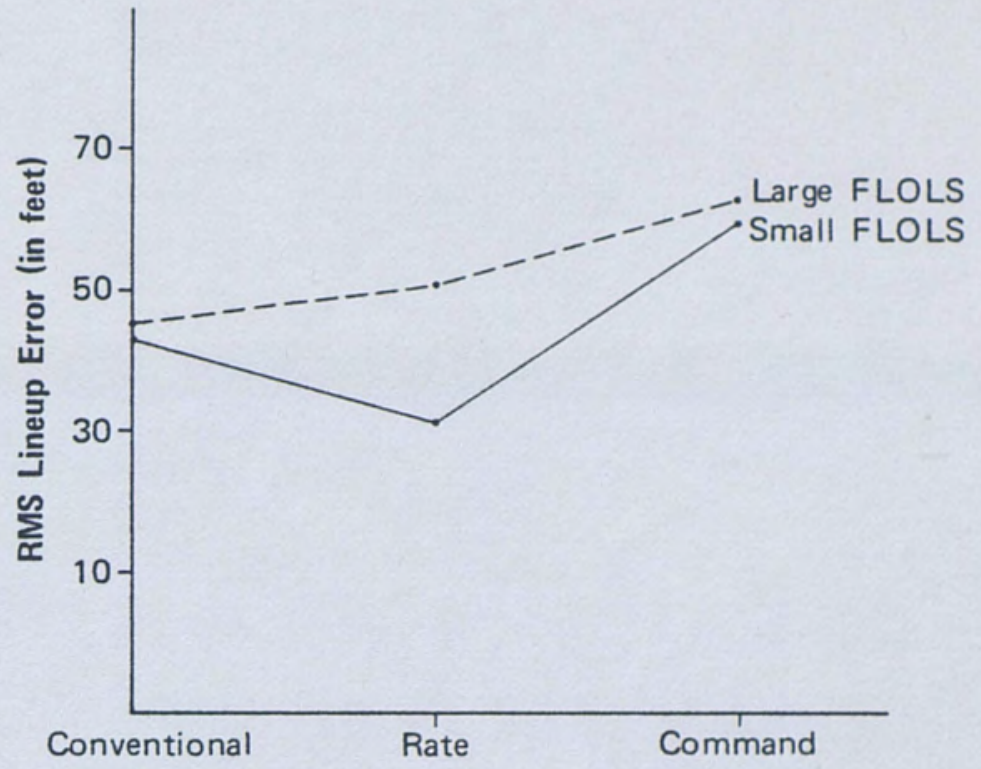

\section{(A) Middle Segment}

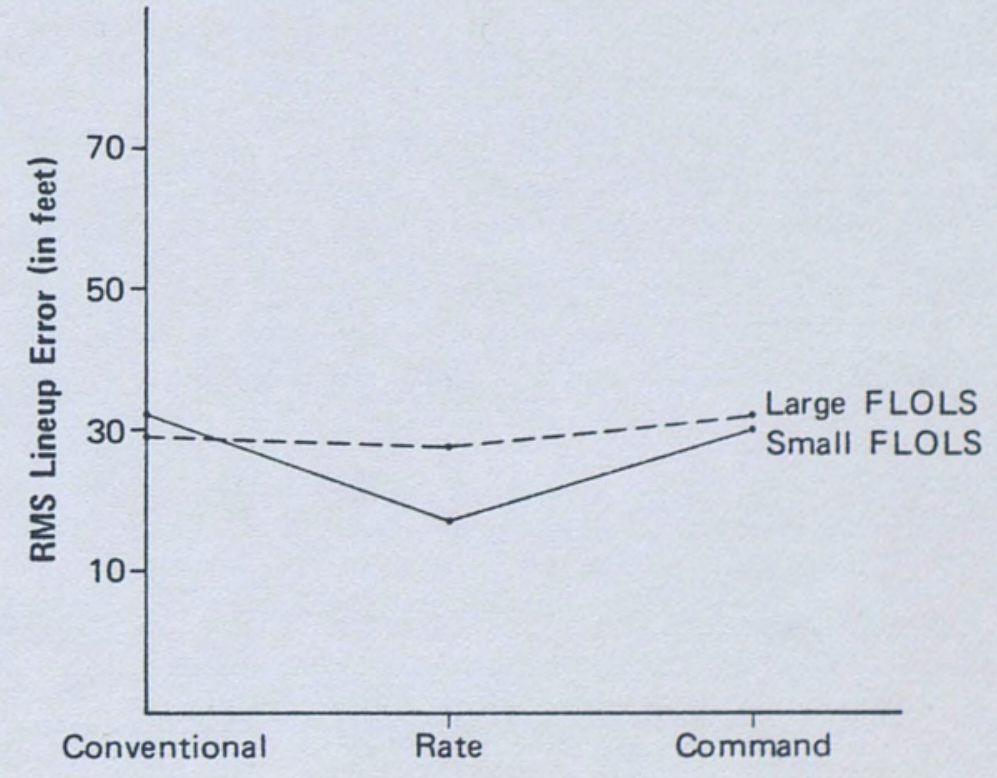

\section{(B) Close-In Segment}

Figure 19. FLOLS size x FLOLS type interactions for RMS lineup error during transfer. 
trained with the CONVENTIONAL display in trials $1-5$ and reversed order in trials 26-3ø (Figure 2ø). For the close-in segment, RMS lineup error was substantially lower for subjects trained with the RATE display versus those trained with the CONVENTIONAL display in trials 1-5 (Figure 2ø).

There was a block $x$ task $X$ FLoLs size interaction $(\mathrm{p}<.5)$ in the middle segment (Table 14). This effect accounted for $7 \%$ of the within-subjects experimental variance in the segment.

The ATARI covariate was significant $(p<. \emptyset 1)$ and accounted for a substantial $29 \%$ of the between-subjects experimental variance in the middle segment and $25 \%$ in the close-in segment. 


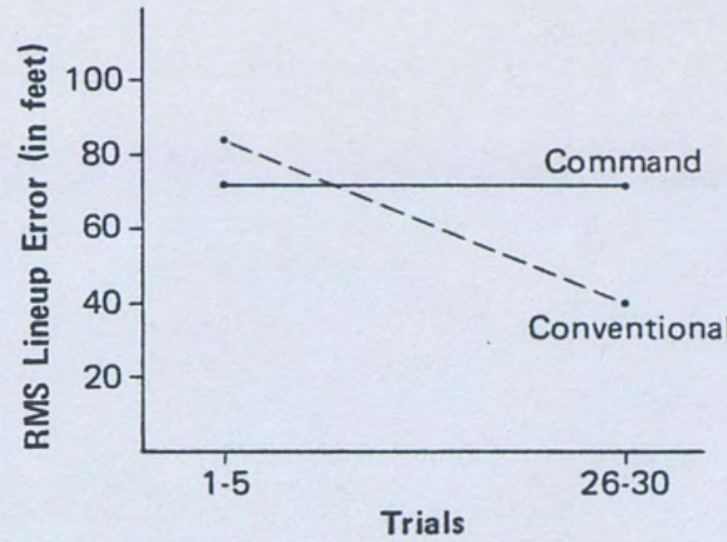

(A) Conventional $\times$ Command

[Middle Segment]

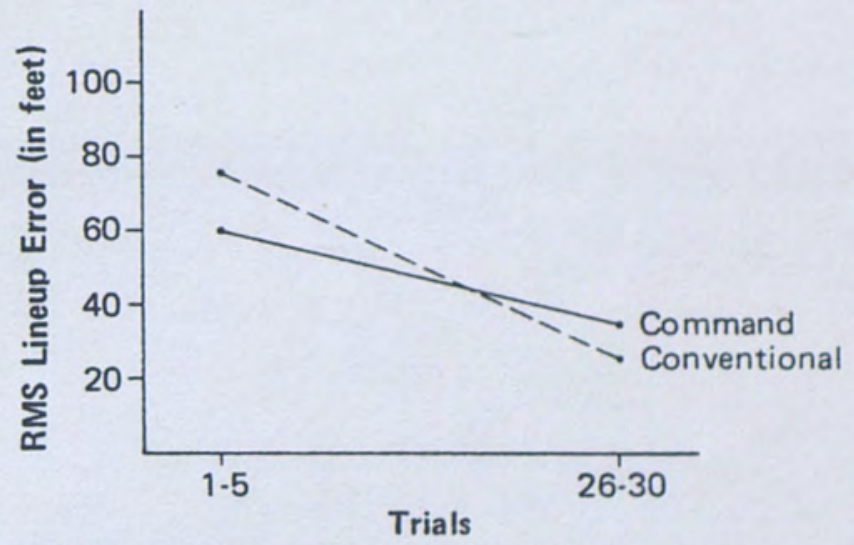

(B) Conventional $\times$ Command [Close-In Segment]

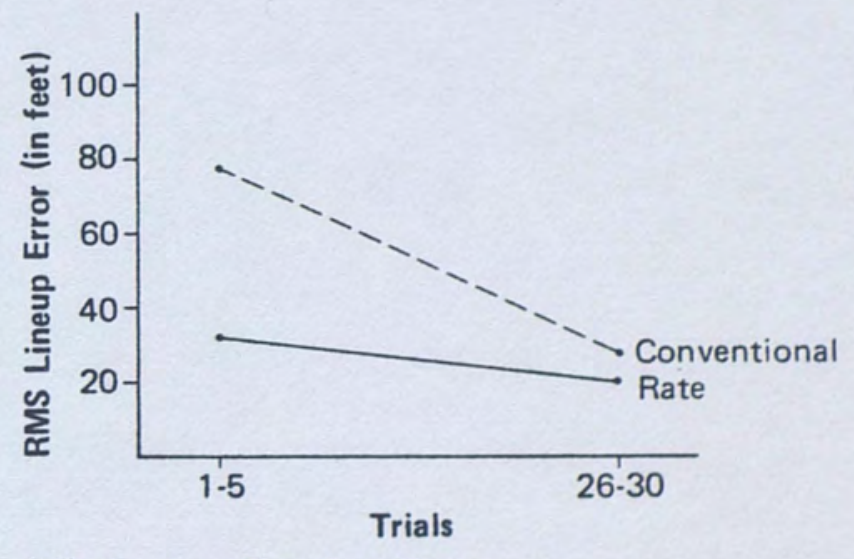

(C) Conventional $\times$ Rate

[Close-In Segment]

Figure 20. FLOLS type interactions for RMS lineup error during transfer. 
TABLE 2

REPEATED MEASURES ANALYSIS OF COVARIANCE OF RMS GLIDESLOPE ERROR FOR THE MIDDLE SEGMENT DURING TRANSFER

\begin{tabular}{|c|c|c|c|c|c|}
\hline $\begin{array}{l}\text { Source of } \\
\text { Variance }\end{array}$ & $\begin{array}{l}\text { Sum of } \\
\text { Squares }\end{array}$ & $\underline{d f}$ & $\begin{array}{c}\text { Mean } \\
\text { Squares } \\
\end{array}$ & $\underline{F}$ & $\begin{array}{l}\text { Proportion } \\
\text { of Variance }\end{array}$ \\
\hline
\end{tabular}

\section{Between Factor}

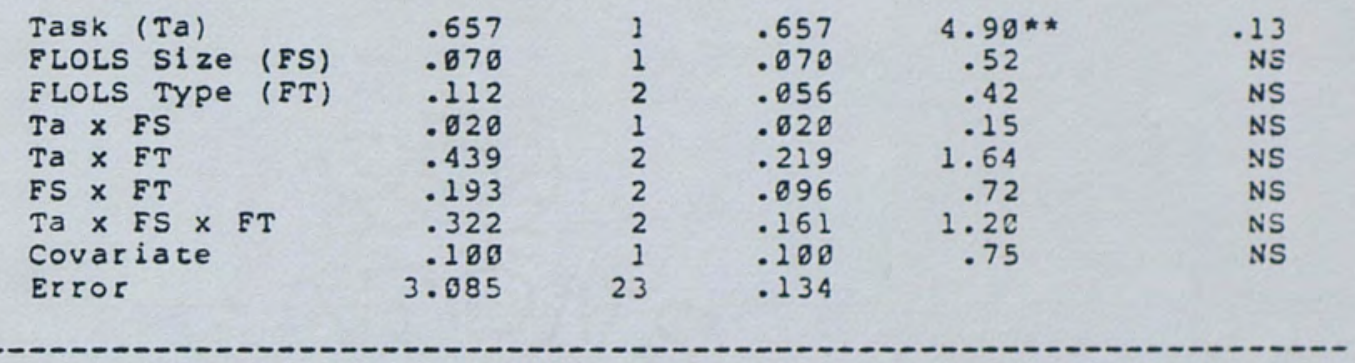

Within Factor

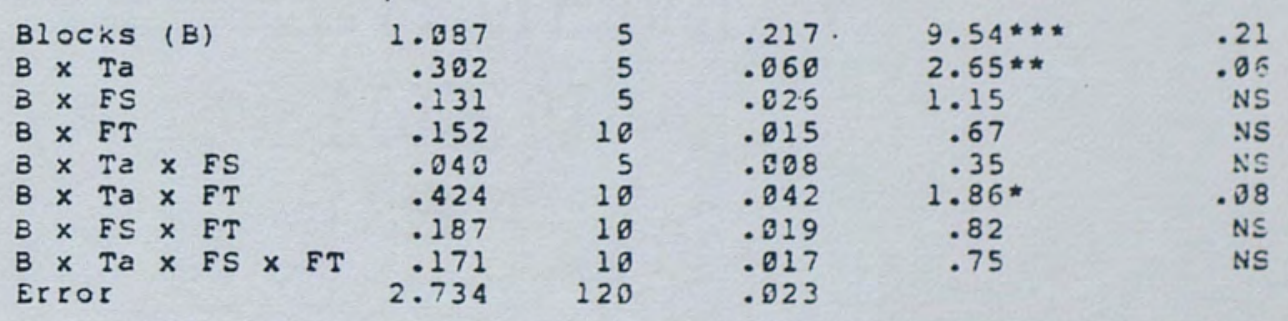

\footnotetext{
*: $P<.10$

**:P<.35

$\star \star \star: P<.01$
} 
TABLE 3

MEAN GLIDESLOPE RMS ERROR (IN FEET) FOR THE MIDDLE SEGMENT DURING TRANSFER

\begin{tabular}{|c|c|c|c|c|c|c|}
\hline 5-Trial Means & $\underline{1-5}$ & $\underline{5-10}$ & $\underline{12-15}$ & $\underline{16-2 \mathbb{E}}$ & $21-25$ & $25-30$ \\
\hline ask ( $\mathrm{Ta})$ & & & & & & \\
\hline $\begin{array}{l}\text { Whole } \\
\text { Part }\end{array}$ & $\begin{array}{l}23.4 \\
47.6\end{array}$ & $\begin{array}{l}20.5 \\
29.6\end{array}$ & $\begin{array}{l}20.4 \\
23.9\end{array}$ & $\begin{array}{l}21.2 \\
21.4\end{array}$ & $\begin{array}{l}16.6 \\
28.7\end{array}$ & $\begin{array}{l}15.2 \\
28.6\end{array}$ \\
\hline
\end{tabular}

FLOLS Size (FS)

Small

Large $\begin{array}{lll}34.0 & 25.7 & 21.4 \\ 37.8 & 24.4 & 22.8\end{array}$
23.3

22.3

16.4

21.0

16.2

ELOLS IYPe (FT)

\begin{tabular}{llllllll} 
Conventional (Cv) & 41.8 & 24.3 & 19.2 & 21.2 & 16.8 & 15.7 \\
Rate (Ra) & 38.3 & 24.5 & 21.3 & 19.2 & 19.1 & 17.3 \\
Command (Cm) & 34.4 & 26.3 & 25.9 & 23.5 & 23.1 & 20.7 \\
\hline
\end{tabular}


TABLE 4

REPEATED MEASURES ANALYSIS OF COVARIANCE OF RMS GLIDESLOPE ERROR FOR THE CLOSE-IN SEGMENT DURING TRANSFER

\begin{tabular}{|c|c|c|c|c|c|}
\hline $\begin{array}{l}\text { Source of } \\
\text { Variance }\end{array}$ & $\begin{array}{l}\text { Sum of } \\
\text { Squares }\end{array}$ & $\underline{d f}$ & $\begin{array}{l}\text { Mean } \\
\text { Squares }\end{array}$ & $\underline{\mathbf{F}}$ & $\begin{array}{l}\text { Proportion } \\
\text { of Variance }\end{array}$ \\
\hline \multicolumn{6}{|l|}{ Between Eactor } \\
\hline $\begin{array}{l}\text { Task (Ta) } \\
\text { FLOLS Size (FS) } \\
\text { FLOLS TYPe (FT) } \\
\text { Ta X FS } \\
\text { Ta X FT } \\
\text { FS X FT } \\
\text { Ta X FS X FT } \\
\text { Covariate } \\
\text { Error }\end{array}$ & $\begin{array}{r}.550 \\
.000 \\
.193 \\
.010 \\
.155 \\
.094 \\
.853 \\
1.061 \\
2.695\end{array}$ & $\begin{array}{r}1 \\
1 \\
2 \\
1 \\
2 \\
2 \\
2 \\
1 \\
23\end{array}$ & $\begin{array}{r}.550 \\
.096 \\
.096 \\
.010 \\
.078 \\
.047 \\
.426 \\
1.051 \\
.117\end{array}$ & $\begin{array}{l}4.69^{\star \star} \\
.80^{*} \\
.82 \\
.89 \\
.66 \\
.48 \\
3.64^{\star \star} \\
9.05^{\star \star \star}\end{array}$ & $\begin{array}{l}.10 \\
\text { NS } \\
\text { NS } \\
\text { NS } \\
\text { NS } \\
\text { NS } \\
.15 \\
.19\end{array}$ \\
\hline \multicolumn{6}{|l|}{ Within Factor } \\
\hline $\begin{array}{l}\text { Blocks }(B) \\
B \times \mathrm{Ta} \\
\mathrm{B} \times \mathrm{FS} \\
\mathrm{B} \times \mathrm{FT} \\
\mathrm{B} \times \mathrm{Ta} \times \mathrm{FS} \\
\mathrm{B} \times \mathrm{Ta} \times \mathrm{FT} \\
\mathrm{B} \times \mathrm{FS} \times \mathrm{FT} \\
\mathrm{B} \times \mathrm{Ta} \times \mathrm{FS} \times \mathrm{FT} \\
\text { ErroT }\end{array}$ & $\begin{array}{r}1.923 \\
.329 \\
.165 \\
.276 \\
.053 \\
.218 \\
.113 \\
.084 \\
2.398\end{array}$ & $\begin{array}{r}5 \\
5 \\
5 \\
10 \\
5 \\
10 \\
10 \\
10 \\
120\end{array}$ & $\begin{array}{l}.385 \\
.066 \\
.021 \\
.027 \\
.011 \\
.022 \\
.011 \\
.008 \\
.020\end{array}$ & $\begin{array}{r}19.24^{\star \star *} \\
3.29 * \star \\
1.85 \\
1.35 \\
.54 \\
1.89 \\
.56 \\
.42\end{array}$ & $\begin{array}{l}.35 \\
.07 \\
\text { NS } \\
\text { NS } \\
\text { NS } \\
\text { NS } \\
\text { NS } \\
\text { NS }\end{array}$ \\
\hline
\end{tabular}

* $\mathrm{p}<.10$

$\#: p<.05$

$* *: \mathrm{p}<.01$ 
TABLE 5

MEAN GLIDESLOPE RMS ERROR (IN FEET) FOR THE CLOSE-IN SEGMENT DURING TRANSFER

\begin{tabular}{|c|c|c|c|c|c|c|}
\hline 5-Trial Means & $\underline{1-5}$ & $\underline{6-10}$ & $11-15$ & $15-20$ & $21-25$ & $25-30$ \\
\hline \multicolumn{7}{|l|}{ Task (Ta) } \\
\hline $\begin{array}{l}\text { Whole } \\
\text { Part }\end{array}$ & $\begin{array}{l}17.7 \\
44.6\end{array}$ & $\begin{array}{l}12.8 \\
21.6\end{array}$ & $\begin{array}{l}14 \cdot 4 \\
19 \cdot 3\end{array}$ & $\begin{array}{l}13 \cdot 2 \\
15 \cdot 8\end{array}$ & $\begin{array}{l}10.6 \\
14.7\end{array}$ & $\begin{array}{l}11.1 \\
14.8\end{array}$ \\
\hline \multicolumn{7}{|l|}{ FLOLS Size (FS) } \\
\hline $\begin{array}{l}\text { Small } \\
\text { Large }\end{array}$ & $\begin{array}{l}32.9 \\
29.3\end{array}$ & $\begin{array}{l}19.5 \\
14.9\end{array}$ & $\begin{array}{l}16.5 \\
17.2\end{array}$ & $\begin{array}{l}13.5 \\
15.5\end{array}$ & $\begin{array}{l}11.4 \\
13.8\end{array}$ & $\begin{array}{l}12.6 \\
13.4\end{array}$ \\
\hline \multicolumn{7}{|l|}{ FLOLS TYPe (FT) } \\
\hline $\begin{array}{l}\text { Conventional ( } \mathrm{CV}) \\
\text { Rate (Ra) } \\
\text { Command }(\mathrm{Cm})\end{array}$ & $\begin{array}{l}36 \cdot 3 \\
25 \cdot 1 \\
32 \cdot 1\end{array}$ & $\begin{array}{l}20.5 \\
15.5 \\
15.7\end{array}$ & $\begin{array}{l}14 \cdot 9 \\
15 \cdot 3 \\
26 \cdot 3\end{array}$ & $\begin{array}{l}13.4 \\
13.8 \\
15.8\end{array}$ & $\begin{array}{l}11 \cdot 8 \\
11 \cdot 6 \\
14 \cdot 4\end{array}$ & $\begin{array}{l}10 \cdot 2 \\
11 \cdot 4 \\
17 \cdot 4\end{array}$ \\
\hline
\end{tabular}


TABLE 6

REPEATED MEASURES ANALYSIS OF COVARIANCE OF AVERAGE GLIDESLOPE ERROR FOR THE MIDDLE SEGMENT DURING TRANSFER

\begin{tabular}{|c|c|c|c|c|c|}
\hline $\begin{array}{l}\text { Source of } \\
\text { Variance }\end{array}$ & $\begin{array}{l}\text { Sum of } \\
\text { Squares }\end{array}$ & $\underline{d E}$ & $\begin{array}{c}\text { Mean } \\
\text { Squares }\end{array}$ & $\underline{F}$ & $\begin{array}{l}\text { Proportion } \\
\text { of Variance }\end{array}$ \\
\hline Between Factor & & & & & \\
\hline $\begin{array}{l}\text { Task (Ta) } \\
\text { FLOLS Size (FS) } \\
\text { FLOLS TYPe (FT) } \\
\text { Ta X FS } \\
\text { Ta X FT } \\
\text { FS X FT } \\
\text { Ta X FS X FT } \\
\text { Covariate } \\
\text { Error }\end{array}$ & $\begin{array}{r}7705 \\
179 \\
2330 \\
17 \\
1919 \\
917 \\
947 \\
354 \\
18493\end{array}$ & $\begin{array}{r}1 \\
1 \\
2 \\
1 \\
2 \\
2 \\
2 \\
1 \\
23\end{array}$ & $\begin{array}{r}7706 \\
179 \\
1165 \\
17 \\
960 \\
459 \\
474 \\
355 \\
804\end{array}$ & $\begin{array}{l}9.58 \star \star \star \\
.22 \\
1.45 \\
.02 \\
1.19 \\
.57 \\
.59 \\
.44\end{array}$ & $\begin{array}{l}.23 \\
\text { NS } \\
\text { NS } \\
\text { NS } \\
\text { NS } \\
\text { NS } \\
\text { NS } \\
\text { NS }\end{array}$ \\
\hline Within Factor & & & & & \\
\hline 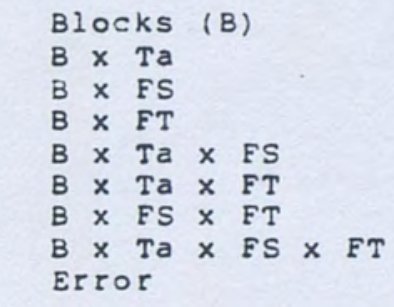 & $\begin{array}{r}6175 \\
6696 \\
517 \\
1866 \\
445 \\
2128 \\
1666 \\
1201 \\
25945\end{array}$ & $\begin{array}{r}5 \\
5 \\
5 \\
10 \\
5 \\
18 \\
10 \\
10 \\
128\end{array}$ & $\begin{array}{r}1235 \\
1339 \\
163 \\
180 \\
89 \\
212 \\
167 \\
120 \\
216\end{array}$ & $\begin{array}{l}5.71^{\star \star \star} \\
6.19 \star \star \star \\
.76 \\
.83 \\
.41 \\
.98 \\
.77 \\
.56\end{array}$ & $\begin{array}{l}.13 \\
.14 \\
\text { NS } \\
\text { NS } \\
\text { iNS } \\
\text { NS } \\
\text { NS } \\
\text { NS }\end{array}$ \\
\hline
\end{tabular}


TABLE 7

MEAN AVERAGE GLIDESLOPE ERROR (IN FEET, $+=$ HIGH) FOR THE MIDDLE SEGMENT DURING TRANSFER

\begin{tabular}{|c|c|c|c|c|c|c|}
\hline 5-Trial Means & $\underline{1-5}$ & $6-10$ & $11-15$ & $\underline{16-20}$ & $\underline{21-25}$ & $\underline{26-38}$ \\
\hline \multicolumn{7}{|l|}{ Task (Ta) } \\
\hline $\begin{array}{l}\text { Whole } \\
\text { Part }\end{array}$ & $\begin{array}{l}-5.2 \\
-39.1\end{array}$ & $\begin{array}{l}-5.5 \\
-20.9\end{array}$ & $\begin{array}{l}-6.2 \\
-17.8\end{array}$ & $\begin{array}{l}-11.4 \\
-11.4\end{array}$ & $\begin{array}{l}-4.9 \\
-8.8\end{array}$ & $\begin{array}{l}-3.0 \\
-8.4\end{array}$ \\
\hline \multicolumn{7}{|l|}{ FLOLS Size (FS) } \\
\hline $\begin{array}{l}\text { Small } \\
\text { Large }\end{array}$ & $\begin{array}{l}-20.2 \\
-24.1\end{array}$ & $\begin{array}{l}-13.6 \\
-12.8\end{array}$ & $\begin{array}{r}-14.4 \\
-\quad 9.7\end{array}$ & $\begin{array}{l}-11.2 \\
-11.6\end{array}$ & $\begin{array}{l}-4.8 \\
-8.9\end{array}$ & $\begin{array}{l}-2.6 \\
-9.3\end{array}$ \\
\hline \multicolumn{7}{|l|}{ FLOLS TYPe (FT) } \\
\hline $\begin{array}{l}\text { Conventional (CV) } \\
\text { Rate (Ra) } \\
\text { Command (Ca) }\end{array}$ & $\begin{array}{l}-31.0 \\
-13.5 \\
-22.0\end{array}$ & $\begin{array}{l}-19.4 \\
-6.1 \\
-14.1\end{array}$ & $\begin{array}{l}-12.4 \\
=7.7 \\
-15.9\end{array}$ & $\begin{array}{l}-13.8 \\
=8.0 \\
-12.5\end{array}$ & $\begin{array}{l}-6.5 \\
=3.1 \\
-12.9\end{array}$ & $\begin{array}{l}-3.6 \\
-5.8 \\
-7.7\end{array}$ \\
\hline
\end{tabular}


TABLE 8

REPEATED MEASURES ANALYSIS OF COVARIANCE OF AVERAGE GLIDESLOPE ERROR FOR THE CLOSE-IN SEGMENT DURING TRANSFER

\begin{tabular}{|c|c|c|c|c|c|}
\hline $\begin{array}{l}\text { Source of } \\
\text { Variance }\end{array}$ & $\begin{array}{l}\text { Sum of } \\
\text { squares }\end{array}$ & $d f$ & $\begin{array}{c}\text { Mean } \\
\text { squares }\end{array}$ & $\underline{F}$ & $\begin{array}{l}\text { Proportion } \\
\text { of Variance }\end{array}$ \\
\hline
\end{tabular}

\begin{tabular}{|c|c|c|c|c|c|}
\hline \multicolumn{6}{|l|}{ Between Factor } \\
\hline $\begin{array}{l}\text { Task (Ta) } \\
\text { FLOLS Size (FS) } \\
\text { FLOLS TyPe (FT) } \\
\text { Ta X FS } \\
\text { Ta X FT } \\
\text { FS X FT } \\
\text { Tax FS X FT } \\
\text { Covariate } \\
\text { Error }\end{array}$ & $\begin{array}{r}2498 \\
5 \\
1121 \\
545 \\
496 \\
297 \\
892 \\
421 \\
13766\end{array}$ & $\begin{array}{r}1 \\
1 \\
2 \\
1 \\
2 \\
2 \\
2 \\
1 \\
23\end{array}$ & $\begin{array}{r}2493 \\
5 \\
560 \\
545 \\
248 \\
149 \\
446 \\
421 \\
599\end{array}$ & $\begin{array}{l}4.17 \star \\
.81 \\
.94 \\
.91 \\
.41 \\
.25 \\
.74 \\
.78\end{array}$ & $\begin{array}{l}.12 \\
\text { NS } \\
\text { NS } \\
\text { NS } \\
\text { NS } \\
\text { NS } \\
\text { NS } \\
\text { NS }\end{array}$ \\
\hline \multicolumn{6}{|l|}{ within Factor } \\
\hline $\begin{array}{l}\text { Blocks }(B) \\
B \times T a \\
B \times F S \\
B \times F T \\
B \times \text { Ta } \times \text { FS } \\
B \times \text { Ta } X \text { FT } \\
B \times F S \times F T \\
B \times \text { Ta } \times \text { FS } \times F T \\
\text { Error }\end{array}$ & $\begin{array}{r}8020 \\
4853 \\
533 \\
1912 \\
923 \\
2379 \\
938 \\
726 \\
23543\end{array}$ & $\begin{array}{r}5 \\
5 \\
5 \\
16 \\
5 \\
10 \\
13 \\
10 \\
120\end{array}$ & $\begin{array}{r}1604 \\
978 \\
187 \\
191 \\
185 \\
237 \\
94 \\
73 \\
196\end{array}$ & $\begin{array}{r}2.18^{* \star \star *} \\
4.95^{\star * \star} \\
.54 \\
.97 \\
.94 \\
1.21 \\
.48 \\
.37\end{array}$ & $\begin{array}{l}.18 \\
.11 \\
\text { NS } \\
\text { NS } \\
\text { NS } \\
\text { NS } \\
\text { NS } \\
\text { NS }\end{array}$ \\
\hline
\end{tabular}

\footnotetext{
$\star p<.10$

$\#: p<.85$

$* \star *: p<. \varepsilon 1$
} 
TABLE 9

MEAN AVERAGE GLIDESLOPE ERROR (IN FEET, $+=$ HIGH) FOR THE CLOSE-IN SEGMENT DURING TRANSFER

\begin{tabular}{|c|c|c|c|c|c|c|}
\hline 5-Trial Means & $\underline{1-5}$ & $6-10$ & $11-15$ & $16-20$ & $\underline{21-25}$ & $25-30$ \\
\hline \multicolumn{7}{|l|}{ Task (Ta) } \\
\hline $\begin{array}{l}\text { Whole } \\
\text { Part }\end{array}$ & $\begin{array}{l}-7.6 \\
-36.8\end{array}$ & $\begin{array}{l}-5.0 \\
-12.1\end{array}$ & $\begin{array}{l}-4.9 \\
-9.5\end{array}$ & $\begin{array}{l}-5.9 \\
-5.7\end{array}$ & $\begin{array}{l}-2 \cdot 1 \\
-6 \cdot 4\end{array}$ & $\begin{array}{l}-1 \cdot 8 \\
-6.1\end{array}$ \\
\hline \multicolumn{7}{|l|}{ FLOLS Size (FS) } \\
\hline $\begin{array}{l}\text { Small } \\
\text { Large }\end{array}$ & $\begin{array}{l}-22.7 \\
-20.9\end{array}$ & $\begin{array}{l}-10.6 \\
-\quad 7.5\end{array}$ & $\begin{array}{l}-8.4 \\
-6.1\end{array}$ & $\begin{array}{l}-5.9 \\
-6.7\end{array}$ & $\begin{array}{l}-2 \cdot 3 \\
-6 \cdot 2\end{array}$ & $\begin{array}{l}-1 \cdot 3 \\
-6 \cdot 5\end{array}$ \\
\hline \multicolumn{7}{|l|}{ FLOLS TYPe (FT) } \\
\hline $\begin{array}{l}\text { Conventional (Cv) } \\
\text { Rate (Ra) } \\
\text { Command (Cm) }\end{array}$ & $\begin{array}{l}-28.8 \\
-12.8 \\
-23.9\end{array}$ & $\begin{array}{l}-16.3 \\
-\quad 4.7 \\
-6.1\end{array}$ & $\begin{array}{l}-7 \cdot 3 \\
-\quad 3 \cdot 9 \\
-10.5\end{array}$ & $\begin{array}{l}-5 \cdot 9 \\
-5.2 \\
-7.8\end{array}$ & $\begin{array}{l}-4 \cdot 1 \\
-2 \cdot 7 \\
-5 \cdot 0\end{array}$ & $\begin{array}{l}-1 \cdot 6 \\
-3 \cdot 3 \\
-6 \cdot 8\end{array}$ \\
\hline
\end{tabular}


TABLE 10

REPEATED MEASURES ANALYSIS OF COVARIANCE OF RMS ANGLE OF ATTACK ERROR FOR THE MIDDLE SEGMENT DURING TRANSFER

\begin{tabular}{|c|c|c|c|c|c|}
\hline $\begin{array}{l}\text { Source of } \\
\text { Variance }\end{array}$ & $\begin{array}{l}\text { Sum of } \\
\text { Squares }\end{array}$ & df & $\begin{array}{l}\text { Mean } \\
\text { Squares }\end{array}$ & $\underline{\mathbf{E}}$ & $\begin{array}{l}\text { Proportion } \\
\text { of Variance }\end{array}$ \\
\hline Between Factor & & & & & \\
\hline $\begin{array}{l}\text { Task (Ta) } \\
\text { FLOLS Size (FS) } \\
\text { FLOLS TYPe (FT) } \\
\text { Ta } \times \text { FS } \\
\text { Ta } \times \text { FT } \\
\text { FS } \times \text { FT } \\
\text { Ta } \times \text { FS } \times \text { FT } \\
\text { Covariate } \\
\text { Error }\end{array}$ & $\begin{array}{l}.0357 \\
.0121 \\
.0491 \\
.0637 \\
.0287 \\
.0646 \\
.0353 \\
.0337 \\
.5227\end{array}$ & $\begin{array}{r}1 \\
1 \\
2 \\
1 \\
2 \\
2 \\
2 \\
1 \\
23\end{array}$ & $\begin{array}{l}.8357 \\
.8121 \\
.0245 \\
.8037 \\
.8143 \\
.8923 \\
.8177 \\
.8937 \\
.8227\end{array}$ & $\begin{array}{r}1.57 \\
.53 \\
1.08 \\
.16 \\
.63 \\
.18 \\
.78 \\
.16\end{array}$ & $\begin{array}{l}\text { NS } \\
\text { NS } \\
\text { NS } \\
\text { NS } \\
\text { NS } \\
\text { NS } \\
\text { NS } \\
\text { NS }\end{array}$ \\
\hline Within Factor & & & & & \\
\hline 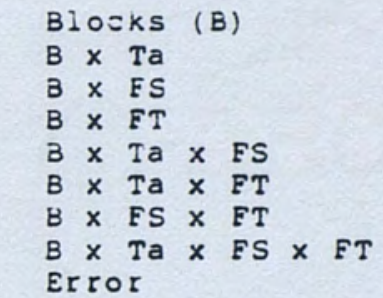 & $\begin{array}{l}.0124 \\
.0651 \\
.0045 \\
.0127 \\
.0984 \\
.0045 \\
.0068 \\
.0085 \\
.0629\end{array}$ & $\begin{array}{r}5 \\
5 \\
5 \\
10 \\
5 \\
10 \\
10 \\
10 \\
120\end{array}$ & $\begin{array}{l}.0024 \\
.0010 \\
.0089 \\
.0013 \\
.0017 \\
.0004 \\
.0007 \\
.0009 \\
.0005\end{array}$ & $\begin{array}{l}4.72^{\star \star \star} \\
1.93^{\star} \\
1.72^{\star} \\
2.43^{\star \star} \\
3.21^{\star \star \star} \\
.86 \\
1.29 \\
1.62\end{array}$ & $\begin{array}{l}.16 \\
.94 \\
\text { NS } \\
.18 \\
.07 \\
\text { NS } \\
\text { NS } \\
\text { NS }\end{array}$ \\
\hline
\end{tabular}

$\star: p<.10$

$\star *: p<.35$

$\star \star \star: p<.01$ 
TABLE 11

MEAN ANGLE OF ATTACK RMS ERROR (IN AOA UNITS) FOR THE MIDDLE SEGMENT DURING TRANSFER

\begin{tabular}{|c|c|c|c|c|c|c|}
\hline 5-Trial Means & $\underline{1-5}$ & $6-10$ & $11-15$ & $16-2 c$ & $21-25$ & $26-30$ \\
\hline Task (Ta) & & & & & & \\
\hline $\begin{array}{l}\text { Whole } \\
\text { Part }\end{array}$ & $\begin{array}{l}.611 \\
.498\end{array}$ & $\begin{array}{l}.549 \\
.426\end{array}$ & $\begin{array}{l}.533 \\
.438\end{array}$ & $\begin{array}{l}.535 \\
.423\end{array}$ & $\begin{array}{l}.510 \\
.423\end{array}$ & $\begin{array}{l}.522 \\
.508\end{array}$ \\
\hline \multicolumn{7}{|l|}{ FLOLS Size (FS) } \\
\hline $\begin{array}{l}\text { Small } \\
\text { Large }\end{array}$ & $\begin{array}{l}.505 \\
.603\end{array}$ & $\begin{array}{l}.446 \\
.529\end{array}$ & $\begin{array}{l}.453 \\
.517\end{array}$ & $\begin{array}{l}.454 \\
.564\end{array}$ & $\begin{array}{l}.448 \\
.485\end{array}$ & $\begin{array}{l}.518 \\
.511\end{array}$ \\
\hline \multicolumn{7}{|l|}{ FLOLS TYPe (FT) } \\
\hline $\begin{array}{l}\text { Conventional (Cv) } \\
\text { Rate (Ra) } \\
\text { Command (Cm) }\end{array}$ & $\begin{array}{l}.551 \\
.634 \\
.478\end{array}$ & $\begin{array}{l}.548 \\
.542 \\
.380\end{array}$ & $\begin{array}{l}.484 \\
.578 \\
.393\end{array}$ & $\begin{array}{l}.501 \\
.528 \\
.487\end{array}$ & $\begin{array}{l}.465 \\
.522 \\
.413\end{array}$ & $\begin{array}{l}.472 \\
.557 \\
.514\end{array}$ \\
\hline
\end{tabular}


TABLE 12

REPEATED MEASURES ANALYSIS OF COVARIANCE OF RMS ANGLE OF ATTACK ERROR FOR THE CLOSE-IN SEGMENT DURING TRANSFER

\begin{tabular}{|c|c|c|c|c|c|}
\hline $\begin{array}{l}\text { Source of } \\
\text { Variance }\end{array}$ & $\begin{array}{l}\text { Suin of } \\
\text { Squares }\end{array}$ & $\underline{d f}$ & $\begin{array}{c}\text { Mean } \\
\text { Squares } \\
\end{array}$ & $\underline{\mathbf{E}}$ & $\begin{array}{l}\text { Proportion } \\
\text { of Variance }\end{array}$ \\
\hline \multicolumn{6}{|l|}{ Between Factor } \\
\hline $\begin{array}{l}\text { Task (Ta) } \\
\text { FLOLS Size (FS) } \\
\text { FLOLS TYPe (FT) } \\
\text { TaX FS } \\
\text { Ta X FT } \\
\text { FS X FT } \\
\text { Ta X FS X FT } \\
\text { Covariate } \\
\text { Error }\end{array}$ & $\begin{array}{l}.8116 \\
.0817 \\
.8482 \\
.0011 \\
.0871 \\
.8197 \\
.0487 \\
.0687 \\
.4939\end{array}$ & $\begin{array}{l}1 \\
1 \\
2 \\
1 \\
2 \\
2 \\
2 \\
1 \\
23\end{array}$ & $\begin{array}{l}.8116 \\
.0817 \\
.8241 \\
.0011 \\
.8035 \\
.8099 \\
.0204 \\
.0587 \\
.0215\end{array}$ & $\begin{array}{r}.54 \\
.08 \\
1.12 \\
.65 \\
.16 \\
.46 \\
.95 \\
3.28\end{array}$ & $\begin{array}{l}\text { NS } \\
\text { NS } \\
\text { NS } \\
\text { NS } \\
\text { NS } \\
\text { NS } \\
\text { NS } \\
\text {. } 10\end{array}$ \\
\hline \multicolumn{6}{|l|}{ Within Factor } \\
\hline $\begin{array}{l}\text { Blocks (B) } \\
B \times \text { Ta } \\
B \times F S \\
B \times F T \\
B \times \text { Ta } \times \text { FS } \\
B \times \text { Ta } \times \text { FT } \\
B \times F S \times F T \\
B \times T a \times \text { FS } \times \text { FT } \\
\text { Error }\end{array}$ & $\begin{array}{l}.0199 \\
.0354 \\
.0165 \\
.0223 \\
.0199 \\
.0213 \\
.0238 \\
.0202 \\
.2134\end{array}$ & $\begin{array}{r}5 \\
5 \\
5 \\
18 \\
5 \\
18 \\
18 \\
10 \\
120\end{array}$ & $\begin{array}{l}.0040 \\
.0611 \\
.0833 \\
.0822 \\
.0840 \\
.0021 \\
.0024 \\
.8028 \\
.6018\end{array}$ & $\begin{array}{l}2.23^{\star} \\
.61 \\
1.87 \\
1.25 \\
2.24^{\star} \\
1.28 \\
1.34 \\
1.14\end{array}$ & $\begin{array}{r}.05 \\
\text { NS } \\
\text { NS } \\
\text { NS } \\
.05 \\
\text { NS } \\
\text { NS } \\
\text { NS }\end{array}$ \\
\hline
\end{tabular}

\footnotetext{
$\because p<.10$

**: $: p<.05$

$\star \star \star: p<.01$
} 
TABLE 13

MEAN ANGLE OF ATTACK RMS ERROR (IN AOA UNITS) FOR THE CLOSE-IN SEGMENT DURING TRANSFER

\begin{tabular}{|c|c|c|c|c|c|c|}
\hline 5-Trial Means & $\underline{1-5}$ & $6-10$ & $\underline{11-15}$ & $\underline{16-20}$ & $21-25$ & $\underline{26-38}$ \\
\hline \multicolumn{7}{|l|}{ Task (Ta) } \\
\hline $\begin{array}{l}\text { Whole } \\
\text { Part }\end{array}$ & $\begin{array}{l}.778 \\
.785\end{array}$ & $\begin{array}{l}.698 \\
.617\end{array}$ & $\begin{array}{l}.644 \\
.652\end{array}$ & $\begin{array}{l}.615 \\
.652\end{array}$ & $\begin{array}{l}.649 \\
.619\end{array}$ & $\begin{array}{l}.671 \\
.721\end{array}$ \\
\hline \multicolumn{7}{|l|}{ FLOLS Size (FS) } \\
\hline $\begin{array}{l}\text { Small } \\
\text { Large }\end{array}$ & $\begin{array}{l}.706 \\
.777\end{array}$ & $\begin{array}{l}.624 \\
.691\end{array}$ & $\begin{array}{l}.614 \\
.682\end{array}$ & $\begin{array}{l}.617 \\
.659\end{array}$ & $\begin{array}{l}.616 \\
.651\end{array}$ & $\begin{array}{l}.776 \\
.615\end{array}$ \\
\hline \multicolumn{7}{|l|}{ FLOLS TYPe (FT) } \\
\hline $\begin{array}{l}\text { Conventional (CV) } \\
\text { Rate (Ra) } \\
\text { Command (Cm) }\end{array}$ & $\begin{array}{l}.717 \\
.899 \\
.637\end{array}$ & $\begin{array}{l}.629 \\
.762 \\
.593\end{array}$ & $\begin{array}{l}.676 \\
.693 \\
.576\end{array}$ & $\begin{array}{l}.685 \\
.656 \\
.574\end{array}$ & $\begin{array}{l}.648 \\
.675 \\
.586\end{array}$ & $\begin{array}{l}.623 \\
.718 \\
.746\end{array}$ \\
\hline
\end{tabular}


TABLE 14

REPEATED MEASURES ANALYSIS OF COVARIANCE OF RMS LINEUP ERROR FOR THE MIDDLE SEGMENT DURING TRANSFER

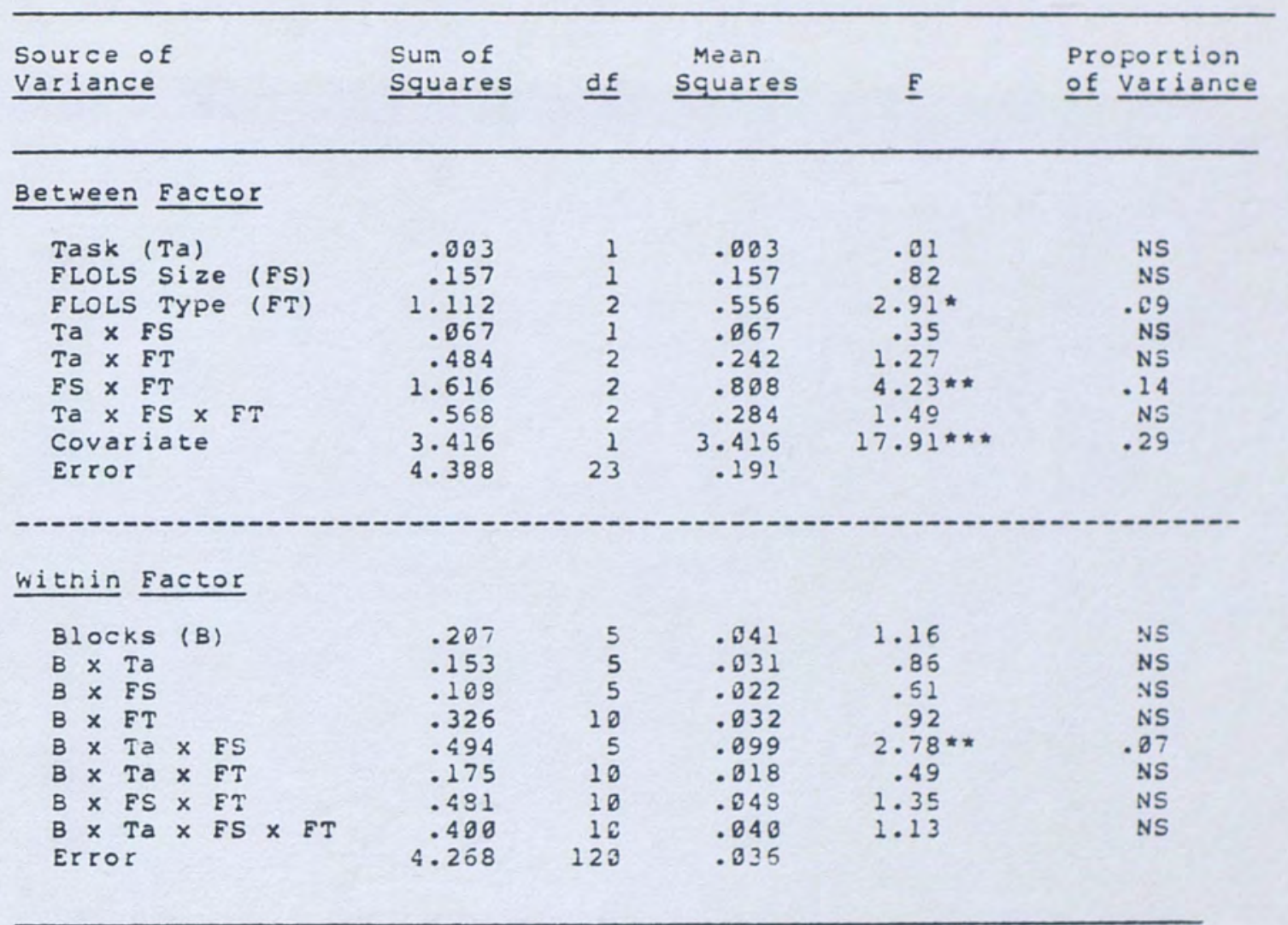

\footnotetext{
$*: \mathrm{p}<.1 \mathrm{e}$

$* *: p<.85$

$\star \star \star * \mathrm{p}<.01$
} 
TABLE 15

MEAN LINEUP RMS ERROR (IN FEET) FOR THE MIDDLE SEGMENT DURING TRANSFER

\begin{tabular}{|c|c|c|c|c|c|c|}
\hline 5-Trial Means & $1-5$ & $5-10$ & $\underline{11-15}$ & $16-22$ & $\underline{21-25}$ & $25-3 i$ \\
\hline \multicolumn{7}{|l|}{ Task (Ta) } \\
\hline $\begin{array}{l}\text { Whole } \\
\text { Part }\end{array}$ & $\begin{array}{l}50.5 \\
90.7\end{array}$ & $\begin{array}{l}44 \cdot 5 \\
55 \cdot 3\end{array}$ & $\begin{array}{l}40.6 \\
60.1\end{array}$ & $\begin{array}{l}49.4 \\
47.5\end{array}$ & $\begin{array}{r}46.9 \\
43.5\end{array}$ & $\begin{array}{l}46.5 \\
54.9\end{array}$ \\
\hline \multicolumn{7}{|l|}{ FLOLS Size (FS) } \\
\hline $\begin{array}{l}\text { Small } \\
\text { Large }\end{array}$ & $\begin{array}{l}63 \cdot 4 \\
77.8\end{array}$ & $\begin{array}{l}49.2 \\
50.7\end{array}$ & $\begin{array}{l}45.8 \\
54.8\end{array}$ & $\begin{array}{l}39.4 \\
57.6\end{array}$ & $\begin{array}{l}40.7 \\
49.5\end{array}$ & $\begin{array}{l}49.1 \\
52.3\end{array}$ \\
\hline FLOLS Type (FT) & & & & & & \\
\hline $\begin{array}{l}\text { Conventional (Cv) } \\
\text { Rate ( } \mathrm{Ra}) \\
\text { Command }(\mathrm{Cm})\end{array}$ & $\begin{array}{l}84.7 \\
53.4 \\
73.6\end{array}$ & $\begin{array}{l}44 \cdot 2 \\
46.3 \\
58.7\end{array}$ & $\begin{array}{l}57 \cdot 9 \\
41 \cdot 5 \\
51 \cdot 7\end{array}$ & $\begin{array}{l}39 \cdot 5 \\
38 \cdot 1 \\
67 \cdot 8\end{array}$ & $\begin{array}{l}40.7 \\
39.3 \\
55.6\end{array}$ & $\begin{array}{l}40.5 \\
38.5 \\
73.0\end{array}$ \\
\hline
\end{tabular}


TABLE 16

REPEATED MEASURES ANALYSIS OF COVARIANCE OF RMS LINEUP ERROR FOR THE CLOSE-IN SEGMENT DURING TRANSFER

\begin{tabular}{|c|c|c|c|c|c|}
\hline $\begin{array}{l}\text { Source of } \\
\text { Variance }\end{array}$ & $\begin{array}{l}\text { Sum of } \\
\text { Squares }\end{array}$ & $\underline{d f}$ & $\begin{array}{c}\text { Mean } \\
\text { Squares } \\
\end{array}$ & $\underline{E}$ & $\begin{array}{l}\text { Proportion } \\
\text { of Variance }\end{array}$ \\
\hline Between Factor & & & & & \\
\hline $\begin{array}{l}\text { Task (Ta) } \\
\text { FLOLS Size } \\
\text { FLOLS TYPe } \\
\text { Ta } \times \text { FT) } \\
\text { Ta } \times \text { FT } \\
\text { FS } \times \text { FT } \\
\text { Ta } \times \text { FS } \times \text { FT } \\
\text { Covariate } \\
\text { Error }\end{array}$ & $\begin{array}{r}.323 \\
.259 \\
.735 \\
.819 \\
.668 \\
1.190 \\
.868 \\
3.101 \\
5.263\end{array}$ & $\begin{array}{l}1 \\
1 \\
2 \\
1 \\
2 \\
2 \\
2 \\
1 \\
23\end{array}$ & $\begin{array}{r}.323 \\
.209 \\
.358 \\
.019 \\
.334 \\
.595 \\
.434 \\
3.181 \\
.229\end{array}$ & $\begin{array}{c}1.41 \\
.91 \\
1.51 \\
.88 \\
1.46 \\
2.60^{\star} \\
1.96 \\
13.55^{\star \star \star}\end{array}$ & $\begin{array}{l}\text { NS } \\
\text { NS } \\
\text { NS } \\
\text { NS } \\
\text { NS } \\
.10 \\
\text { NS } \\
.25\end{array}$ \\
\hline
\end{tabular}

\section{Within Factor}

Blocks (B)

$B \times$ Ta

$B \times$ FS

$B \times$ FT

$B \times$ Ta $x$ FS

$B \times$ Ta $\times$ FT

$B \times$ ES $x$ ET

$B \times$ Ta $\times$ FS $\times$ FT

Errot

.495
.234
.128
.447
.159
.249
.297
.338
.798

2.798

.099
.047
.026
.045
.032
.025
.036
.034
.023

.10

.85

NS

.89

NS

NS

NS

NS

\footnotetext{
$\star: p<.10$

$* *: p<.85$
}

$\star \star \star: \mathrm{p}<.01$ 
TABLE 17

MEAN LINEUP RMS ERROR (IN FEET) FOR THE CLOSE-IN SEGMENT DURING TRANSFER

\begin{tabular}{|c|c|c|c|c|c|c|}
\hline 5-Trial Means & $\underline{1-5}$ & $6-10$ & $11-15$ & $\underline{15-20}$ & $\underline{21-25}$ & $26-30$ \\
\hline \multicolumn{7}{|l|}{ Task (Ta) } \\
\hline $\begin{array}{l}\text { Whole } \\
\text { Part }\end{array}$ & $\begin{array}{l}27.2 \\
85.9\end{array}$ & $\begin{array}{l}21.4 \\
39.8\end{array}$ & $\begin{array}{l}21.2 \\
48.6\end{array}$ & $\begin{array}{l}24.9 \\
28.8\end{array}$ & $\begin{array}{l}22.3 \\
27.4\end{array}$ & $\begin{array}{l}22.8 \\
32.9\end{array}$ \\
\hline \multicolumn{7}{|l|}{ FLOLS Size (FS) } \\
\hline $\begin{array}{l}\text { Small } \\
\text { Large }\end{array}$ & $\begin{array}{l}51.9 \\
61.2\end{array}$ & $\begin{array}{l}32.6 \\
28.4\end{array}$ & $\begin{array}{l}28.8 \\
33.8\end{array}$ & $\begin{array}{l}21.5 \\
32.2\end{array}$ & $\begin{array}{l}24.1 \\
25.7\end{array}$ & $\begin{array}{l}25.7 \\
29.2\end{array}$ \\
\hline \multicolumn{7}{|l|}{ FLOLS TYPe (FT) } \\
\hline $\begin{array}{l}\text { Coventional (Cv) } \\
\text { Rate (Ra) } \\
\text { Command }(\mathrm{Cm})\end{array}$ & $\begin{array}{l}77.1 \\
33.4 \\
59.1\end{array}$ & $\begin{array}{l}32.5 \\
25.2 \\
32.9\end{array}$ & $\begin{array}{l}42.9 \\
22.5 \\
27.3\end{array}$ & $\begin{array}{l}25.0 \\
21.7 \\
33.8\end{array}$ & $\begin{array}{l}25.3 \\
28.8 \\
27.4\end{array}$ & $\begin{array}{l}26.7 \\
26.6 \\
35.1\end{array}$ \\
\hline
\end{tabular}




\section{DISCUSSION}

\section{Training Performance}

Substantial learning occurred in the training phase of the experiment as evidenced by the reliable block (learning) effects and the amount of variance accounted for by these effects for all measures of performance.

Task Effect. There was no difference between training performance of the part-task and the whole-task groups on any glideslope measures of performance. Hence, the part-task method appears to have been successful in providing an effective (although not superior) learning environment for glideslope tracking.

Training performance of the part-task subjects versus whole-task subjects was reliably better on angle-of-attack control. This may have been the result of the greater demand on attitude control for the part-task group. The view of the carrier in the part-task condition was slightly different as a result of the need to start with and maintain zero vertical velocity to stay on glideslope. It took less attitude change in the part-task condition as 
opposed to the whole-task condition to lose sight of the aircraft carrier beneath the nose of the cockpit.

FLOLS Size. The interaction of FLOLS size and task type was interesting. The large FLoLs when used in the whole-task condition was effective in helping subjects learn the essential glideslope skills in the simulator more quickly. However, the large FLOLS was not as effective when used in the part-task condition. The latter result is puzzling since the large FLOLS was effective in providing more explicit glideslope information for the whole task.

FLOLS Type. There were no reliable training advantages with either the RATE or COMMAND displays. These results are surprising considering both the RATE and COMMAND display significantly improved glideslope tracking for experienced carrier pilots (Kaul et al., 1981). However, these data are consistent with Westra (1982) who also found no training advantage with the COMMAND display in early learning of the carrier-landing task.

The within-factor interactions of FLOLS size and FLOLS type indicated that subjects learned at different rates under different conditions. No one combination of FLOLS size and FLoLS type had a significant performance advantage over the others at the end of training. 
Transfer

Task Type. The results indicate that glideslope control of the part-task group was not as efficient as that of the whole-task group. Transfer from part to whole produced early negative transfer that did not appear to be entirely overcome by the end of transfer. There was a three-way interaction which indicated that part-task practice with the RATE display and small FLOLS was as effective for glideslope control as whole-task practice. However, while the power to test the overall interaction was adequate there was not enough power to resolve or verify the interpretation of this interaction in relation to paired comparisons of cells. Nevertheless, the implications of this interaction are considerable and will be discussed along with relative inefficiency of the part-task display for glideslope control.

In general, glideslope control of the carrier-landing task required the learning and integration of both perceptual and control skills. The training data suggest that control and perceptual learning did occur in the part-task group. Thus, the lack of similarity between training and transfer tasks appears to be the contributing factor to the general inefficiency of the part-task training schedule (Briggs and Naylor, 1962). However, 
while this may have some credence and should be given careful consideration, there are some inconsistencies in the data which suggest further consideration for interpretation of the results. First, the lack of similarity between the training and transfer tasks does not account for the effectiveness of part-task training when used in conjunction with the RATE display and small FLOLS. Second, Stammers (198ø) found that the differences in performance between whole- and part-practice schedules at time of transfer are short lived and dissipate with further practice on the criterion task. The results indicate otherwise which suggests another factor may be influencing transfer performance of the part-task group besides the lack of similarity between the part- and whole-tasks. It is suggested that display gain (the way deviations from glideslope are reflected in the displays) may be the critical factor affecting transfer performance. That is, subjects' sensitivity to glideslope error information (display gain) in the part-task condition may not have been near optimum. Thus, the glideslope control skills learned in the part-task group were not sufficient for effective transfer performance to the whole task.

As noted previously, the FLoLs display is less than optimum because the error information from the meatball is 
of zero-order (displacement only). However, the gain of the FLoLs display constantly changes along the approach that the meatball becomes much more sensitive to glideslope error in the close-in segment. Consequently, some judgement of the rate of movement of the meatball can be learned from the FLOLS display. This is especially true in the close-in segment. In the part-task display, subjects practiced glideslope control at only one point along the glideslope. While the point chosen appeared to be of moderate difficulty, there were no changes in display gain and the practice point was located in the middle segment. While changes in display gain were not considered critical to learning, effective glideslope control, especially in the close-in segment, demands an awareness of anticipated meatball movement and appropriate control responses. The gain of the flols display (meatball sensitivity) may not have been sensitive enough at the point at which the part-task subjects practiced glideslope control to learn rate interpretation skills. The glideslope control techniques that were learned were probably based primarily on displacement error. Thus, the part-task trained subjects were at a distinct disadvantage at time of transfer. Consequently, it took them many trials of practice on the criterion task to learn to respond to rate information and they never did attain the glideslope performance achieved by the whole-task group at the end of 
transfer (the differences in performance at the end of transfer, although not statistically significant, could be operationally critical in actual flight).

The addition of the RATE display appears to have helped the part-task trained subjects to interpret elements of the FLoLs display and respond to rate information provided by the arrows. Thus, the part-task trained subjects may have been able to learn rate interpretation skills that were effective for transfer to the whole-task. Glideslope control was more effective when the part-task trained subjects had both the RATE display and small FLOLS. This indicates that there may have been a confounding problem in the part-task approach with the RATE display and large FLOLS in transferring to the small FLOLS. It is suggested then, that the part-task training strategy when used with the RATE display and small FLOLS may be a viable training technique for teaching glideslope control in a simulator. However, there is not enough power for comparison of pairs of cells to verify this interpretation.

Part-task trained subjects did have slightly better AOA control at the start of transfer although the effect was brief and significant only for the part on which they were trained. Nevertheless, this finding is encouraging for the part-task training strategy since AOA control is 
often considered to be almost as important as glideslope control. A training strategy that could provide superior training on AOA control along with adequate training on glideslope control for the carrier-landing task would be beneficial.

As expected, a moderate amount of transition training in the whole task was sufficient to coordinate the skills essential for lateral control. In addition, it is expected that the amount of transition training to coordinate lateral control would be much less for students who have some flight experience. Thus, an inexpensive part-task trainer would also be justified on the basis of expected savings in time on the criterion system.

FLOLS Type. Initial transfer showed a performance advantage with the RATE display on several measures of glideslope control. Glideslope improvement was especially apparent with average error where subjects trained with the RATE display tended to fly closer to glideslope throughout transfer although the advantage was significant only in the early transfer trials. This is important from an operational viewpoint because the lower the approach, the more serious and potentially dangerous it is. 
RMS glideslope error performance after transfer from the COMMAND display was also slightly better than after transfer for the conventional display. However, glideslope performance in latter transfer trials was worse after transfer from the COMMAND display in comparison to transfer from the CONVENTIONAL display. This indicates that there may be a dependency problem in training with the COMMAND display in that the command bars may have attracted some of the attention that should have been paid to the interpretation of the conventional FLoLs display in training.

The COMMAND display did encourage better AOA control through most of the transfer phase while the RATE display tended to produce the worst AOA control in transfer. Subjects trained with the COMMAND display apparently made glideslope corrections with power (correct procedure), while subjects trained with the RATE display may have preferred pitch corrections. While it is possible to track glideslope by adjusting pitch attitude, it is not the correct technique for carrier landings. Pitch adjustments for glideslope tracking are not only dangerous in-close, but can lead to incorrect airspeed and pitch attitude at touchdown which could result in structural damage to the aircraft. 
There was a marked increase in AOA error for the COMMAND display at the end of transfer. This indicates that for some unexpected reason, subjects started using more pitch attitude to track glideslope. This large increase in AOA error is inconsistent with the rest of the transfer data. It is odd that it occurred in the very last block of transfer trials but may account for the poor RMS glideslope error for command-trained subjects at the end of transfer. After careful study of the data, it is suggested that the sudden increase in $A O A$ error at the end of transfer, which may also have affected RMS glideslope error, is not a true representation of the actual ability of subjects trained with the COMMAND display. It is suggested that the COMMAND display does encourage better $A O A$ control regardless of the sudden increase in AOA error in the very last block of transfer trials which may have been caused by fatigue or a number of other reasons.

The concept of reduced workload would suggest that if a first-order display assisted glideslope control, it may also assist 1 ineup control because the subject could divert some of his attention to lineup control (Kaul et al., 1980). The results indicate that the RATE display did produce the best lineup performance although its effectiveness was primarily a result of its use in conjunction with the small FLOLS. 
There was a lineup problem in the middle segment for subjects trained with the COMMAND display. The COMmAnD display may have attracted more than its share of attention to the detriment of lineup although this was not apparent in the training data. Lineup control was better for the COMMAND display in the close-in segment. However, in an operational environment, a large lineup error in the middle may result in a wave off prior to reaching the close-in segment.

The results indicate that the RATE display may be an appropriate aid to glideslope tracking in simulator training of the carrier-landing task. The RATE display did provide a slight performance advantage over the conventional FLOLS although the effect was transitory. Furthermore, better lineup control may be an added benefit of training with the RATE display. Although there is a possible $A O A$ problem with the RATE display, this effect was also transitory and was not significantly different from performance after training with the conventional FLoLs. Secondly, even though glideslope and $A O A$ control were emphasized equally in the instructions, flight naive subjects may tend to view $A O A$ control as less important than glideslope control. It is suggested that subjects who have some flight training or experience would have a more 
basic understanding of $A O A$ and its importance in carrier landings. As a result, $A O A$ would not suffer because of lack of understanding of its relative importance.

While the COMMAND display did encourage better AOA control after transfer, there was no glideslope performance advantage over the conventional FLoLs. The latter finding is consistent with Westra (1981) and supports his hypothesis that the performance advantage in glideslope control for experienced carrier pilots using the COMMAND display (Kaul et al., 198ø) does not apply to inexperienced pilots who are in the early stages of learning the task. In addition, there were potential problems in glideslope and lineup control. Subjects may have allocated too much of their attention to the command arrows and may not have learned to use the conventional FLoLs very effectively.

FLOLS Size. Transition from a large to a small FLOLS produced no sigificant advantages or disadvantages on glideslope dimensions of performance. There was a significant interaction for RMS glideslope error in both segments where the large FLoLs had lower glideslope errors in trials 6-1ø, while the small FLoLs had lower glideslope errors in trials 21-25. However, since there were no glideslope performance effects upon transfer from the large 
to the small Flols, these interactions appear to be unimportant for training issues. Secondly, the interaction in the middle segment was primarily a result of the lower glideslope error of the small fLoLs in trials 21-25 while the interaction in the close-in segment was primarily a result of lower glideslope error of the large FLoLs in trials 6-1ø. Since there were no apparent negative effects in initial transfer from large to small FLoLs and the interactions were poorly defined, they were judged not to be operationally important.

However, there appeared to be a potential problem in $A O A$ control with the large FLOLS. AOA error increased in transition from the large to the small FloLs. While this effect was brief, it could be critical if it occurred in actual flight. Furthermore, the whole-task large FLoLS condition consistently had higher AOA errors throughout transfer as opposed to the whole-task small FLOLS.

Nevertheless, the cost and potential training benefits (time-to-train) of using a large FLoLs are attractive. Thus, it is suggested that if a large FLOLs is used in simulator training of the carrier-landing task, adequate care be taken to emphasize AOA control to alleviate potential $A O A$ problems in transition from a large (simulator) to a small (aircraft) FLoLS. 
Covariate. The selection of the ATARI video game appears to be an appropriate covariate for the carrier-landing task. The ATARI video game accounted for a useful amount of the between-subject variance in the close-in segment for all measures of performance except average glideslope error. It was especially effective for lineup error where it accounted for an average of $27 \%$ of the variance in both segments.

Research Recommendations. The part-task training strategy appears to be ineffective except for the possibility of using it in conjunction with the RATE display and small FloLs. Due to the limited power of the experiment, it is not possible to conclude that this is an effective training technique or that there is no confounding problem with the large FLOLS and RATE display in the part-task strategy. Because of the implications for cost and training effectiveness, this issue is worthy of additional research.

It may also be worthwhile to have subjects practice glideslope control in the close-in segment where meatball sensitivity is at its optimum and essential rate information can be learned. A potential problem with practicing glideslope control in the close-in segment is 
that it may be too difficult for a novice pilot to maintain control of the aircraft for any length of time to learn proper glideslope control skills. An optional strategy may be to learn the basic control skills in the middle segment prior to practice in the close-in segment.

Research should also be directed towards further evaluation of the RATE display as a visual aid for simulator carrier-landing training. While the findings of this study are encouraging, the value of the RATE display needs to be more thoroughly defined. In addition, while the COMMAND display is not an effective visual aid for students in the early stages of learning the carrier-landing task, previous research has shown a considerable performance advantage in glideslope control for experienced carrier pilots using the COMMAND display. It may be worthwhile to examine the COMMAND display in the context of the ideal point, if any, to introduce it in a pilot's training regimen. For the present, it is suggested that the commmand display should not be introduced to pilots until they have become carrier qualified with the conventional FLOLS. 


\section{CONCLUSIONS}

This study was conducted with flight naive subjects to investigate visual and part-task manipulations for teaching simulated carrier landings. Part-vs whole-task training and two visual factors, Flols type (descent rate cuing) and FLOLS size were investigated at the Visual Technology Research simulator. Subjects performed $3 \emptyset$ training trials with instructional feedback under a particular condition and then transferred to $3 \emptyset$ test trials under the condition most representative of the carrier-landing task (9øøø ft. straight-in approach, conventional and small FLOLS).

In general, part-task training was not as effective as whole-task training and the difference was sustained throughout transfer. The RATE display did result in a glideslope transfer advantage compared to training with a conventional FLoLs although the effect was temporary and primarily affected average glideslope error. Better lineup control may also be an added benefit of training with the RATE display. Further evaluation of the RATE display is desirable. While the Command display did encourage better $A O A$ control, it did not result in a glideslope transfer 
advantage compared to a conventional FLoLs. In addition, there may be a dependency problem with the COMMAND display where subjects spend too much time attending to the command arrows and too little to interpretation of the conventional FLOLS displacement information.

There was no glideslope transfer advantage or disadvantage from training with a large FLoLs although there may be a time-to-train advantage from using a large FLOLS with whole-task training. In addition, a large FLoLs is desirable from an engineering cost perspective. While both the RATE display and large FLOLS showed problems with $A O A$ performance, it is suggested that a more basic understanding of AOA (possibly a result of flight experience) and emphasis of $A O A$ by the instructor would help alleviate this potential problem. Otherwise, care must be taken in the transition from simulator to aircraft to avoid any decrement in $A O A$ performance in actual flight.

While the visual manipulations did not substantially improve transfer performance, the implications of cost and training effectiveness of the large FLOLS and RATE display suggest further research on optimizing visual displays for simulator training of operational flight tasks. In addition, while the overall part-task training strategy was 
ineffective, there was evidence that it did produce good transfer to the whole task when used in conjunction with the RATE display and small FLoLS. Furthermore, Wightman (1983) successfully used a part-task sgmented approach in teaching carrier approaches in a simulator. Thus, departures from reality do show promise as effective training techniques of operational flight tasks and may prove to be cost effective and possibly superior to conventional methods. 
APPENDIX A

CARRIER LANDING INSTRUCTIONS 


\section{BRIEFING}

\section{CARRIER LANDINGS}

IN THE

\section{VISUAL TECHNOLOGY RESEARCH SIMULATOR}

\section{Innovative Instructional Techniques}

$$
\begin{gathered}
\text { By } \\
\text { Gavan Lintern } \\
\text { and } \\
\text { Daniel J. Sheppard }
\end{gathered}
$$

With

Contributions and Assistance

$$
\begin{gathered}
\text { From } \\
\text { Fred Berry, USMC (Ret) } \\
\text { Ted Lyon, Major, USMC } \\
\text { Jerry Singleton, LCDR, USN }
\end{gathered}
$$

21 October 1981 
INTRODUCTION

Welcome to the Visual Technology Research Simulator (VTRS). This is a Naval Research Facility developed to study the use of simulators for teaching flight skills.

The VTRS simulates a T-2C aircraft and consists of a single seat cockpit, a ten foot radius spherical screen which surrounds the cockpit, and control computers which run the simulator. The cockpit controls and instruments operate just as they do in a real aircraft. A picture of an aircraft carrier is projected on the screen, and when the simulator is running, the scene will look just as it would if you were flying a real carrier approach.

We have been investigating instructional methods of carrier landings. This experiment is a continuation of that work.

Because this is a controlled experiment, we will be using a special sequence and schedule to instruct you in what you are to learn. This is to assure that each person in the experiment receives the same material in exactly the same manner. However be sure to ask for clarification on any points you do not understand.

We are teaching different people under different conditions. While we do not believe that knowledge about other conditions will affect your performance, we would like you to inhibit your curiosity about what others are doing until your experimental work is over. It is possible that viewing the displays at the control station could affect your performance, so we would like you to wait in the subject room if you arrive early for a session. Brief exposure to the control station displays or those found elsewhere in the VTRS building will not affect you, but please do not spend any substantial amount of time studying them. Also, please do not watch the video game or the visual acuity testing.

We will tell you when you have finished the experiment and will be prepared to describe other conditions at that time, or to let you view the control station operation if you wish.

Equipment problems and conflict with other high priority tasks will occasionally force us to reschedule sessions. We will try to contact you if you are to be rescheduled. However, if you are unavailable at the telephone numbers we have for you during the morning prior to your session, you could contact us just before you 
start your trip to the simulation laboratory. You should call Karen Thomley, Dan Sheppard, Gavan Lintern or Dennis Wightman at 277-5353, 5356 or 5402 .

We appreciate your participation in this experiment and we hope that it will be a meaningful experience for you.

\section{ABOUT THE EXPERIMENT}

This study has been designed to tell us something about how simulation can be used to teach carrier landings. We are examining the training efficiency of several different instructional techniques by teaching carrier landings with the various methods and then testing landing ability in a simulator configuration that is as close to full fidelity as we can get. While the experiment will be conducted entirely in the simulator we intend to use the information gathered from it to help us design a study in which pilots will be taught first in the simulator and then tested in the aircraft.

Note that this experiment is aimed at testing the simulator, and is not a test of your ability.

Nevertheless there will be differences between individuals and we need to account for these when we analyze the data. Differences will be minimized if everyone does their best. We would like you to concentrate on learning the task in the correct manner and as quickly as possible. We would also like you to do your best on every trial.

\section{THE CARRIER APPROACH}

Precise aircraft control is essential in a carrier approach. Vertical displacement errors at the ramp (threshold of the landing deck) of a few feet can be disastrous, as can descent rate, airspeed or attitude errors at touchdown. Thus, the pilot must maintain a precise glideslope (generally set at $3.5^{\circ}$ ) and maintain the correct descent rate, airspeed and attitude. Conventional landings permit some deviations in these parameters but Navy carrier pilots must establish them early in the approach and maintain them to touchdown. Neither is it acceptable for a Navy pilot to fly a loose early approach with the aim of establishing better control near the carrier. The potentially disastrous consequences of errors makes the uncertainty associated with this type of behavior quite unacceptable. In this experiment you will learn some of the skills needed for carrier landings. 
In this experiment you will need to manipulate the:

o control stick

- rudder pedals

o throtties

o pitch trim

When seated in the cockpit you will find the control stick between your knees. Push forward to pitch the aircraft down (i.e., push the nose down) and pull back to pitch it up. Push it to the right to turn to the right and to the left to turn to the left. You will find the rudder pedals on the floor near your feet. When turning to the right or left, light pressure on the right or left pedal will assist the turn. Do not be misled by the common miconception that aircraft is turned with its rudder. The turn is made by rolling with its ailerons. The rudder merely assists the turn, and in many aircraft has a marginal effect.

A pair of throttles, one for the left and one for the right engine, are to the left of the seat within easy reach of your left hand. Push forward to increase power, and pull back to decrease power.

If you move the stick forwards or backwards some distance and need to hold it there, it will exert a constant pressure. Pitch trim can be used to neutralize the pressure. Of course if you retrim in this manner, and you then move the stick back to its original position, you will again need to retrim. The simulator should be trimmed close to optimum when you enter the cockpit, and your pitch adjustments should be so slight during the experiment that there will be no need to retrim. However, the use of the trim button will be explained when you enter the cockpit. You may wish to use it when you are first released on each trial to adjust the trim slightly so that it is most suitable for you.

PARAMETERS FOR APPROACH CONTROL

In making an approach the carrier pilot must be concerned with:

(1) current position in relation to the glideslope, 
(2) current descent rate--is it correct, if not is it taking him away from the glideslope

(3) airspeed and pitch attitude--integrated into one instrument known as the Approach (Angle-ofAttack) Indexer, and

\section{(4) 1 ineup.}

\section{GLIDESLOPE POSITION}

Glideslope guidance is normally given by the Fresnel Lens Optical Landing System (FLOLS). We have simulated this system with two horizontal bars (to represent the datum bars) and a moving dot (referred to as the ball or the meatball). The system is illustrated in Figure 1 and Figure 2 a to e. A center ball indicates that the aircraft is on the glideslope (later discussion will note that correct aircraft attitude is necessary for that to be true). A high ball indicates that the aircraft is above glideslope, and a low ball that it is below glideslope. At two balis low the meatball starts to flash. Plus or minus two balls is the maximum effective range of the system. The ball will be lost off the top or the bottom at larger deviations from glideslope.

A real FLOLS projects cones of light from the ship as shown in Figure 3. Thus the system is angular. Larger errors are required far from the ship to see meatball movement than are required near the ship. At $3 / 4$ mile a 12 foot glideslope displacement is needed to move the ball off center while at the ramp, a one foot displacement will move the ball off center. The range of the FLOLS is approximately $\pm 3 / 4^{\circ}$ (precisely $\pm 47.5^{\prime}$ ) or, if set for a $3.5^{\circ}$ glideslope $\bar{e}$, from $2.75^{\circ}$ to $4.25^{\circ}$ (approximately).

\section{CARRIER LANDINGS}

In making a carrier landing the pilot attempts to follow the FLOLS center beam to the deck of the carrier. If he can maintain a center ball, and keeps the aircraft in the correct pitch attitude, a hook fixed to the tail of the aircraft (Figure 4) will follow a glide path that is parallel to, but lower than the center FLOLS beam. It is intended that the hook contact the deck midway betwen the second and third of four cables stretched across the deck (these cables are known as arrestment wires). The hook travels forward from this point to snag the third wire, and so the aircraft is halted. 


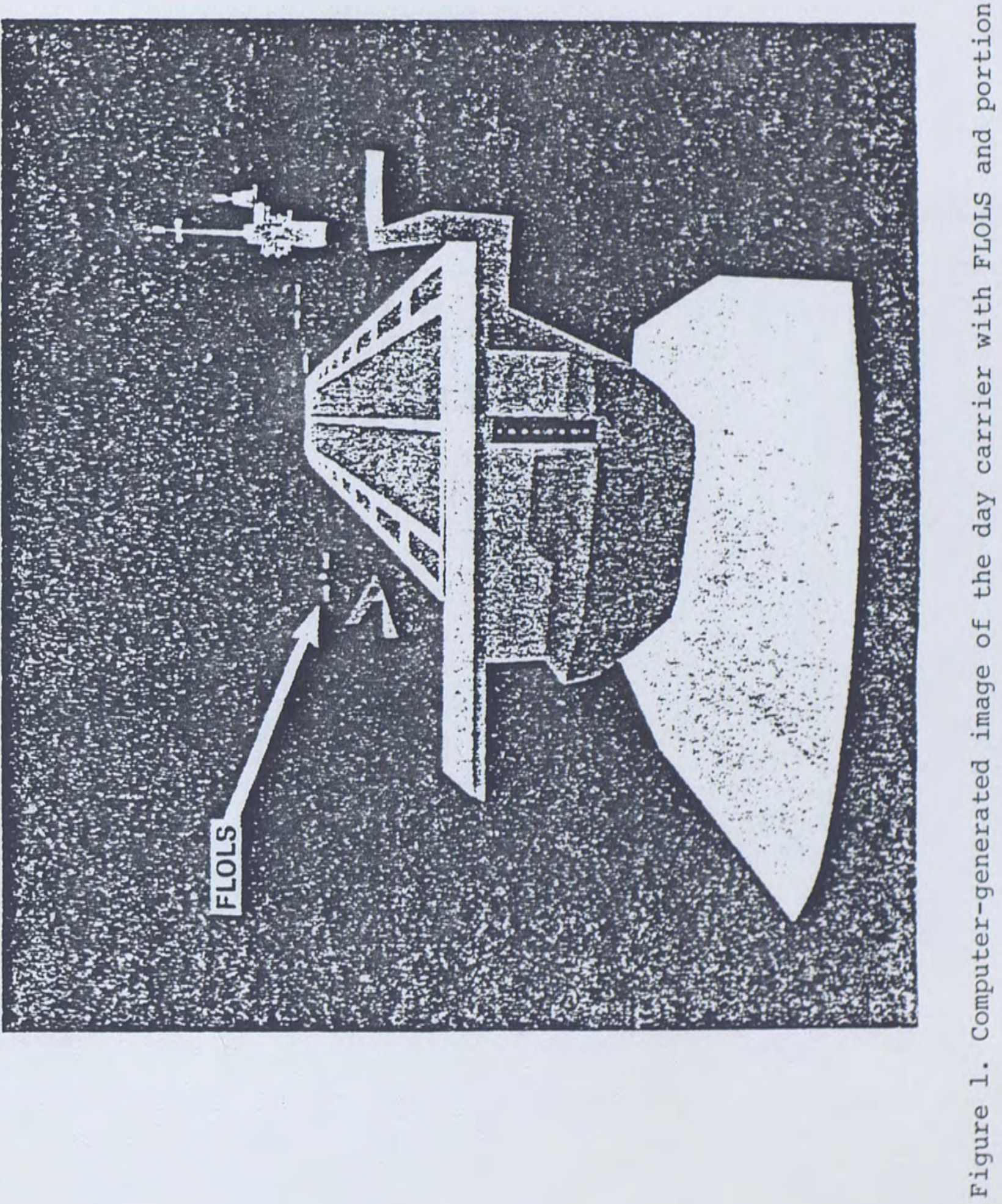




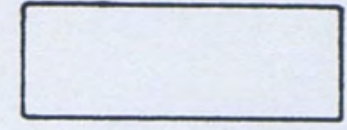

a)

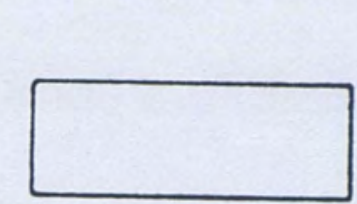

b)

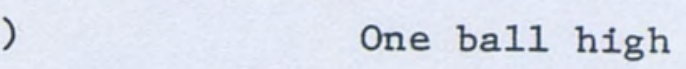

c)

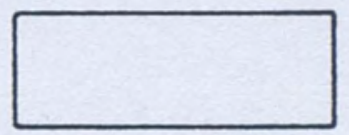

d)
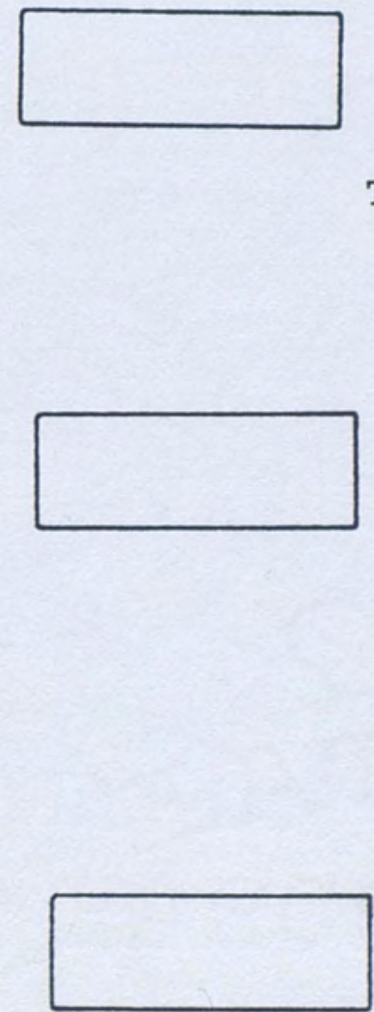

One ball low

○

Two balls high

0

arall 1ow
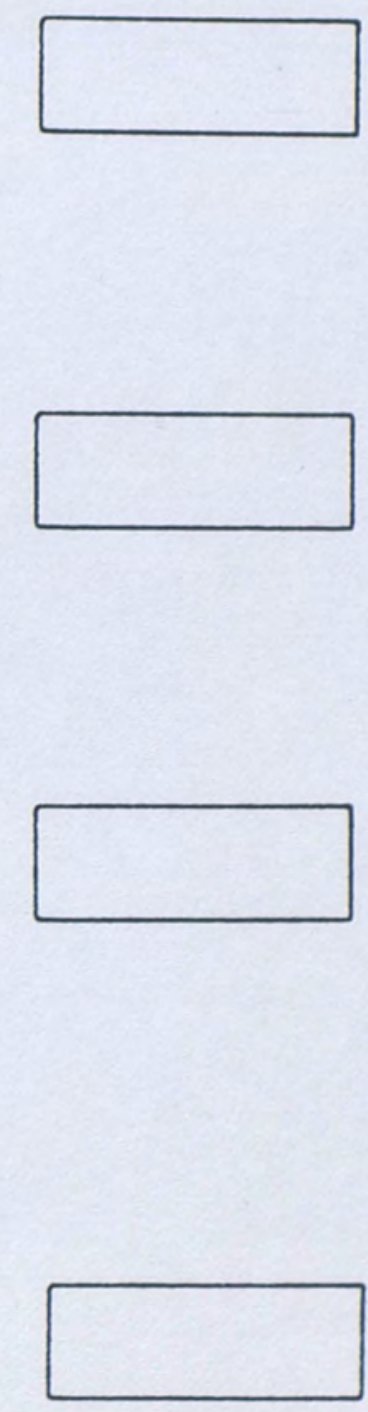

(flashing)

e)

Two balls low

Figure 2. The fresnel lens optical landing system. 


$$
\begin{aligned}
& \text { ए } \\
& \text { 峁范 }
\end{aligned}
$$

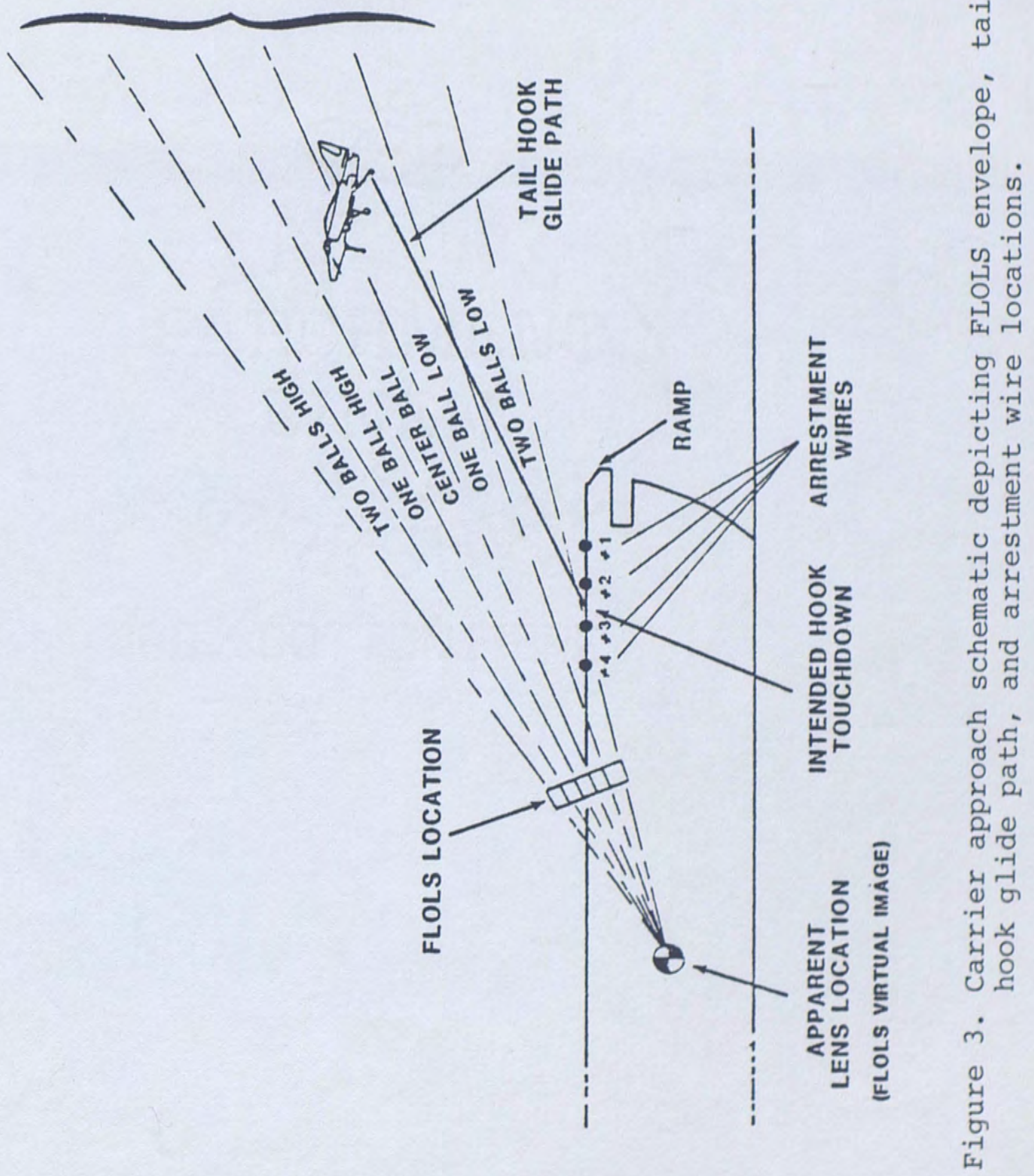




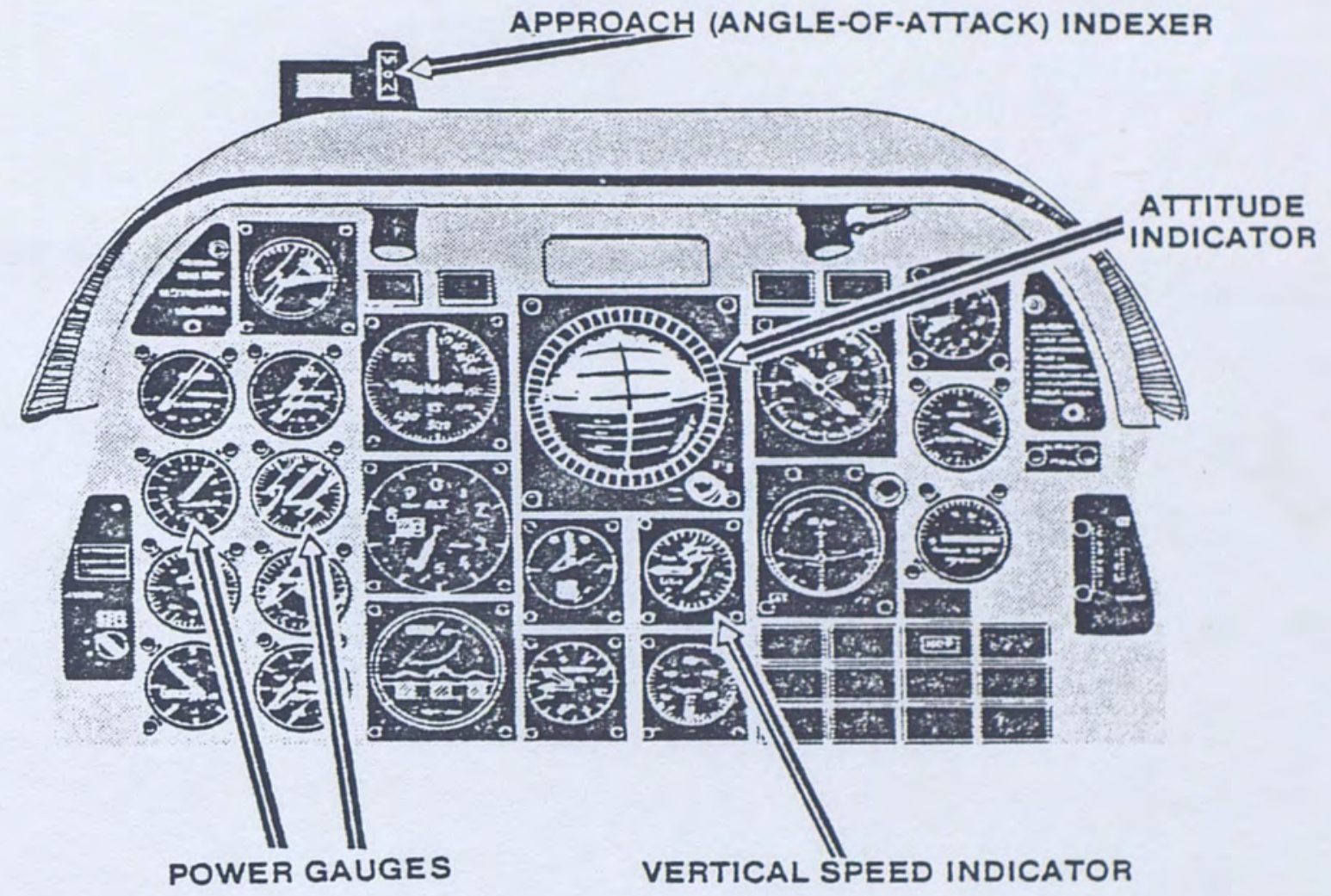

Figure 4. T-2C instrument panel.

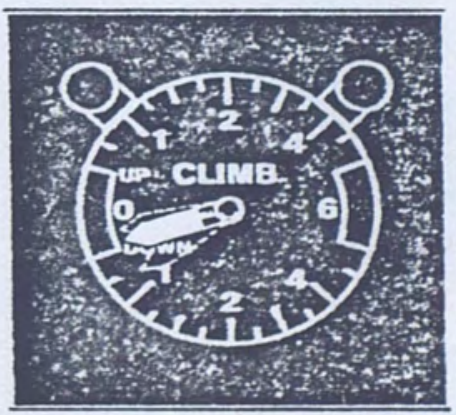

Figure 5. Vertical speed indicator. 
If the pilot is slightly low on the approach he may snag the first or second wires. If he is very low (actually an error of 10 feet may be enough) he may hit the ramp, thereby bringing disgrace and physical harm to himself, and severely damaging a multi-million dollar aircraft. If a pilot is slightly high on the approach he may snag the fourth wire. If higher (possibly only two feet higher than optimum he may miss the wires altogether and fly off the end of the carrier. A missed approach of this type is called a bolter. Fortunately bolters do no lasting damage (about $5 \%$ of approaches result in bolters), but they do detract from shipboard efficiency. Thus the ability to follow the glideslope contributes to a Navy pilot's health, happiness and self-esteem.

\section{DESCENT RATE}

The aircraft has a Vertical Speed Indicator (VSI) (Figure 4), with hash marks shown at 200 fpm intervals (Figure 5). The reference descent rate for the $\mathrm{T}-2$ in the configuration that you will be flying is $515 \mathrm{fpm}$. That is, if the aircraft is on the glideslope and with the correct attitude and airspeed, it will stay on the glideslope if the reference descent rate is maintained.

If you are above glideslope you will need to establish a descent rate of up to $800 \mathrm{fpm}$, while if you are below glideslope you will need to establish a descent rate of as low as $200 \mathrm{fpm}$. These corrections will return you to the glideslope at an appropriate rate. Maximum, minimum, and optimum vertical speeds are indicated in Figure 5.

Note that if you perceive an incorrect vertical speed, it will probably not be sufficient merely to correct back to the reference rate $(515 \mathrm{fpm})$ even if you are on glideslope. By the time your correction has taken effect you will probably be off glideslope and will need to correct in a direction opposite to that which caused the error. The techniques for correcting glideslope errors are central to good carrier landings, and will be discussed in detail in a later section.

Descent rate information can also be obtained from the meatball. If you have a center ball, but see it moving, you can judge that your descent rate is incorrect. In addition, if you are high, you need to start the ball moving down, and if low, start it moving up. You can use the rate of ball movement to establish an appropriate corrective descent rate. This can be useful because it means that you do not have to look inside the cockpit at the VSI. Unfortunately, it is possible to discern movement of the meatbali only when the aircraft is 
approximately 1500 feet from the ship. At greater

distances the rate of movement is so low that it is below the threshold for the psychological process that interprets changes in position as rates of movement.

Thus, you will have to rely on the VSI until you close on the carrier.

\section{ANGLE - OF - ATTACK}

The angle-of-attack (AOA) is the angle at which the wing meets the air (Figure 7) or more precisely, the angle between the no-lift 1 ine of the wing and the relative wind (i.e., the flow of air due to both the movement of the aircraft and to natural wind).

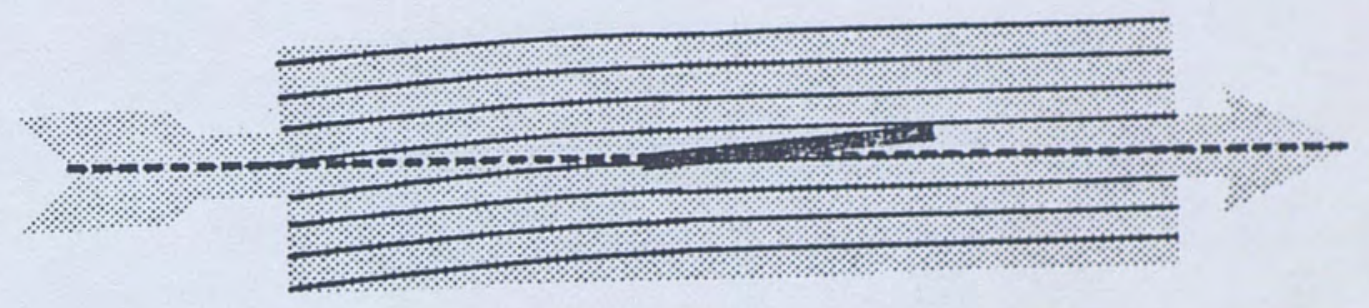

(a) A wing is an inclined plane, set into a wind so as to deflect the air downward.

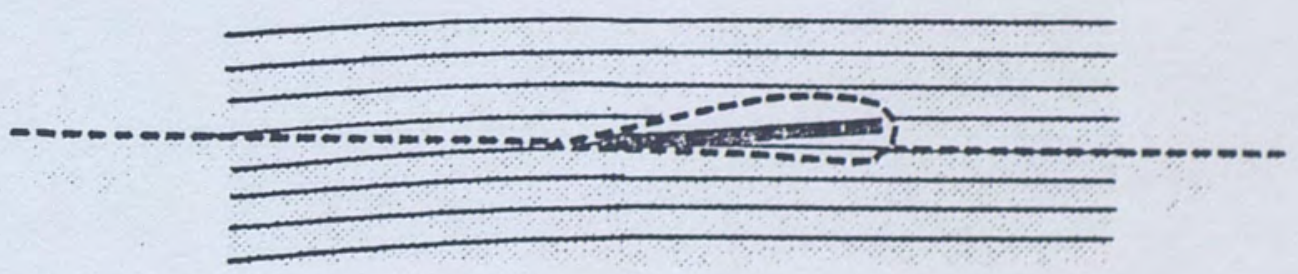

(b) For greater efficiency, this basic inclined plane is enclosed by a curved outer shape. In aerodynamic theory Angle of Attack is defined as the angle between the Relative Wind and the "no-lift Iine" -. the no-lift line being really the basic inclined plane, seen in cross section.

Figure 7. Angle of Attack. 
AOA, pitch attitude, and airspeed are closely related. For level flight, or for a constant descent, a high angle of attack implies a high pitch attitude and a low airspeed while a low angle of attack implies a low pitch attitude and high airspeed (the fact that the relationship between AOA and pitch attitude varies depending upon whether the aircraft is climbing, descending, turning, etc. is not important here). You need not concern yourself much with pitch attitude or airspeed, even though these are critical to a safe carrier landing. Just remember that, if you establish the correct $A O A$, the pitch attitude and airspeed will be correct.

To monitor AOA the Navy pilot is provided an instrument called the Approach Indexer. You will find it above and to the left of the instrument panel (Figure 4). It consists of an upper and lower chevron and a center circle (donut). It is possible for one chevron, or the donut, or a chevron-donut pair to be illuminated. The readings and their interpretations are shown in Figure 8 .

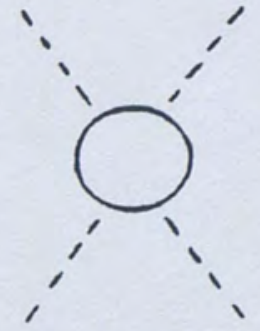

Correct AOA (15 Units) i.e., on speed, correct attitude

\section{5 to 15.5 units}

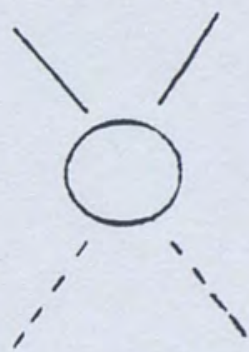

15.5 to 16.0

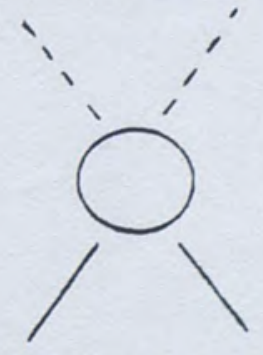

14.0 to 1.4 .5

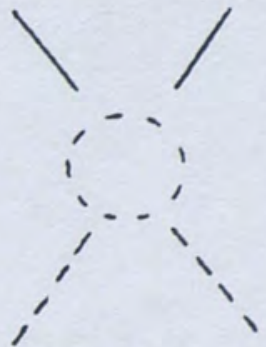

$16+$ units

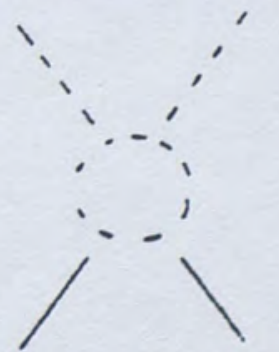

14.0 units
High AOA (more than 15 Units) i.e., slow, with high pitch attitude
Low AOA (1ess than 15 Units) i.e., fast, with low pitch attitude

Figure 8. Indications from the Approach

(Angle of Attack) Indexer. 
A chevron-donut pair can generally be regarded as acceptable. This would allow a range of $15+1$ units. More extreme AOA errors should be corrected as is described in a later section of this reading.

\section{LINEUP}

In carrier landings the pilot 1 ines up with the extended center line of the landing deck. Note that the landing deck is canted at $10.5^{\circ}$ to the longitudinal axis of the ship. It is not, therefore, appropriate to use the carrier wake or the main deck for 1 ineup. Lineup errors are corrected with small banking turns to the left or right. You will need to use fine control pressures in moving the stick to the left or right, and on the rudder pedals, to start these turns. In turning onto the center line, you should anticipate closing on it: that is, start your lineup turn before you reach it. If you start your lineup turn when you reach the center line, you will find yourself a long way past it by the time you are heading the simulator in the right direction.

\section{GLIDESLOPE CORRECTIONS: SOME BASIC PRINCIPLES}

Glideslope control is the specific issue of this experiment. All glideslope corrections will be started with power. You may find this puzzling. It would seem easier to leave the power as it is and to adjust the pitch attitude to make the aircraft go up or down. Although this is possible in real carrier landings it is an almost inevitable road to disaster. However, first a basic lesson in momentum that will clarify some of the issues to be discussed in glideslope control.

Consider a massive ball on a horizontal, frictionless plane as shown in Figure 9.

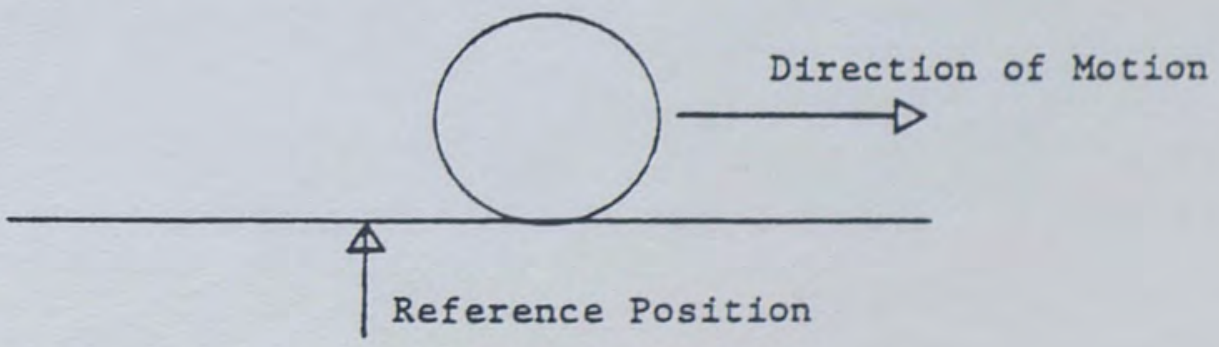

Figure 9. Inertia demonstration.

It is moving to the right, and you want to return it to the reference point. You need to apply a force to the left to initially stop the movement to the right and then 
to start movement to the left. Once the left movement has built up to a suitable value, you could remove the force. At some point you should apply a force to the right. You should apply this force before the ball reaches the reference position, and if you anticipate it just right, and if you apply just the right amount of force, the ball will stop precisely at the reference point. Now you must remove the force you have applied to the right or the ball will start rolling to the right again.

$$
\begin{aligned}
& \text { Note the four distinct actions. } \\
& \text { o Application of force to the left } \\
& \text { o Removal of force to the left } \\
& \text { - Application of force to the right } \\
& \text { o Removal of force to the right }
\end{aligned}
$$

Now is we tip the frictionless plane to a vertical position and apply a sufficient reference up force that will maintain the ball at a constant height, we can go through a similar procedure. This time we need to consider up or down forces as additional components to the basic upwards reference force. The resultant force is always upwards, but we must increase or decrease it by applying up or down forces to the reference value. If the ball is moving up or down away from the reference point, we can go through a similar process as that used for the horizontal plane.

- Apply a corrective force to the reference value to reverse the direction of movement.

- Remove the corrective force.

- Apply a corrective force to the basic reference value at the right $t$ ime, and of the correct magnitude to stop the ball at the reference point.

- Remove the corrective component.

This is similar to the way you correct the glideslope errors in the aircraft or simulator. The corrective forces are the changes in aerodynamic lift that result from changes in power. Again, you could effect these changes in lift by adjusting pitch attitude, but this is NOT correct technique for carrier landings. While it is apparently easier to track the glideslope by adjusting 
pitch attitude, you will arrive at the deck of the carrier with the wrong airspeed and pitch attitude. Structural damage to the aircraft could result.

\section{RELATIONSHIP BETWEEN GLIDESLOPE AND ANGLE OF ATTACK}

Furthermore the greater glideslope accuracy achieved by this method of control is only apparent. The FLOLS is a passive optical system, and the pilot sees a center ball when his eye is in the center beam. The center beam is set so that, at the correct aircraft attitude, the tail hook of the aircraft is proceeding on a glide path of its own, towards a point on the carrier deck midway between the second and third arrestment cable (Figure 3 ).

However, the hook is at the other end of the aircraft from the pilot's eye, and simple geometry would suggest that an incorrect pitch attitude will move the hook above or below its glide path even when the pilot's eye is on the correct FLOLS glideslope. In fact, the hook is the critical point of the aircraft for touchdown accuracy, not the eye of the pilot. The only means the pilot has of ensuring that the hook is in the correct position is by following the FLOLS beam with his eye, and flying the correct AOA (which will ensure correct pitch attitude).

So by now you may have the message. Glideslope position and AOA are equally important. We are measuring both to assess your performance, and we are measuring glideslope errors by measuring deviations of the tail hook from its reference glidepath. You may even be impressed that AOA control is more important than glideslope control because, if you have AOA correct, you are at least scoring on one dimension. If your AOA is incorrect you almost certainly have nothing right whether you see a center ball or not.

\section{ERROR CORRECTION: GLIDESLOPE AND AOA}

To start a trial you will be set up in the simulator $1.0 \mathrm{miles}$ from the carrier, on the glideslope and on the extended centerline of the landing deck. The simulator will be in its landing configuration (wheels down, flaps at one half, hook down, and speed brakes out) with 15 units angle of attack, $7.5^{\circ}$ pitch up, $83 \%$ power, and on a center meatball. When the simulator is taken out of freeze, assume control and fly along the glideslope to the carrier deck.

Always keep in mind your glideslope position (i.e., meatball position), your vertical speed (noted from the VSI and the rate of movement of the meatbali), and your 
AOA. Try to determine a reference power level that will maintain you on the glideslope. the location of the left and right power gauges is shown in Figure 4, while Figure 10 shows approximate optimum, maximum, and minimum

values. Also, note on Figure 10 that each minor hash mark (small guage, top center) represents $1 \%$ of power and major hash marks represent $10 \%$ of power. A reference power of about $83 \%$ should work well. Lead corrections with power (except as noted in 2)c) below); changes of $2 \%$ to $4 \%$ should be sufficient. Certainly do not go above $90 \%$ or below $75 \%$.

Remember that corrections are almost always started with a power adjustment and AOA errors should generally be corrected before glideslope errors (except as noted in 2)c) below). The power adjustments for a correction will be made in three (and sometimes four) steps. First increase

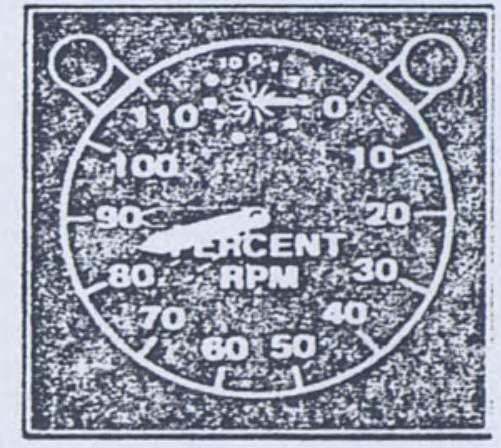

Diagram of $\mathrm{T}-2 \mathrm{C}$ power gauge, showing hash marks - note the needle at $83 \%$, and dotted needles at $90 \%$ and $75 \%$.

Figure 10. Power Gauge (Both Left and Right Gauges are Identical).

or decrease power to initiate the correction. Secondly, take out the correction as you approach the correct AOA or glideslope position. In taking out the correction go past your reference power to null any acceleration or unwanted velocity component that you have introduced in the first step. The third step; to return the power to its reference level, follows the second step almost immediately.

Follow with small pitch changes to correct or maintain AOA. Pitch up and pitch down can be estimated from the attitude indicator (artificial horizon). Its location is shown in Figure 4. The horizon line and aircraft symbol are shown more clearly in Figure 11 . If the horizon line is zeroed (adjust the knob to the lower right), the aircraft symbol will indicate the aircraft is pitched up if it is above the horizon 1 ine. Hash marks are set $5^{\circ}$ apart, and the dot at the center of the aircraft symbol corresponds to $1^{\circ}$. 


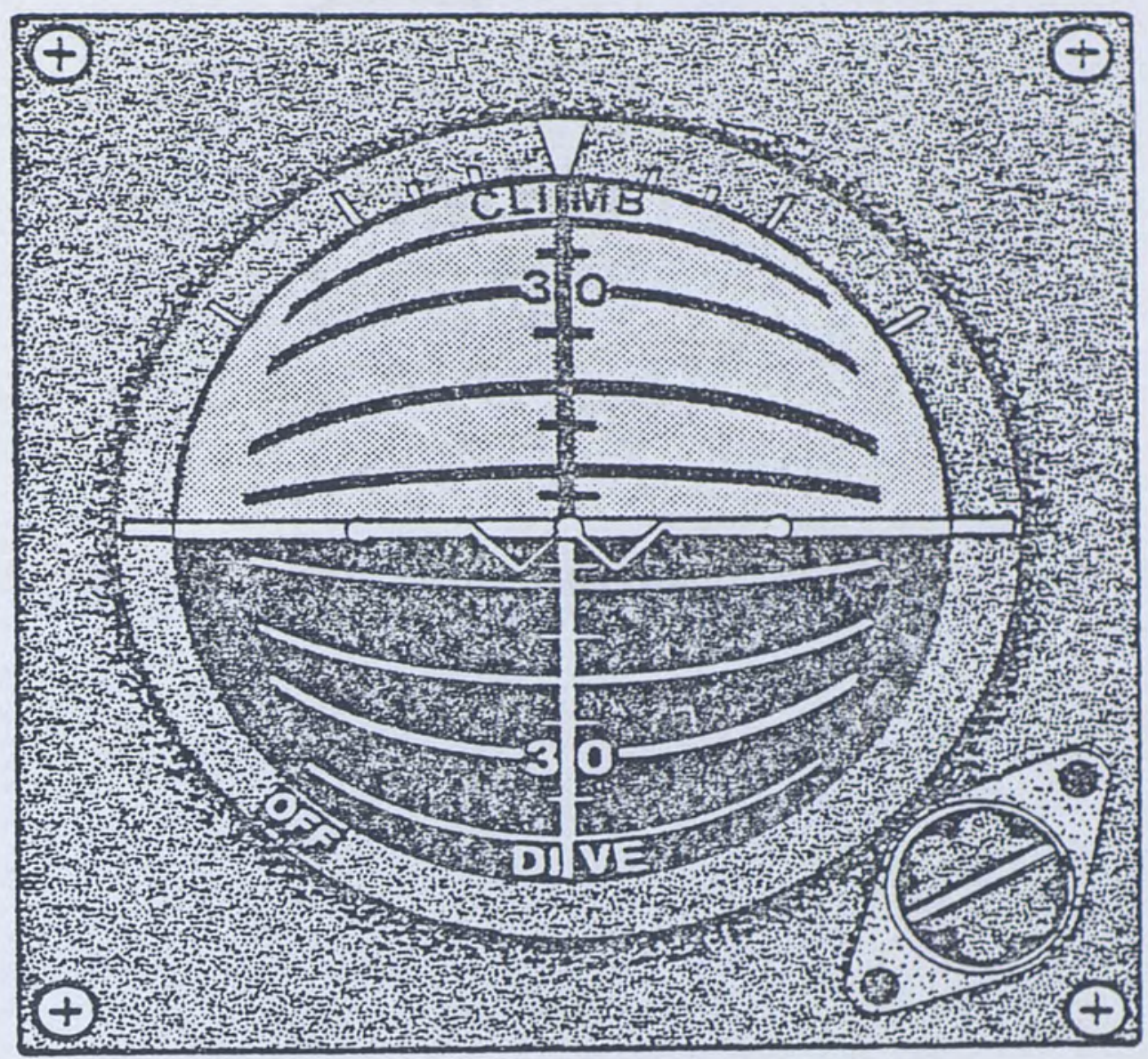

Figure 11. Attitude indicator.

An $8.5^{\circ}$ pitch up is correct; and corrections for $A O A$ should not require pitch movements to below $7^{\circ}$ or above $10^{\circ}$. Greater changes than that will indicate that you are overcontrolling in pitch.

If you need to make a large power correction for a glideslope error, you may find it necessary to insert another power adjustment between the first and second steps. After the initial correction you should look for a target descent rate that will return you to the glideslope quickly enough, but not so quickly that you will not be able to stop on the glideslope. You may achieve the target descent rate before you near the glideslope. If so, you should take out some of your power correction (probably about half) so that you do not go past your target descent rate. Specific types of errors are discussed below.

(1) $\mathrm{AOA}$ errors

If on glideslope and correct vertical speed, 
(a) high AOA (slow): add power, smoothly push the stick forward (slightly) to correct AOA; as aircraft accelerates reduce power

to slightly less than reference level, and then almost immediately adjust back to reference level.

(b) low AOA (fast): decrease power, smoothly pull stick back (slightly) to correct AOA; as aircraft decelerates increase power to slightly higher than reference level and then almost immediately decrease power to reference level.

\section{(2) Glideslope errors}

Note that if your AOA is correct and you add power to make a glideslope correction, you will need to pull the stick back slightly to maintain the correct AOA (because with the same stick pressure the extra surge of power will push the aircraft a little faster and tend to lower its attitude). If you decrease power you will need to push the stick forward slightly to maintain AOA.

(a) Going high: decrease power (if AOA is low the decrease in power will tend to correct the AOA error before it corrects the glideslope error; otherwise you need to push the stick forward). When you see that you have started back to the glideslope add about half the power you have taken out. As you near the glideslope add more power so that the power level is now slightly above the reference level. Almost immediately reduce power to the reference level.

(b) Going low: increase power to start the ball moving up (if $A O A$ is high, the increase in power will tend to correct the AOA error, but let the ball start moving up before you ensure that AOA is closing on the correct value. When you see that you have started back to the glideslope, take out about half the power you have added. As you near the glideslope take out more power so that the power level is now slightly below the reference level. Almost immediately increase power to the reference level. 
(c) Correcting for a low or a high in close (less than $1000 \mathrm{ft}$ from touchdown): for a low add power to start the ball moving up. Stop the ball moving up by adjusting the pitch (this is the only time that pitch should lead power in making an adjustment). Use power to get back on speed.

If the ball is moving up in close or has stopped with a high indication in close (either as a result of an overcorrection from a low, a slightly low descent rate from farther out, or for some other reason), do not recenter.

A correction at this point can lead to an excessive descent rate at touchdown (correction for a high ball in close can produce a $5^{\circ}$ glideslope). If the ball develops a rapid motion towards the bottom of the lens, apply enough power to stop the movement.

\section{SLUGG ISHNESS}

The most difficult feature of glideslope control is the sluggish response of the aircraft to control inputs. Corrections to $A O A$ and glideslope require some time to take effect., Because of their inertia the engines will take about 0.25 seconds to respond to a throttle adjustment. Then the aircraft, because of its mass, will take some time to respond to the change in power. Once you have made a correction you will be tempted to increase it because you see no effect. You may add another corrective control input near the time the first is showing its effect so that you may find you have overcorrected to an extent that you will have an opposite and greater error than the one you have attempted to correct. This can lead to wild swings in control behavior, often known as control instability. It should be avoided but you should also avoid being too tentative. Very small control movements may not do the job. That is what you have to learn: the type and magnitude of control movements that will do the job.

Because of the sluggishness you will be tempted to lead your corrections with pitch changes. The aircraft will respond faster, but you will not be able to maintain the correct AOA. 
In real carrier approaches a Landing Signal officer (LSO) is stationed to the side of the landing deck and advises the approaching pilot by radio on the suitability of his approach. He may, for example, advise the pilot that he is high or low, or to the left or right. He may give instructions, such as "POWER" to indicate that the pilot should add power. He may instruct the pilot to discontinue his approach, and go around to set up for another approach by flashing two vertical light arrays on the FLOLS and calling "WAVEOFF".

The role of the LSO is also instructional, in that he will make a record of the pilot's performance, and use this in a debrief to point out errors, and to advise him on how to improve his approaches.

In this experiment there will be no calls made during the approach. However, the instructional role of the LSO will be filled by an experimenter who has been trained by an LSO for this task. He will comment on the significant features of your approach at the end of each trial, and will suggest ways to improve. These suggestions will not cover new material. Anything that should be explained to you already has been explained. The LSO - experimenter's comments will be taken from this briefing, and will serve to remind you of the material covered, and to orient you towards the errors that you are making and the appropriate corrective action. Common terminology that might be used during these instructions is shown in Table 1 . 
1. Groove - The final 18 - 15 seconds of the approach.

2. Cocked up - Flying tou slowly or at too high an angle of attack, causing the use of excessive power to maintain altitude or rate of descent.

3. Dive for the deck - Pushing the nose over and establishing an excessive rate of descent in close. This causes either a three-point landing (all gear hitting the deck at the same time) or possible nose wheel first.

4. Ramp - The aft end of the flight deck or the downwind end of the platform of the runway.

5. Bolter - A touchdown on board the carrier in which the arresting hook does not engage an arresting wire, usually caused by landing past the wire area or by the hook skipping over the arresting wires.

6. Meatball - Terminology used to describe the mirror presentation of the source lights as seen by the pilot. 
SUMMARY

You must learn to make the correct control movements, and to make them decisively. Flying an aircraft can be likened to dealing with a partially trained animal. Calm, consistent, and authoritative commands will produce the desired performance. Indecisiveness, aggression, and inconsistency will lead to confusion. You will never know what is happening, nor will you understand how it happened. On the other hand, precise and decisive behavior will be amply rewarded - - you will begin to understand how to achieve control.

It requires care and effort to learn the control techniques for carrier landings. Navy pilots complete more than 100 approaches in a simulator or to a shore-based landing strip before they attempt a carrier landing. Our research indicates that even after hundreds of carrier landings pilots continue to improve their glideslope control. We will be measuring your performance throughout the trial, not just at the deck of the carrier. Follow the recommended procedures, and in particular try to set yourself on the glideslope, and with the correct AOA early in the approach. Your errors along the glideslope will be assessed. Avoid the temptation to correct by leading with pitch adjustments. Also avoid the temptation to trap a wire at all costs. If you are high as you approach the wires, accept it. A sudden dive for the deck at this point will downgrade your overall rating for that approach more than will a bolter. You should approach the task with care and perseverence. Review this lesson, and note the feedback during the trials. There is something to learn from even a bad performance. 
APPENDIX B

SPECIAL INSTRUCTIONS 
Frozen on Glideslope

The aircraft has a Vertical speed Indicator (VSI). The reference descent rate for the $\mathrm{T}-2$ in the configuration that you will be flying is $515 \mathrm{fpm}$. That is, if the aircraft is on the glideslope and with the correct attitude and airspeed, it will stay on the glideslope if the reference descent rate is maintained. In this experiment you will not be approaching the carrier until your final trials, but will be frozen in position (but not in altitude) at a fixed distance from the carrier. Because you will not actually be traveling down the glideslope, but will be stopped at one point along it, your reference descent rate will be zero fpm.

If you are above glideslope you will need to establish a descent of up to $4 \emptyset \emptyset \mathrm{fpm}$, while if you are below glideslope you will need to establish an ascent of up to $4 \emptyset \emptyset \mathrm{fpm}$. These corrections will return you to the glideslope at an appropriate rate. 
Rate only

To assist your rate judgments we have added some vertical arrows to the FLOLS as shown in Figure 6.* They are calibrated to give no indication at the reference descent rate, to point down at a higher than reference descent rate, and to point up at a lower than reference descent rate. If you are on glideslope you should null the arrows. If you are above you should push them down, and if below you should push them up.

The arrows will be available during your initial training, but they will not be available in a later test session. Use them for guidance, but do not rely on them at the expense of the other rate information. Use the arrows to help you learn to use the other rate indications.

* This was Figure 6 in the Carrier-Landing Instructions of Appendix A for subjects who had the rate display. 

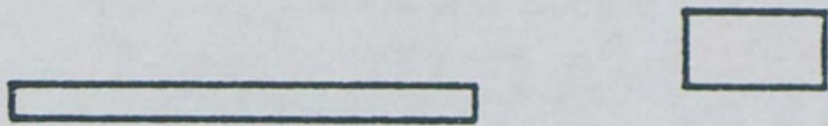

(a) One-ball high and staying there.
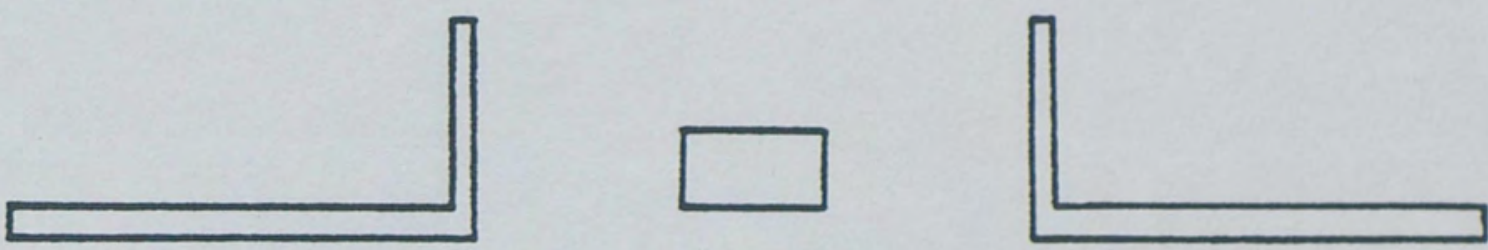

(b) One-ball high; going higher.
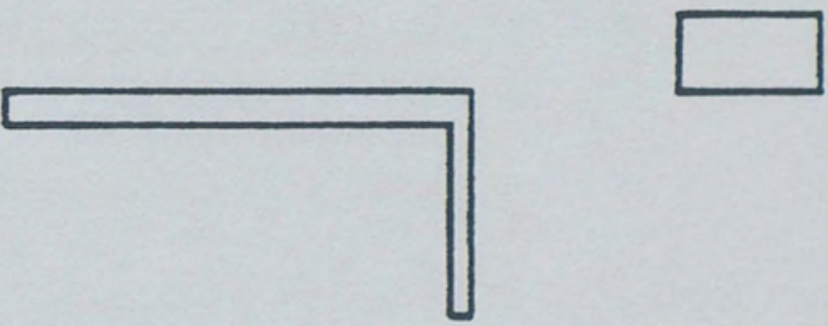

(c) One-ball high; returning to the glideslope.

Figure 6. Three types of indications from the RATE arrows. 
Command only

To assist your rate judgments we have added some vertical arrows to the FLOLS as shown in Figure 6.* They are calibrated to indicate whether you should modify your vertical speed. A null indication while you have a center ball indicates that you are on glideslope and staying there. Arrows up or down indicate that, although you may now have a center ball, you will soon be high or low. If you are above or below glideslope, a null indication shows that you are returning to the glideslope at an appropriate rate. Down arrows mean you are descending too quickly. Up arrows indicate you are not descending quickly enough.

If you are high, up arrows indicate that you are not returning to the glideslope quickly enough, and could even be going further from it. You should descend more quickly. Down arrows indicate that you are returning to the glideslope too quickly and will probably over shoot. Reduce your desent rate.

For a low meatball the interpretations are just the opposite, down arrows indicate that you are not returning to the glideslope quickly enough and may even be flying further from it, while up arrows indicate you are approaching it too quickly and will overshoot.

The basic rule is to null the arrows wherever you are. Up arrows indicate you are not descending quickly enough. Down arrows mean you are descending too quickly.

The arrows will be available during your initial training, but they will not be available in a later test session. Use them for guidance, but do not rely on them at the expense of the other rate information. Use the arrows to help you learn to use the other rate indications.

*This was Figure 6 in the Carrier-Landing Instructions of Appendix A for subjects who had the Command display. 


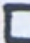

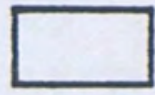

(a) One-ball high; returning to the reference glideslope at an appropriate rate.
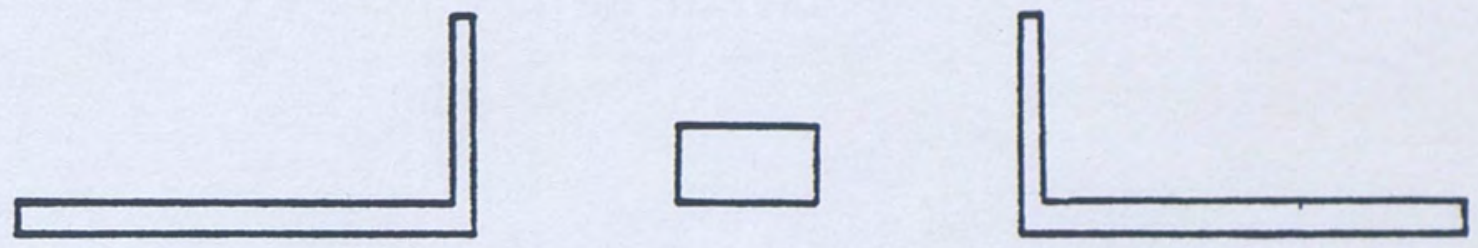

(b) One-ball high; not returning to the glideslope quickly enough (may even be going higher).
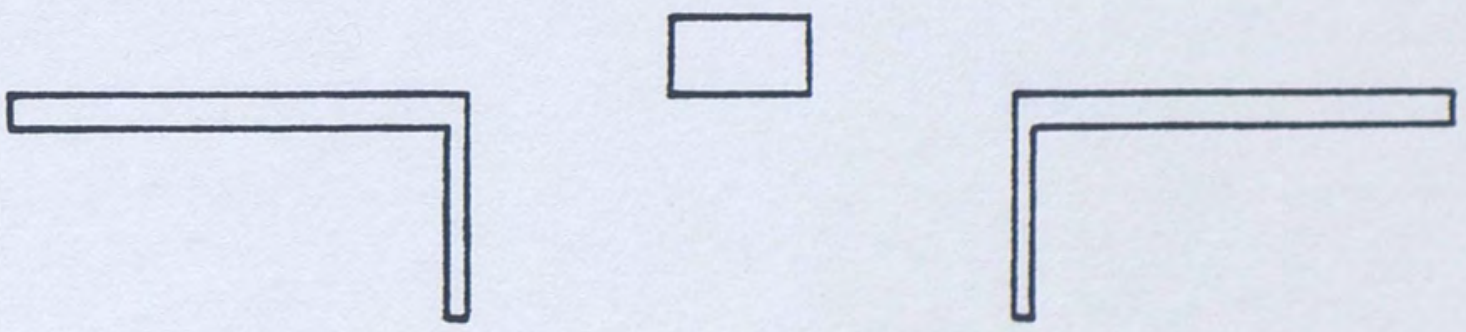

(c) One-ball high; returning to the glideslope too quickly and will probably fly through it.

Figure 6. Three types of indications from the COMMAND arrows. 
APPENDIX C

POWER ANALYSES 
TABLE C-1

POWER ANALYSIS: PROBABILITY OF DETECTING SMALL, MEDIUM AND LARGE EFFECTS OF RMS GLIDESLOPE ERROR FOR THE MIDDLE AND CLOSE-IN SEGMENTS

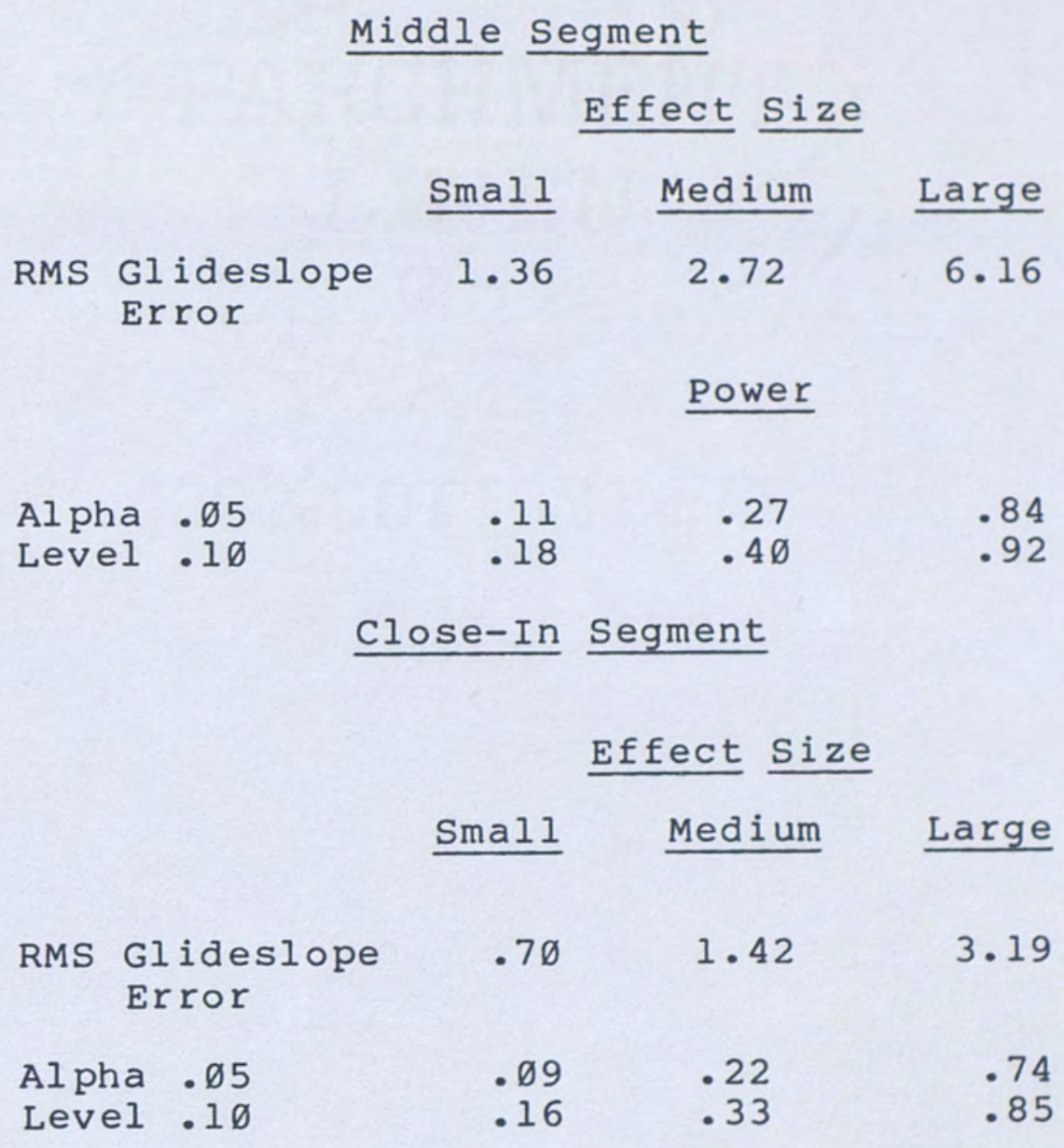


APPENDIX D

MEANS AND REPEATED MEASURES ANALYSIS OF COVARIANCE SUMMARIES OF THE TRAINING DATA 
TABLE D-1

REPEATED MEASURES ANALYSIS OF COVARIANCE OF RMS GLIDESLOPE ERROR FOR THE MIDDLE SEGMENT DURING TRAINING

\begin{tabular}{|c|c|c|c|c|c|}
\hline $\begin{array}{l}\text { Source of } \\
\text { Variance }\end{array}$ & $\begin{array}{l}\text { Sum of } \\
\text { Squares }\end{array}$ & $\underline{\mathrm{df}}$ & $\begin{array}{c}\text { Mean } \\
\text { squares } \\
\end{array}$ & $\underline{\underline{I}}$ & $\begin{array}{l}\text { Proportion } \\
\text { of Variance }\end{array}$ \\
\hline
\end{tabular}

Between Factor

$\begin{array}{lrrrrr}\text { Task (Ta) } & .219 & 1 & .219 & .62 & \text { NS } \\ \text { FLOLS Size (FS) } & .284 & 1 & .204 & .58 & \text { NS } \\ \text { FLOLS TYpe (FT) } & .539 & 2 & .270 & .76 & \text { NS } \\ \text { Ta X FS } & 1.433 & 1 & 1.433 & 4.06 \star & .11 \\ \text { Ta X FT } & .820 & 2 & .410 & 1.16 & \text { NS } \\ \text { FS X FT } & .765 & 2 & .382 & 1.88 & \text { NS } \\ \text { Ta X FS X FT } & .473 & 2 & .236 & .67 & \text { NS } \\ \text { Covariate } & 1.02 & 1 & 1.022 & 2.90 & \\ \text { Error } & 8.110 & 23 & .353 & & \\ \end{array}$

Within Factor

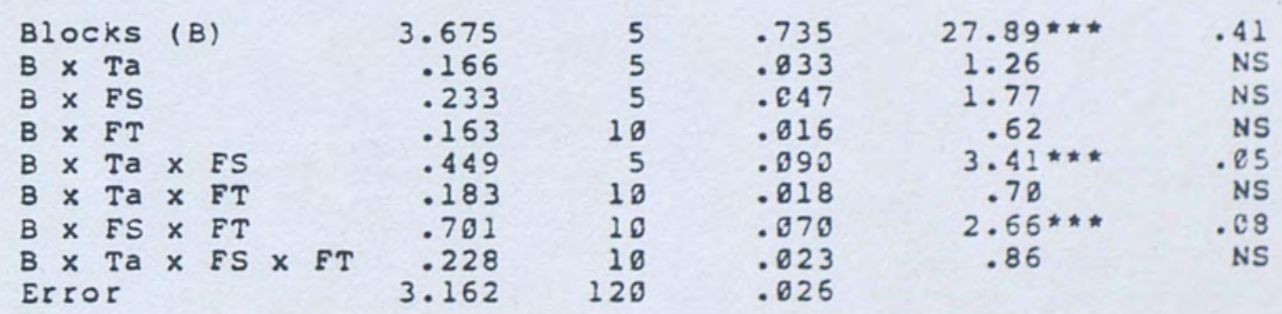

$*: P<.10$

$* * \mathrm{P}<.25$

$\# \star *: P<. \notin 1$ 
TABLE D-2

MEAN GLIDESLOPE RMS ERROR (IN FEET) FOR

THE MIDDLE SEGMENT DURING TRAINING

\begin{tabular}{|c|c|c|c|c|c|c|}
\hline Trial Means & $\underline{1-5}$ & $6-10$ & $11-15$ & $15-20$ & $\underline{21-25}$ & $26-30$ \\
\hline \multicolumn{7}{|l|}{ Task (Ta) } \\
\hline $\begin{array}{l}\text { Whole } \\
\text { Part }\end{array}$ & $\begin{array}{l}74.9 \\
56.1\end{array}$ & $\begin{array}{l}32.0 \\
37.2\end{array}$ & $\begin{array}{l}23.7 \\
27.0\end{array}$ & $\begin{array}{l}24.1 \\
16.4\end{array}$ & $\begin{array}{l}22 \cdot 3 \\
15 \cdot 3\end{array}$ & $\begin{array}{l}17.4 \\
15.8\end{array}$ \\
\hline \multicolumn{7}{|l|}{ FLOLS Size (FS) } \\
\hline $\begin{array}{l}\text { Small } \\
\text { Large }\end{array}$ & $\begin{array}{l}65.2 \\
65.9\end{array}$ & $\begin{array}{l}34 \cdot 3 \\
35 \cdot 8\end{array}$ & $\begin{array}{l}21.1 \\
29.6\end{array}$ & $\begin{array}{l}20.1 \\
20.5\end{array}$ & $\begin{array}{l}18 \cdot 5 \\
19.2\end{array}$ & $\begin{array}{l}17.4 \\
15.8\end{array}$ \\
\hline \multicolumn{7}{|l|}{ FLOLS TYPE (FT) } \\
\hline $\begin{array}{l}\text { Conventional ( } \mathrm{CV}) \\
\text { Rate (Ra) } \\
\text { Command (Cm) }\end{array}$ & $\begin{array}{l}58 \cdot 9 \\
78 \cdot 5 \\
59 \cdot 5\end{array}$ & $\begin{array}{l}35 \cdot 5 \\
32 \cdot 4 \\
35 \cdot 8\end{array}$ & $\begin{array}{l}26 \cdot 7 \\
23 \cdot 1 \\
26 \cdot 3\end{array}$ & $\begin{array}{l}18.2 \\
18.7 \\
24.9\end{array}$ & $\begin{array}{l}14.1 \\
17.9 \\
24.4\end{array}$ & $\begin{array}{l}13.5 \\
16.6 \\
19.7\end{array}$ \\
\hline
\end{tabular}


TABLE D-3

REPEATED MEASURES ANALYSIS OF COVARIANCE OF RMS GLIDESLOPE ERROR FOR THE CLOSE-IN SEGMENT DURING TRAINING

\begin{tabular}{|c|c|c|c|c|c|}
\hline $\begin{array}{l}\text { Source of } \\
\text { Variance }\end{array}$ & $\begin{array}{l}\text { Sum of } \\
\text { Squares }\end{array}$ & df & $\begin{array}{l}\text { Mean } \\
\text { Squares }\end{array}$ & $\underline{\boldsymbol{F}}$ & $\begin{array}{l}\text { Proportion } \\
\text { of Variance }\end{array}$ \\
\hline \multicolumn{6}{|l|}{ Between Factor } \\
\hline $\begin{array}{l}\text { Task (Ta) } \\
\text { FLOLS Size (FS) } \\
\text { FLOLS TyPe (FT) } \\
\text { Ta } x \text { FS } \\
\text { Ta } \times \text { FT } \\
\text { FS } \times \text { FT } \\
\text { Ta } x \text { FS } \text { FT } \\
\text { Covariate } \\
\text { Error }\end{array}$ & $\begin{array}{r}.082 \\
.044 \\
.492 \\
1.574 \\
1.329 \\
.722 \\
1.124 \\
.744 \\
9.253\end{array}$ & $\begin{array}{l}1 \\
1 \\
2 \\
1 \\
2 \\
2 \\
2 \\
1 \\
23\end{array}$ & $\begin{array}{r}.082 \\
.844 \\
.281 \\
1.574 \\
.655 \\
.361 \\
.562 \\
.744 \\
.394\end{array}$ & $\begin{array}{l}.21 \\
.11 \\
.51 \\
4.80^{*} \\
1.69 \\
.92 \\
1.43 \\
1.89\end{array}$ & $\begin{array}{l}\text { NS } \\
\text { NS } \\
\text { NS } \\
.10 \\
\text { NS } \\
\text { NS } \\
\text { NS } \\
\text { NS }\end{array}$ \\
\hline \multicolumn{6}{|l|}{ Within Factor } \\
\hline $\begin{array}{l}\text { Blocks (B) } \\
\text { B } \times \text { Ta } \\
\mathrm{S} \times \mathrm{FS} \\
\mathrm{B} \times \mathrm{FT} \\
\mathrm{B} \times \mathrm{Ta} \times \mathrm{FS} \\
\mathrm{B} \times \mathrm{Ta} \times \mathrm{FT} \\
\mathrm{B} \times \mathrm{FS} \times \mathrm{FT} \\
\mathrm{B} \times \mathrm{Ta} \times \mathrm{FS} \times \mathrm{FT} \\
\text { ErTOT }\end{array}$ & $\begin{array}{r}4.804 \\
.174 \\
.178 \\
.231 \\
.128 \\
.328 \\
.378 \\
.147 \\
2.939\end{array}$ & $\begin{array}{r}5 \\
5 \\
5 \\
10 \\
5 \\
10 \\
10 \\
10 \\
120\end{array}$ & $\begin{array}{l}.961 \\
.835 \\
.036 \\
.023 \\
.826 \\
.832 \\
.838 \\
.815 \\
.024\end{array}$ & $\begin{array}{l}39.23 * * \star \\
1.42 \\
1.45 \\
.94 \\
1.04 \\
1.31 \\
1.54 \\
.60\end{array}$ & $\begin{array}{l}.52 \\
\text { NS } \\
\text { NS } \\
\text { NS } \\
\text { NS } \\
\text { NS } \\
\text { NS } \\
\text { NS }\end{array}$ \\
\hline
\end{tabular}

\footnotetext{
$\#: p<.10$

$\#: p<.85$

$\star \star \star: \mathrm{p}<.31$
} 
TABLE D-4

MEAN GLIDESLOPE RMS ERROR (IN FEET) FOR

THE CLOSE-IN SEGMENT DURING TRAINING

\begin{tabular}{|c|c|c|c|c|c|c|}
\hline Trial Means & $\underline{1-5}$ & $\underline{6-10}$ & $11-15$ & $\underline{16-20}$ & $21-25$ & $25-30$ \\
\hline \multicolumn{7}{|l|}{ Task (Ta) } \\
\hline $\begin{array}{l}\text { Whole } \\
\text { Part }\end{array}$ & $\begin{array}{l}75.8 \\
68.2\end{array}$ & $\begin{array}{l}24.3 \\
46.4\end{array}$ & $\begin{array}{l}19.7 \\
26.6\end{array}$ & $\begin{array}{l}17.6 \\
16.7\end{array}$ & $\begin{array}{l}16.8 \\
16.6\end{array}$ & $\begin{array}{l}12.2 \\
16.9\end{array}$ \\
\hline \multicolumn{7}{|l|}{ FLOLS Size (FS) } \\
\hline $\begin{array}{l}\text { Small } \\
\text { Large }\end{array}$ & $\begin{array}{l}67.1 \\
77.8\end{array}$ & $\begin{array}{l}34.6 \\
36.1\end{array}$ & $\begin{array}{l}22.8 \\
24.3\end{array}$ & $\begin{array}{l}19.0 \\
15.3\end{array}$ & $\begin{array}{l}16.6 \\
16.1\end{array}$ & $\begin{array}{l}14.1 \\
14.9\end{array}$ \\
\hline \multicolumn{7}{|l|}{ FLOLS TYPe (FT) } \\
\hline $\begin{array}{l}\text { Conventional (Cv) } \\
\text { Rate (Ra) } \\
\text { Command }(\mathrm{Cm})\end{array}$ & $\begin{array}{l}72.8 \\
98.4 \\
53.3\end{array}$ & $\begin{array}{l}37.8 \\
30.5 \\
37.6\end{array}$ & $\begin{array}{l}28.6 \\
18.4 \\
22.4\end{array}$ & $\begin{array}{l}15.6 \\
15.9 \\
19.9\end{array}$ & $\begin{array}{l}13.0 \\
15.9 \\
28.0\end{array}$ & $\begin{array}{l}13.1 \\
14.4 \\
16.1\end{array}$ \\
\hline
\end{tabular}


TABLE D-5

REPEATED MEASURES ANALYSIS OF COVARIANCE OF AVERAGE GLIDESLOPE ERROR FOR THE MIDDLE SEGMENT DURING TRAINING

\begin{tabular}{|c|c|c|c|c|c|}
\hline $\begin{array}{l}\text { Source of } \\
\text { variance }\end{array}$ & $\begin{array}{l}\text { Sum of } \\
\text { Squares }\end{array}$ & $\underline{\mathrm{d} f}$ & $\begin{array}{c}\text { Mean } \\
\text { squares }\end{array}$ & $\underline{\mathbf{F}}$ & $\begin{array}{l}\text { Proportion } \\
\text { of Variance }\end{array}$ \\
\hline \multicolumn{6}{|l|}{ Setween Factor } \\
\hline $\begin{array}{l}\text { Task (Ta) } \\
\text { FLOLS Size (FS) } \\
\text { FLOLS TYPe (FT) } \\
\text { Ta X FS } \\
\text { Ta X FT } \\
\text { FS X FT } \\
\text { TaX FS X FT } \\
\text { Covariate } \\
\text { Error }\end{array}$ & $\begin{array}{r}1817 \\
417 \\
1412 \\
5256 \\
218 \\
4396 \\
65 \\
64 \\
25426\end{array}$ & $\begin{array}{l}1 \\
1 \\
2 \\
1 \\
2 \\
2 \\
2 \\
1 \\
23\end{array}$ & $\begin{array}{r}1817 \\
417 \\
705 \\
5256 \\
109 \\
2198 \\
33 \\
64 \\
1105\end{array}$ & $\begin{array}{l}1.64 \\
.38 \\
.64 \\
4.76^{\star \star} \\
.10 \\
1.99 \\
.83 \\
.85\end{array}$ & $\begin{array}{l}\text { NS } \\
\text { NS } \\
\text { NS } \\
.13 \\
\text { NS } \\
\text { NS } \\
\text { NS } \\
\text { NS }\end{array}$ \\
\hline \multicolumn{6}{|l|}{ within Factor } \\
\hline 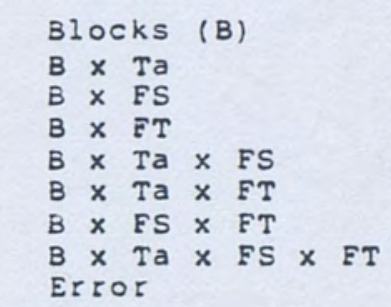 & $\begin{array}{r}41695 \\
3957 \\
1949 \\
5360 \\
7981 \\
6631 \\
5931 \\
8808 \\
84008\end{array}$ & $\begin{array}{r}5 \\
5 \\
5 \\
18 \\
5 \\
10 \\
10 \\
10 \\
120\end{array}$ & $\begin{array}{r}8339 \\
791 \\
389 \\
536 \\
1580 \\
563 \\
598 \\
880 \\
730\end{array}$ & $\begin{array}{c}11.91^{\star \star \star} \\
1.13^{\circ} \\
.56 \\
.77 \\
2.25^{\star} \\
.95 \\
.85 \\
1.26\end{array}$ & $\begin{array}{l}.25 \\
\text { NS } \\
\text { NS } \\
\text { NS } \\
.65 \\
\text { NS } \\
\text { NS } \\
\text { NS }\end{array}$ \\
\hline
\end{tabular}

$\begin{aligned} \star & : P<.10 \\ * \star & : P<.05 \\ * \star \star & : P<.01\end{aligned}$ 
TABLE D-6

MEAN AVERAGE GLIDESLOPE ERROR (IN FEET, $+=$ HIGH) FOR THE MIDDLE SEGMENT DURING TRAINING

\begin{tabular}{|c|c|c|c|c|c|c|}
\hline Trial Means & $1-5$ & $6-10$ & $11-15$ & $16-20$ & $\underline{21-25}$ & $\underline{25-30}$ \\
\hline \multicolumn{7}{|l|}{ Task (Ta) } \\
\hline $\begin{array}{l}\text { Whole } \\
\text { Part }\end{array}$ & $\begin{array}{l}-52.9 \\
-29.2\end{array}$ & $\begin{array}{l}-17.6 \\
-14.9\end{array}$ & $\begin{array}{l}-9.2 \\
-10.5\end{array}$ & $\begin{array}{l}-7.8 \\
-1.3\end{array}$ & $\begin{array}{l}-1.4 \\
-1.3\end{array}$ & -1.6 \\
\hline \multicolumn{7}{|l|}{ FLOLS Size (FS) } \\
\hline $\begin{array}{l}\text { Small } \\
\text { Large }\end{array}$ & $\begin{array}{l}-48.3 \\
-41.9\end{array}$ & $\begin{array}{l}-21.0 \\
-11.5\end{array}$ & $\begin{array}{l}-6.5 \\
-13.2\end{array}$ & $\begin{array}{l}-6.3 \\
-2.8\end{array}$ & $\begin{array}{r}-6.5 \\
3.7\end{array}$ & \\
\hline \multicolumn{7}{|l|}{ FLOLS TYPe (FT) } \\
\hline $\begin{array}{l}\text { Conventional (Cv) } \\
\text { Rate (Ra) } \\
\text { Command (Cm) }\end{array}$ & $\begin{array}{l}-39.3 \\
-56.8 \\
-27.5\end{array}$ & $\begin{array}{l}-19.2 \\
-20.8 \\
-8.3\end{array}$ & $\begin{array}{l}-13.5 \\
-5.5 \\
-16.5\end{array}$ & $\begin{array}{l}-.4 \\
-8 \cdot 1 \\
-5 \cdot 3\end{array}$ & $\begin{array}{r}-3.8 \\
-1.5 \\
.4\end{array}$ & $\begin{aligned} & 1 \cdot 1 \\
&-\quad \cdot 1 \\
&-2 \cdot 3\end{aligned}$ \\
\hline
\end{tabular}


TABLE D-7

REPEATED MEASURES ANALYSIS OF COVARIANCE OF AVERAGE GLIDESLOPE ERROR FOR THE CLOSE-IN SEGMENT DURING TRAINING

\begin{tabular}{llll}
\hline $\begin{array}{l}\text { Source of } \\
\text { Variance }\end{array}$ & $\begin{array}{l}\text { Sum of } \\
\text { Squares }\end{array}$ & df & Mean \\
\hline
\end{tabular}

Between Factor

$\begin{array}{lrrrrr}\text { Task (Ta) } & 1347 & 1 & 1347 & .80 & \text { NS } \\ \text { FLOLS Size (FS) } & 14 & 1 & 14 & .81 & \text { NS } \\ \text { FLOLS TYPe (FT) } & 4396 & 2 & 2198 & 1.31 & \text { NS } \\ \text { Ta X FS } & 7898 & 1 & 7808 & 4.64 * & .14 \\ \text { Ta X FT } & 21 & 2 & 11 & .01 & \text { NS } \\ \text { FS X FT } & 3645 & 2 & 1522 & .98 & \text { NS } \\ \text { Ta F X FT } & 674 & 2 & 337 & .20 & \text { NS } \\ \text { Covariate } & 258 & 1 & 256 & .15 & \text { NS } \\ \text { Error } & 38594 & 23 & 1682 & & \end{array}$

Within Factor

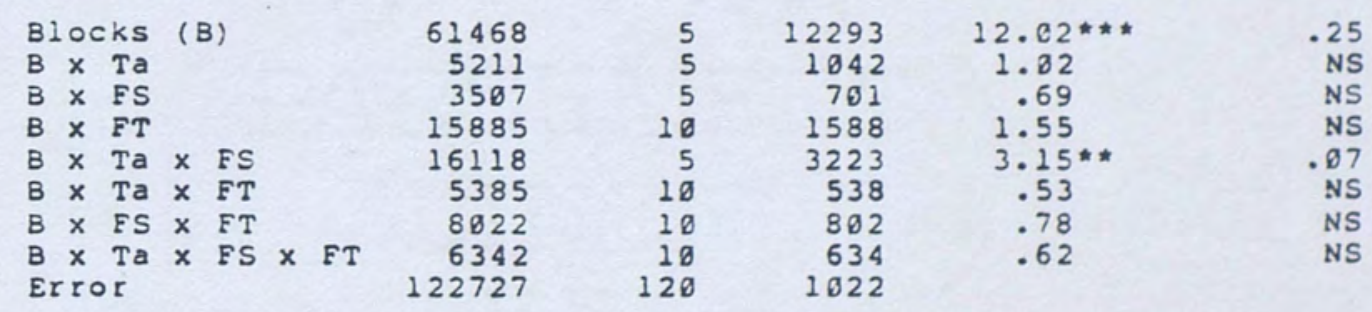

\footnotetext{
*:p<.10

$\star *: p<.85$

$\# * * p<.01$
} 
TABLE D-8

MEAN AVERAGE GLIDESLOPE ERROR (IN FEET, $+=$ HIGH) FOR THE CLOSE-IN SEGMENT DURING TRAINING

\begin{tabular}{|c|c|c|c|c|c|c|}
\hline 5-Trial Means & $\underline{1-5}$ & $6-10$ & $11-15$ & $\underline{16-20}$ & $\underline{21-25}$ & $\underline{26-30}$ \\
\hline \multicolumn{7}{|l|}{$\underline{\text { Task }}$ (Ta) } \\
\hline $\begin{array}{l}\text { Whole } \\
\text { Part }\end{array}$ & $\begin{array}{l}-61.9 \\
-38.4\end{array}$ & $\begin{array}{l}-13.9 \\
-21.6\end{array}$ & $\begin{array}{l}-9 . e \\
-10.8\end{array}$ & $\begin{array}{l}-9.2 \\
-3.9\end{array}$ & $\begin{array}{l}-3.5 \\
-1.8\end{array}$ & $\begin{array}{r}-2.5 \\
3.2\end{array}$ \\
\hline \multicolumn{7}{|l|}{ FLOLS Size (FS) } \\
\hline $\begin{array}{l}\text { Smali } \\
\text { Large }\end{array}$ & $\begin{array}{l}-41.4 \\
-58.9\end{array}$ & $\begin{array}{l}-17.2 \\
-18.3\end{array}$ & $\begin{array}{l}-9.8 \\
-10.8\end{array}$ & $\begin{array}{l}-9.8 \\
-3.3\end{array}$ & $\begin{array}{r}-5.4 \\
.1\end{array}$ & $\begin{array}{l}.6 \\
.2\end{array}$ \\
\hline \multicolumn{7}{|l|}{ FLOLS TYpe (FT) } \\
\hline $\begin{array}{l}\text { Conventional (Cv) } \\
\text { Rate (Ra) } \\
\text { Command }(\mathrm{Cm})\end{array}$ & $\begin{array}{l}-56.4 \\
-74.7 \\
-19.9\end{array}$ & $\begin{array}{l}-25.4 \\
-13.8 \\
-14.1\end{array}$ & $\begin{array}{l}-18.9 \\
-\quad 4.2 \\
-6.5\end{array}$ & $\begin{array}{l}-5.9 \\
-8.1 \\
-5.7\end{array}$ & $\begin{array}{l}-2.8 \\
-2.8 \\
-2.4\end{array}$ & $\begin{array}{r}1.5 \\
-1.7 \\
1.3\end{array}$ \\
\hline
\end{tabular}


TABLE D-9

REPEATED MEASURES ANALYSIS OF COVARIANCE OF RMS ANGLE OF ATTACK ERROR FOR THE MIDDLE SEGMENT DURING TRAINING

\begin{tabular}{|c|c|c|c|c|c|}
\hline $\begin{array}{l}\text { Source of } \\
\text { Variance }\end{array}$ & $\begin{array}{l}\text { Sum of } \\
\text { Squares }\end{array}$ & $\underline{d f}$ & $\begin{array}{c}\text { Mean } \\
\text { Squares } \\
\end{array}$ & $\underline{F}$ & $\begin{array}{l}\text { Proportion } \\
\text { of Variance }\end{array}$ \\
\hline Between ractor & & & & & \\
\hline $\begin{array}{l}\text { Task (Ta) } \\
\text { FLOLS Size (FS) } \\
\text { FLOLS TYPe (FT) } \\
\text { Ta X FS } \\
\text { Ta X FT } \\
\text { FS } \times \text { FT } \\
\text { Ta } \times \text { FS } \times \text { FT } \\
\text { Covariate } \\
\text { Error }\end{array}$ & $\begin{array}{l}.1859 \\
.0018 \\
.0281 \\
.0057 \\
.0679 \\
.0099 \\
.0859 \\
.0062 \\
.6902\end{array}$ & $\begin{array}{r}1 \\
1 \\
2 \\
1 \\
2 \\
2 \\
2 \\
1 \\
23\end{array}$ & $\begin{array}{l}.1869 \\
.1869 \\
.0149 \\
.0657 \\
.0339 \\
.0049 \\
.0435 \\
.0002 \\
.0300\end{array}$ & $\begin{array}{c}6.23^{\# \star} \\
.06 \\
.47 \\
.19 \\
1.13 \\
.15 \\
1.45 \\
.01\end{array}$ & $\begin{array}{l}.17 \\
\text { NS } \\
\text { NS } \\
\text { NS } \\
\text { NS } \\
\text { NS } \\
\text { NS } \\
\text { NS }\end{array}$ \\
\hline
\end{tabular}

Within Factor

\begin{tabular}{|c|c|c|c|c|c|c|c|}
\hline \multicolumn{2}{|c|}{ Blocks } & (B) & .1288 & 5 & .0258 & $9.07 \star \star \star *$ & .20 \\
\hline B & $\times \mathrm{Ta}$ & & .8313 & 5 & .8063 & $2.20 *$ & .85 \\
\hline B & $x$ FS & & .8841 & 5 & .0008 & .29 & NS \\
\hline B & $X F T$ & & .0129 & 10 & .8013 & .46 & NS \\
\hline B & $\times \mathrm{Ta}$ & $x$ FS & .0105 & 5 & .0521 & .74 & NS \\
\hline B & $\times \mathrm{Ta}$ & X FT & .8251 & 10 & .8025 & .88 & NS \\
\hline B & $x$ ES & $\times F T$ & .8757 & 10 & .0376 & $2.67 \star \star \star *$ & .12 \\
\hline B & $\times \mathrm{Ta}$ & $x$ FS $\times$ FT & .8243 & 10 & .8624 & .86 & NS \\
\hline & ror & & .3407 & 120 & .0328 & & \\
\hline
\end{tabular}

* $: p<.10$

$\#: p<.85$

$\star \star \star: \mathrm{p}<. .81$ 
TABLE D-10

MEAN ANGLE OF ATTACK RMS ERROR (IN AOA UNITS)

FOR THE MIDDLE SEGMENT DURING TRAINING

\begin{tabular}{|c|c|c|c|c|c|c|}
\hline 5-Trial Means & $\underline{1-5}$ & $6-10$ & $11-15$ & $16-20$ & $\underline{21-25}$ & $26-38$ \\
\hline \multicolumn{7}{|l|}{ Task (Ta) } \\
\hline $\begin{array}{l}\text { Whole } \\
\text { Part }\end{array}$ & $\begin{array}{l}.754 \\
.811\end{array}$ & $\begin{array}{l}.716 \\
.642\end{array}$ & $\begin{array}{l}.607 \\
.478\end{array}$ & $\begin{array}{l}.531 \\
.327\end{array}$ & $\begin{array}{l}.621 \\
.291\end{array}$ & $\begin{array}{l}.546 \\
.322\end{array}$ \\
\hline \multicolumn{7}{|l|}{ FLOLS Size (FS) } \\
\hline $\begin{array}{l}\text { Small } \\
\text { Large }\end{array}$ & $\begin{array}{l}.791 \\
.775\end{array}$ & $\begin{array}{l}.656 \\
.702\end{array}$ & $\begin{array}{l}.583 \\
.502\end{array}$ & $\begin{array}{l}.481 \\
.446\end{array}$ & $\begin{array}{l}.450 \\
.462\end{array}$ & $\begin{array}{l}.459 \\
.489\end{array}$ \\
\hline \multicolumn{7}{|l|}{ FLOLS TYpe (FT) } \\
\hline $\begin{array}{l}\text { Conventional (Cv) } \\
\text { Rate (Ra) } \\
\text { Command }(\mathrm{Cm})\end{array}$ & $\begin{array}{l}.720 \\
.715 \\
.912\end{array}$ & $\begin{array}{l}.716 \\
.546 \\
.781\end{array}$ & $\begin{array}{l}.523 \\
.459 \\
.645\end{array}$ & $\begin{array}{l}.410 \\
.438 \\
.543\end{array}$ & $\begin{array}{l}.353 \\
.489 \\
.686\end{array}$ & $\begin{array}{l}.403 \\
.401 \\
.498\end{array}$ \\
\hline
\end{tabular}


TABLE D-11

REPEATED MEASURES ANALYSIS OF COVARIANCE OF RMS ANGLE OF ATTACK ERROR FOR THE CLOSE-IN SEGMENT DURING TRAINING

\begin{tabular}{|c|c|c|c|c|c|}
\hline $\begin{array}{l}\text { Source of } \\
\text { Variance }\end{array}$ & $\begin{array}{l}\text { Sum of } \\
\text { Squares }\end{array}$ & $\underline{d f}$ & $\begin{array}{l}\text { Mean } \\
\text { Squares }\end{array}$ & $\underline{\mathbf{F}}$ & $\begin{array}{l}\text { Proportion } \\
\text { of Variance }\end{array}$ \\
\hline Between Factor & & & & & \\
\hline $\begin{array}{l}\text { Task (Ta) } \\
\text { FLOLS Size (FS) } \\
\text { FLOLS TYPe (FT) } \\
\text { Ta X FS } \\
\text { Ta X FT } \\
\text { FS } x \text { FT } \\
\text { Ta X FS X FT } \\
\text { Covariate } \\
\text { Error }\end{array}$ & $\begin{array}{l}.4012 \\
.0001 \\
.0433 \\
.0802 \\
.0681 \\
.0147 \\
.1227 \\
.0238 \\
.8001\end{array}$ & $\begin{array}{l}1 \\
1 \\
2 \\
1 \\
2 \\
2 \\
2 \\
1 \\
23\end{array}$ & $\begin{array}{l}.4612 \\
.0601 \\
.0216 \\
.0902 \\
.0340 \\
.0074 \\
.0614 \\
.0238 \\
.0348\end{array}$ & $\begin{array}{c}11.53^{\star \star \star} \\
.03 \\
.62 \\
.00 \\
.98 \\
.21 \\
1.75 \\
.68\end{array}$ & $\begin{array}{l}.27 \\
\text { NS } \\
\text { NS } \\
\text { NS } \\
\text { NS } \\
\text { NS } \\
\text { NS } \\
\text { NS }\end{array}$ \\
\hline
\end{tabular}

Within Factor

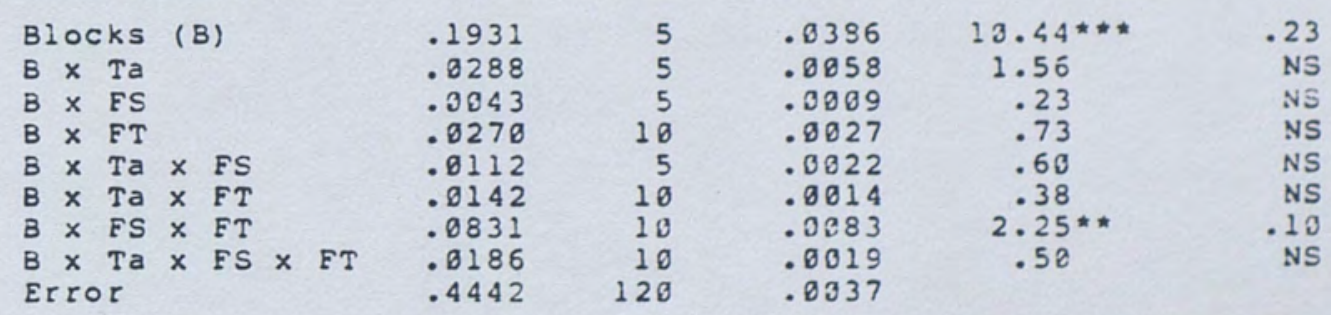

$: p<.10$

$\star *: p<.85$

$\#:: p<.01$ 
TABLE D-12

MEAN ANGLE OF ATTACK RMS ERROR (IN AOA UNITS) FOR THE CLOSE-IN SEGMENT DURING TRAINING

\begin{tabular}{|c|c|c|c|c|c|c|}
\hline 5-Tria! Means & $\underline{1-5}$ & $6-10$ & $11-15$ & $16-20$ & $\underline{21-25}$ & $\underline{26-3 e}$ \\
\hline \multicolumn{7}{|l|}{ Task (Ta) } \\
\hline $\begin{array}{l}\text { Whole } \\
\text { Part }\end{array}$ & $\begin{array}{r}1.65 \\
.838\end{array}$ & $\begin{array}{l}.845 \\
.717\end{array}$ & $\begin{array}{l}.755 \\
.469\end{array}$ & $\begin{array}{l}.747 \\
.321\end{array}$ & $\begin{array}{l}.899 \\
.302\end{array}$ & $\begin{array}{l}.663 \\
.345\end{array}$ \\
\hline \multicolumn{7}{|l|}{ FLOLS Size (FS) } \\
\hline $\begin{array}{l}\text { Small } \\
\text { Large }\end{array}$ & $\begin{array}{l}.956 \\
.934\end{array}$ & $\begin{array}{r}.750 \\
.813\end{array}$ & $\begin{array}{l}.739 \\
.515\end{array}$ & $\begin{array}{l}.523 \\
.544\end{array}$ & $\begin{array}{l}.607 \\
.594\end{array}$ & $\begin{array}{l}.536 \\
.472\end{array}$ \\
\hline \multicolumn{7}{|l|}{ FLOLS TYPe (FT) } \\
\hline $\begin{array}{l}\text { Conventional (Cv) } \\
\text { Rate (Ra) } \\
\text { Command (Cm) }\end{array}$ & $\begin{array}{l}.946 \\
.954 \\
.934\end{array}$ & $\begin{array}{r}.834 \\
.634 \\
.876\end{array}$ & $\begin{array}{l}.457 \\
.589 \\
.791\end{array}$ & $\begin{array}{l}.441 \\
.488 \\
.673\end{array}$ & $\begin{array}{l}.461 \\
.530 \\
.759\end{array}$ & $\begin{array}{l}.460 \\
.499 \\
.552\end{array}$ \\
\hline
\end{tabular}




\section{REFERENCES}

Adams, J.A., and Hufford, L.E. Contributions of a part-task trainer to the learning and relearning of a time-shared flight maneuver. Human Factors, 1962, $\underline{4}$, $159-17 \emptyset$.

Brictson, C.A. Analysis of F-4 aircraft day and night carrier approaches. Aerospace Medicine, 1967, 38, $1219-1224$.

Briggs, G.E., and Naylor, J.C. The relative efficiency of several training methods as a function of transfer task complexity. Journal of Experimental Psychology, $1962, \underline{64}, 505-512$.

Briggs, G.E., and Waters, L.K. Training as a function of component interaction. Journal of Experimental Psychology, $1958, \underline{56}, 492-5 \emptyset \bar{\emptyset}$.

Bunker, M.W. Training effectiveness versus simulation realism. SPIE Visual Simulation and Image Realism, $1978, \underline{162}, \overline{76-82}$.

Caro, P.W. Some factors influencing Air Force simulator training effectiveness. Alexandria, VA: Human Resources Research Organization, Report No. TR-77-2, 1977.

Collyer, S.C., and Chambers, W.S. AWAVS, a research facility for defining flight trainer visual requirements. In proceedings of the Human Factors Society 22nd Annual Meeting (Detroit, Michigan). Santa Monica, CA: Human Factors Society, 1978.

Durand, T.S., and Wasicko, R.J. Factors influencing glidepath control in carrier landing. Journal of Aircraft, $1967, \underline{4}, 146-158$.

Gold, T. Visual perception of pilots in carrier landing . Journal of Aircraft, 1974, 11, 723-729. 
Hennessy, R., Lintern, G., and Collyer, S. Unconventional visual displays for flight training. Orlando, FL: Naval Training Equipment Center, Report No. 78 $-C-\emptyset \emptyset 6 \emptyset-5,1981$.

Holding, D.H. Transfer between difficult and easy tasks. British Journal of Psychology, 1962, 53, 397-467.

Hughes, R.G., Lintern, G., Wightman, D.C., Brooks, R.B., and Singleton, J. Applications of simulator freeze to carrier glideslope tracking instruction. Orlando, FL: Naval Training Equipment Center, Report No. 78-C-øø6ø-9/AFHRL-TR-82-3, 1981.

Jones, M.B., Kennedy, R.S., and Bittner, A.C. A video game for performance testing. American Journal of Psychology, 1981, 94, 143-152.

Kaul, C.E., Collyer, S.C., and Lintern, G. Glideslope descent-rate cuing to aid carrier landings. Orlando, FL: Naval Training Equipment Center, Report No. IH-322, $198 \emptyset$.

Levine, D.W., and Dunlap, W.P. Power of the $F$ test with skewed data: should one transform or not. Psychological Bulletin, 1982, 92, 272-28ø.

Lintern, G. Transfer of landing skill after training with supplemetary visual cues. Human Factors, 198ø, 22, $81-88$.

Lintern, G., and Kennedy, R.S. A video game as a covariate for carrier landing research. Proceedings of the Eighth $\frac{\text { Psychology }}{\text { Colorado Department }}$ Co: United $\frac{\text { Defense }}{\text { States }} \frac{\text { Symposium. }}{\text { Air Force }}$ Academy, April, 1982.

Lintern, G., Nelson, B.E., Sheppard, D.J., Westra, D.P., and Kennedy, R.S. Visual Techology Research Simulator (VTRS) Human Performance Research: Phase III. Orlando, FL: Naval Training Equipment Center, Report No. 78-C-øø6ø-11, 1981 .

Naylor, J.C., and Briggs, G.E. Effects of task complexity and task organization on the relative efficiency of part and whole training methods. Journal of Experimental Psychology, 1963, 65, 217-224. 
Perry, B.L. Optical guidance systems: analysis, design and development. Washington, DC: $\frac{\text { Naval Research }}{\text { sal }}$ Laboratory, Report No. 6581, 1967.

Schendel, J.D., Shields, J.L., and Katz, M.S. Retention of motor skills: review. Alexandria, VA: U.S. Army Research Institute for the Behavioral and Social Sciences. Technical Paper 313, 1978.

Stammers, R.B. Part and whole practice for a tracking task: effects of task variables and amount of practice. Perceptual and Motor Skills, 1980, $\underline{50}$, $2 \emptyset 3-21 \emptyset$.

Staples, K.J. Current problems of flight simulators for research. Aeronautical Journal, January 1978, 12-32.

Stark, E.A. Simulation technology and the fixation phase. Aviation Space and Environment Medicine, 1982, 53, 984-991.

Weller, D.R. predictor displays in carrier landing training. Orlando, FL: Naval Training Equipment Center, Report No. IH-311, 1979.

Westra, D.P. Simulator design features for carrier landing: II. In-simulator transfer of training. Orlando, FL: Naval Training Equipment Center, Report No. 81-C-ø1ø5-1, 1982 .

Wightman, D. Part-task training strategies in simulated carrier landing final approach training. Unpublished Doctoral Dissertation, University of South Florida, 1983. 